\title{
DIGITALCOMMONS
}

@WAYNESTATE -

Wayne State University

$1-1-2012$

\section{Global Health Initiatives and Health System Development: The Historic Quest for Positive Synergies}

Peter J. Hammer

Wayne State University, phammer@wayne.edu

Charla M. Burill

North Carolina Board of Dietetics/Nutrition

\section{Recommended Citation}

Peter J. Hammer \& Charla M. Burill, Global Health Initiatives and Health System Development: The Historic Quest for Positive Synergies, 9 Ind. Health L. Rev. 567 (2012).

Available at: https://digitalcommons.wayne.edu/lawfrp/230 


\title{
GLOBAL HeALTh INITIATIVES AND HeALTH SYSTEM DEVELOPMENT: The Historic Quest for Positive SyNergies
}

\author{
Peter J. Hammer ${ }^{*} \&$ Charla M. Burill ${ }^{*}$
}

"The struggle against human oppression is the strug-
gle between memory and forgetfulness."

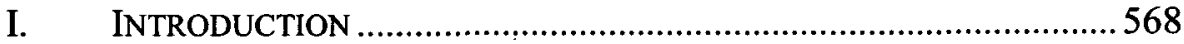

II. Political Challenges - The WHO's Positive Synergies

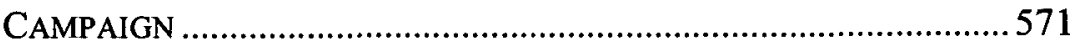

A. First Expert Consultation in Geneva (May 29-30, 2008)....... 572

B. Second Expert Consultation in Mexico City (August 4-5, 2008) 574

C. 3rd Expert Consultation in Geneva (October 2-3, 2008)........ 577

D. The Lancet Article and Venice Recommendations....................582

III. ThEORETICAL CHALLENGES-CONCEPTUALIZING HEALTH

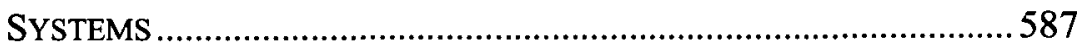

A. A Team of Rivals: 2000 World Health Report ....................... 587

B. A Team No More: Differences Between the World Bank and

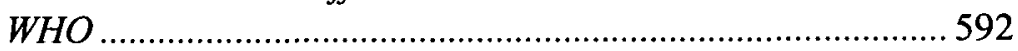

C. Confronting Complexity: An Introduction to Systems Thinking597

IV. ADMINISTRATIVE CHALLENGES-THE GLOBAL FUND'S EXPERIENCE WITH HEALTH SYSTEMS ................................................................603

A. Rounds 1-4 (2002-2004): Is There any Real There, There for Health Systems?. 604

B. Rounds 5-7 (2005-2007): Experimentation, Consultation but Retrenchment.

C. Rounds 8-10 (2008-2010): Time, Persistence and the Power of Adaptation

V. COMMUNITY CHALLENGES-INCORPORATING A ROLE FOR CIVIL SOCIETY 626

A. The Convergence of Civil Society, Community Systems and Health Systems.

\footnotetext{
* Professor of Law and Director of the Damon J. Keith Center for Civil Rights, Wayne State University Law School.

** Executive Director of the North Carolina Board of Dietetics/Nutrition.

1. Dr. Halfdan Mahler, Address to the 61st World Health Assembly (May 20, 2008) (paraphrasing MILAN KUNDERA, BOOK OF LAUGHTER AND FORGETTING (1978)) (transcript available at $\mathrm{http}: / / \mathrm{www}$.who.int/mediacentre/events/2008/wha61/hafdan_mahler_speech/en/ index.html).
} 
B. A Functional Approach to Community Systems.

1. Civil Society a Surrogate Health Service Provider.

2. Communities as a Bridge to the Social-Economic Determinants of Health.

C. Enabling the Enabling Environment: Capacity Building and Learning.

VI. HISTORICAL CHALLENGES-LESSONS FROM PRIMARY HEALTH

CARE AND ALMA-ATA

A. The Positive Synergies Campaign and the Pre-History of Alma-

Ata.

B. Connecting Actions to Communities-Past and Present .

VII. CONCLUSION

EPILOGUE: GLOBAL Fund's RoUND 11 CANCELATION 658

\section{INTRODUCTION}

Global Health Initiatives ("GHIs") have ushered in revolutionary changes in the international public health architecture. In the late 1990s, we were busy fighting over the price of essential AIDS drugs, without serious visions of implementing clinically effective HIV/AIDS treatment worldwide. ${ }^{2}$ Today, groups such as the Global Fund to Fight AIDS, Tuberculosis and Malaria (Global Fund), the President's Emergency Plan for AIDS Relief ("PEPFAR"), the Gates Foundation and the Global Alliance for Vaccines and Immunizations ("GAVI") have initiated a wide range of public health programs across the planet that are starting to meaningfully link the global-to-the-national-to-the local.

Such news is not all good. The more GHIs try to do, the clearer it becomes how much their work is constrained by endemic weaknesses within the existing health systems of most developing countries. Worse still, these fragile systems can be damaged by the distorting effects of GHIs attempting to work through and sometimes around them. This article is not an effort to resurrect old debates between vertical and horizontal interventions or between selective and comprehensive primary care. ${ }^{3}$ Rather, it is an effort to

2. Peter J. Hammer, Differential Pricing of Essential AIDS Drugs: Markets, Politics and Public Health, 5 J. INT'L ECON. L. 883 (2002) (examining efforts to lower the prices of essential AIDS drugs and broaden the scope of compulsory licensing under the World Trade Organization's Agreement on Trade-Related Aspects of Intellectual Property Rights).

3. Tensions between vertical and horizontal interventions are mainstays in debates over global health policy. Vertical interventions are structured international programs that target specific diseases or objectives, often to the neglect of other public health problems. Horizontal interventions are projects that stress multiple and integrated programs, often with insufficient focus, direction or resources. See generally Anne Mills, Mass Campaigns Versus General Health Services: What have we Learned in 40 Years about Vertical Versus Horizontal Approaches?, 83 BULL.WORLD HEALTH ORG. 315 (2005). Similar debates have 
draw attention to the neglected and often invisible infrastructure that lies behind any successful public health intervention. No challenge is more central to the lives of disadvantaged people around the world than the challenge of constructing a new science of Health System Development ("HSD"), in real time, as GHIs continue to design and implement more effective public health programming. ${ }^{4}$ This is the essence of the quest for "positive synergies."

The relationship between GHIs and HSD presents a range of difficult and complicated puzzles. But, there is good news based on the World Health Organization's ("WHO") Positive Synergies Campaign ("PSC") elevating the issue of HSD and its relationship to GHIs to the top of the global health agenda in relatively short order. "Positive synergies" seek to define areas where the work of GHIs and HSD overlap and complement each other, examining how building health systems can further the diseasespecific work of GHIs and where the disease-specific work of GHIs can further the ends of strengthening the overall public health infrastructure. PSC has further forged a political strategy and has begun to outline an intellectual framework that should lead to a better understanding of what future steps should be taken. ${ }^{5}$

This article examines these important efforts. Complexity is a defining characteristic of the GHI/HSD interface. The PSC mantra is that health systems are "complex, context-specific, and changing." As such, HSD is a diffuse and a moving target. Moreover, GHIs and the entire international public health architecture are in a near constant state of flux, which creates expositional as well as organizational challenges. Our goal is to give the reader a comprehensive understanding of the current quest for positive syn-

raged between those who advocate selective versus comprehensive approaches to primary health care. See J. A. Walsh and K.S. Warren, Selective Primary Health Care, an Interim Strategy for Disease Control in Developing Countries, 301 NEw ENG. J. MED. 967 (1979); Oscar Gish, Selective Primary Health Care: Old Wine in New Bottles, 16 Soc. SCl. MED. 1049 (1982). The focus on "positive synergies" provides a frame that can potentially mediate and perhaps even transcend these tensions.

4. We define Health System Development ("HSD") to encompass the entire field of work on health systems, their operations and efforts to improve their performance, with a particular focus on developing countries. Health System Strengthening ("HSS") is a term of art that has arisen at the intersection of GHI and HSD, focusing on how GHIs can work in a manner that enhances the operation of health systems. In our taxonomy, HSS is a subset of HSD.

5. PSC is a remarkably innovative policy making experiment. With PSC, the WHO is embarking on an on open, process-oriented initiative with a conscious awareness: (1) that the unknowns of the endeavor dominate the knowns; (2) that learning and adaptation must be built into the very DNA of the policy making process; and (3) that simultaneous progress must be made on the theoretical as well as the empirical front, all while holding together a sometimes fragile international political coalition. This unusual combination of factors alone makes PSC an important case study for those interested in policy making processes more generally.

6. World Health Organization, Maximizing Positive Synergies Collaborative Group, An Assessment of Interactions between Global Health Initiatives and Country Health Systems, 373 LANCET 2137, 2140 (June 20, 2009) [hereinafter PSC Lancet Article]. 
ergies, as well as the numerous difficulties such efforts face. That said, it will not be a simple, linear narrative. In examining the relationship between GHIs and HSD, we have settled on five interrelated challengespolitical, theoretical, administrative, community and historical challenges.? Understanding these different challenges will provide the reader an appreciation of the multidimensional relationships between GHIs and HSD.

Part II (Political Challenges) places the story of the WHO PSC at center stage, highlighting its effort to create the political space necessary for effective international cooperation, as well as the intellectual framework needed for future action. PSC is an unusual example of an open, processoriented experiment in policy making. Beyond the political dimensions of the problem, the PSC narrative provides the uninitiated reader the background necessary to understand GHIs, HSD and the concept of positive synergies. Part III (Theoretical Challenges) explores efforts to address the question of what health systems are and how one might develop a conceptual framework that could forge better synergies between GHIs and HSD. Limitations in existing theoretical understandings place serious constraints on future planning and action. Part IV (Administrative Challenges) provides a comprehensive case study of the difficulties the Global Fund has encountered in attempting to implement policies that pursue its own objectives, while trying to be sensitive to the needs of HSD. Since its inception, the Global Fund has recognized the significance of HSD. Moreover, given its structure and ethos, one would have thought that the Fund was ideally situated to combine the efforts of a GHI with the objectives of HSD. Despite this, the Global Fund got off to a slow and unsuccessful start, and is only now beginning to make meaningful progress on the HSD front. Part V (Community Challenges) considers where grassroots organizations and civil society fit within HDS. Recent efforts at Community System Strengthening (CSS), particularly in rural settings, are an essential piece of the overall GHI/HSD puzzle.

Part VI (Historical Challenges) ends with a cautionary tale of the primary health care movement, which serves as a counterpoint to Part II's optimistic assessment of PSC. The late 1960s and early 1970 s was another era of ambition and optimism at the WHO, accompanied by a similar awareness of complexity and the importance of process-oriented policy making to seek new answers to old questions. These efforts faltered, as un-

7. The various "challenges" are presented as self-contained narratives. As such, the chronologies of a number of the stories overlap. The story of the political challenges (the PSC process itself) covers the period 2008-09. The story of theoretical challenges (the conceptual framework for HSD) covers a period from 2000-09. Administrative challenges (the case study of the Global Fund) covers a period from 2002-10. Community challenges (new efforts at community system strengthening) covers a period from 2008-10. Historical challenges (the story of the primary health care movement) covers a period from the late $1960 \mathrm{~s}$ to the mid-1980s. 
derdeveloped notions of primary health care became enshrined in the 1978 Declaration of Alma-Ata. ${ }^{8}$ The pre-history of Alma-Ata illustrates how these types of process-oriented policy initiatives are inherently difficult to sustain. History may well prove such efforts to be episodic cycles in the ongoing struggle against human oppression. A brief Epilogue examines the implications of the Global Fund's tragic decision to cancel its latest round of grant funding in the wake of the global financial crisis.

\section{Political Challenges - The WHO's Positive Synergies CAMPAIGN}

It is easy to forget that global health policy is forged in a highly contested political environment. ${ }^{9}$ In this sometimes volatile arena, the WHO PSC has pushed the relationship between GHIs and HSD to the front of the international health agenda in a campaign that could fundamentally transform the future of international public health. The WHO sponsored meetings in May, August and October of 2008. These meetings culminated in the publication of the Campaign's work in the June 20, 2009 issue of The Lancet, An Assessment of the Interactions between Global Health Initiatives

8. Declaration of Alma-Ata, International Conference on Primary Health Care, AlmaAta, USSR (Sept. 6-12, 1978), available at http:/www.who.int/hpr/NPH/docs/declaration almaata.pdf.

9. With the dawn of the new century, GHIs emerged and started to redefine the global health architecture, challenging the traditional dominance of the WHO and the World Bank. In the years following, both the WHO and the World Bank struggled to redefine their role and mission. Significantly, each organization settled upon "health systems" as a central part of their new agendas. In 2007, the World Bank published its Health Nutrition and Population ("HNP") Sector Paper, Healthy Development, arguing that HSD was essential to future global health programming and advocating, based upon its alleged comparative advantage, that the World Bank should play the leading role. WORLD BanK, HEALTHY DEVELOPMENT: The World Bank Strategy for Health, Nutrition, and Population Results (2007) [hereinafter 2007 HEALTHY DEVELOPMENT], available at http://siteresources.worldbank.org/ HEALTHNUTRITIONANDPOPULATION/Resources/281627-1154048816360/HNP StrategyFINALApril302007.pdf. The year before, Alexander Shakow, a retired World Bank consultant, prepared a report asserting that the Global Fund should remain narrowly focused on those aspects of HSD that were directly related to AIDS, Tuberculosis and Malaria (vertical aspects of its GHI mandate), while leaving it to the World Bank to specialize in HSD more generally. AlEXANDER SHAKOW, GLOBAL FUND-WORLD BANK HIV/AIDS Programs Comparative Advantage Study (2006), available at http://siteresources. worldbank.org/TNTHIVAIDS/Resources/375798-1103037153392/GFWBReportFinalVer sion.pdf. Partially in response to that report, the Global Fund ended an innovative, one-year experiment where it had independently financed HSD efforts through a separate window. For further discussion of this episode see infra notes 196-212 and accompanying text. 2007 was also an important year for the WHO, with the publication of 2007 Everybody's Business: Strengthening Health Systems to Improve Health Outcomes. WorLd HEALTH ORG., 2007 EVERYBODY's BUSINESS: STRENGTHENING HEALTH SYSTEMS TO IMPROVE HEALTH OUTCOMES: WHO'S FRAMEWORK FOR ACTION (2007) [hereinafter 2007 EVERYBODY's BUSINESS] available at http://www.who.int/healthsystems/strategy/everybodys_business.pdf. 2007 Everybody's Business similarly proclaimed the importance of HSD, as well as the central role it believed the WHO should play in its advancement. 
and Country Health Systems ${ }^{10}$ and the subsequent High Level Dialogue of stakeholders, which produced the Venice Recommendations. " This section examines the evolution of that process and the intricate technical and political agendas that PSC has developed to guide future action. ${ }^{12}$

\section{A. First Expert Consultation in Geneva (May 29-30, 2008)}

"In May 2008, the World Health Organization (WHO) convened a meeting that signaled the beginning of a broad-based, international consultative process for driving forward the rapid development of global guidance on maximizing positive synergies between health systems and Global Health Initiatives (GHIs)." ${ }^{13}$ The first PSC meeting was a consensus building exercise, based, in part, on the common desire to meet the Millennium Development Goals ("MDGs"). The central motivation for the initiative was the belief that GHIs and HSD are both essential to improving public health and that these objectives can be better accomplished through collaborative efforts. GHIs, such as the Global Fund, GAVI and PEPFAR, have marshaled unprecedented resources and implemented concrete clinical efforts that would have been thought impossible in past decades. The problem is that existing health systems are weak, too weak to meet the broad range of health needs that they are being asked to address.

The underdeveloped state of health systems makes it difficult and perhaps impossible for GHIs to achieve their disease-specific objectives. At the same time, as GHIs seek to work through and sometimes around existing health systems, there is a substantial possibility that they will distort, damage and further weaken these fragile structures.

In sum, in a vicious circle, weak health systems can limit the effectiveness of the Global Health Initiatives and the Global Health Initiatives can place unwarranted stress on already weak systems. This dilemma drives a wedge between health systems strengthening efforts and the work of the Global Health Initiatives and limits the capacity of both to achieve their full po-

10. PSC Lancet Article, supra note 6.

11. World Health ORg., Maximizing Positive Synergies Between Health Systems and Global Health Initiatives: Initial Recommendations (World Health Org., Working Paper) [herinafter Venice Recommendations], available at http://www.who.int/healthsystems /Venice_recommendations.pdf.

12. This is an exercise in storytelling relying principally on the WHO's own publications. It is not intended to be an authoritative history.

13. World Health Org., Report on the Expert Consultation on Positive SyNERGIES BETWEen Health SySTEM AND Global HEalth INITIATIVES 1 (2008) [hereinafter IST EXPERT CONSULTATION], available at www.who.int/healthsystems/hs_\&_ghi.pdf. 
tential. $^{14}$

On the positive side, if properly designed, actions taken in furtherance of the objectives of GHIs could also help strengthen domestic health systems and visa-versa. This is the essence of "positive synergies." The development and exploitation of such synergies defines the cooperative framework driving PSC. The questions then become "are these synergies being vigorously exploited by all stakeholders to ensure maximum mutual added value? Or are new opportunities for improving public health in lowand middle-income countries being missed?"15 These are complicated questions with both technical and political dimensions. "[S] uccess will demand work on two fronts: technical guidance," as well as "advocacy for a change of mindset."16 PSC's strategy is to push hardest on the technical side first, on the hope and expectation that a better understanding of the problem may increase the opportunities for the political consensus to be maintained. ${ }^{17}$

The 1st Expert Consultation outlined an ambitious agenda for building an intellectual framework capable of defining the scope of positive synergies. $^{18}$ This agenda will require a number of innovations in our understanding of health services research. As much as anything else, PSC is significant for its critique of the ability of traditional social science and policy making epistemologies to address complex global problems. "The research endeavor will need to utilize multiple methodologies in order to capture knowledge wherever it exists. A particular challenge will be to find a methodology that can accommodate the possible disparities between information which is formally recorded and knowledge of 'the reality' that is only informally shared." 19 Often, the practical knowledge of what needs to be done falls outside the frame of traditional "scientific" methods.

How will this new technical framework be used? The intent is to create an open architecture for policymaking that is capable of adapting itself

14. World Health Org., Maximizing Positive Synergies Between Health Systems AND Global HEALTH InItIATIVES 4 (2008), available at http://www.who.int/ healthsystems/MaximizingPositiveSynergies.pdf.

15. 1sT EXPERT CONSULTATION, supra note 13, at 2.

16. Id. at 9 .

17. As examined in greater detail in Part IV, infra, GHIs, like the Global Fund, are open to being more active on HSD. A large part of the problem is that they simply do not know what to do. How willing GHIs will be to make substantial changes in their own policies and programs, however, is still an unresolved question.

18. 1sT EXPERT CONSULTATION, supra note 13, at 2 ("Translating this knowledge into action that is evidence-based demands the urgent development and implementation of a global policy and technical framework. This will serve to guide both health systems, and GHIs, to ensure that mutual threats are recognized and avoided and that synergies are identified and built upon."). Part of this process will entail a systematic review of the experiences, good and bad, of past and ongoing initiatives. Id. at 3-5.

19. Id. at 6 . 
to different local contexts. "The guidance that is produced should aim to provide a flexible scaffolding from which different countries can draw and build on what is useful and relevant to their particular country situation."20 If this were not difficult enough, the policy making process is further intended to be inclusive and participatory. "Reaching and engaging key stakeholders, including decision makers, civil society, the private sector and affected communities, must be at the centre of the effort." ${ }^{, 21}$ All involved in PSC understand the urgency of the undertaking.

There is no time to lose. The current commitment of country leaders, donors and international stakeholders to achieve the health-related MDGs offers a window of opportunity that must not be missed. Therefore the timeframe is ambitious. The aim will be to reach agreement on preliminary policy and technical guidance within approximately 12 months from the date of this expert consultation. ${ }^{22}$

The label of ambitious for the preliminary PSC agenda is a gross understatement.

\section{B. Second Expert Consultation in Mexico City (August 4-5, 2008)}

PSC's dual political and technical tracks structurally defined its work in August 2008. There were two events. One session was a Positive Synergies Panel at the XVII International AIDS Conference. ${ }^{23}$ This was a gathering of some of the most important stakeholders in the GHI/HSD debate. The Panel discussion worked the political end of the problem, and emphasized areas of alleged "growing consensus." ${ }^{24}$ The other event was the PSC's 2nd Expert Consultation. This consultation focused on further refining the technical aspects of the agenda. ${ }^{25}$

The International AIDS Conference Panel consisted of a who's who of global health, with leading representatives from the WHO, the Gates Foun-

20. Id. at 9 .

21. Id.

22. $I d$.

23. World Health Org., The Mexico Panel on Maximizing Positive Synergies Between Health Systems and Global Health InItiatives: A WHO Satellite MeEting at THE XVII InTERnational AIDS ConferenCe, MeXico City, 4 August, 2008 (2008) [hereinafter MEXICO PANEL], available at http://www.who.int/healthsystems/PS_Mexico PanelReport2b.pdf.

24. Id. at 4 .

25. World Health ORg., RePORT ON the 2ND EXPERT Consultation on POSITIVE Synergies Between Health Systems and Global Health Initiatives, Mexico City, 5 AUG. 2008 (2008) [hereinafter 2ND EXPERT CONSULTATION], available at http://www.who. int/healthsystems/PosSyn2ndExptCons_HR.pdf. 
dation, the Global Fund, UNAIDS, PEPFAR, the World Bank, academics, and national governments. How does one gain consensus and garner effective cooperation in such an environment? Given the absence of binding international law, the dynamics of this problem have more in common with private corporate law than with traditional public law. Undertakings like the PSC can only succeed if there is a framework in which all actors perceive that cooperation is in their own organizational self-interest. From this perspective, one can appreciate the power and wisdom of "positive synergies" as a cooperative framework. By definition, if something is a positive synergy, it constitutes one of those rare win-win scenarios, falling within the perceived self-interest of all involved. In theory, at least, everyone should be willing to agree to pursue authentic positive synergies.

The difficulty is in credibly identifying the scope of real synergies at the GHI-HSD interface. This involves complicated theoretical and empirical questions. There are a number of conceivable relationships between GHIs and HSD:

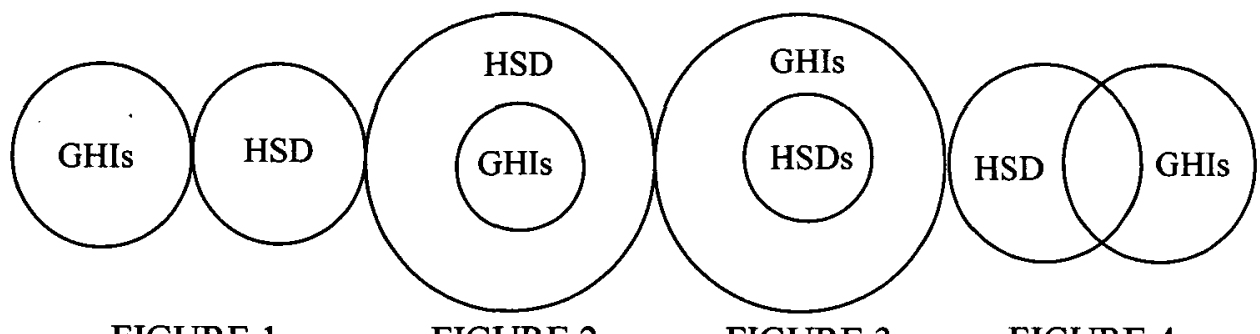

FIGURE 1

FIGURE 2

FIGURE 3

FIGURE 4

GHIs and HSD could be completely unrelated. GHIs could be viewed as a subset of HSD. HSD could be viewed as a subset of GHIs. Alternatively, GHIs and HSD could be viewed as constituting two separate but intersecting domains. Most would agree that separate but intersecting GHIs and HSD domains is the most appropriate frame, but this does not reveal the size of the intersection (positive synergies), and, hence, the feasible domain of win-win cooperation.

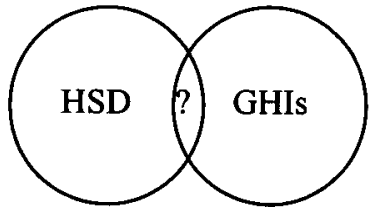

FIGURE 1

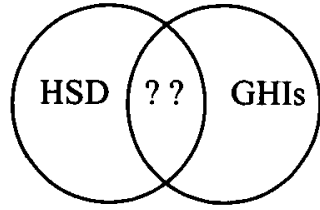

FIGURE 2

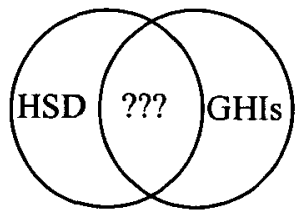

FIGURE 3

PSC's primary gamble is to work the technical side of the equation, hoping that it will credibly demonstrate a large overlapping area of positive synergies, and, hence, a large domain for prospective international cooperation. If this is the strategy, then the short-term political objective is to minimize potential disagreements and to hold the coalition together long 
enough to deliver on the technical mandate.

This approach is exactly what PSC tried to do. The body of the report summarizing the results of the Mexico Panel is captioned, "The Mexico Panel-a growing consensus." 26 The document indicates that there is reported consensus on the nature of the problem: "[w]ithout properly functioning health systems, neither disease-specific initiatives, nor comprehensive health services can achieve satisfactory and sustainable outcomes." 27 There is reported consensus around the nature of the agreed-to cooperative framework:

This is the right time to develop consensus around evidence-based guidance on maximizing positive synergies between health systems and all Global Health Initiatives. . . . The challenge is to generate mutual added value for both health systems and diseasespecific work by ensuring the greatest possible synergy between the different investments. ${ }^{28}$

There is further agreement about the nature of the daunting technical challenges involved in defining positive synergies: health systems are complex, existing data are inadequate and there is no agreed upon conceptual framework. $^{29}$ Addressing these issues is the responsibility of the technical track. $^{30}$

Other areas of reported consensus have the overtones of doing whatever is necessary to maintain the political coalition while the technical issues are addressed. The report lavishly praises the existing efforts of GHIs. ${ }^{31}$ Furthermore, the WHO makes it clear that PSC is not a Trojan horse seeking the reallocation of resources from GHIs to HSD. ${ }^{32}$ Finally, the WHO is trying to ensure that PSC does not become a forum to rehash old debates, such as those about vertical versus horizontal initiatives or comprehensive versus selective primary care. The focus must remain on a common future. ${ }^{33}$ This may be easier said than done.

26. MEXICO PANEL, supra note 23 , at 4 .

27. Id.

28. Id. at 6 .

29. Id. at 5 .

30. One striking and significant aspect of PSC is its willingness to acknowledge both what is known and what is unknown. Ironically, consciously acknowledging the "unknowns" may actually help create the political space the project needs to proceedparticipants must give the technical process sufficient time to develop a defensible roadmap.

31. See MEXICO PANEL, supra note 23, at 4 ("Disease-specific initiatives have made a defining impact ... and helped save many lives. ... [C] [C should be taken not to jeopardize these much needed investments.").

32. Id. at 5 ("Stakeholders can be assured that the objective is to make better use of all the available resources, and to leverage new and additional resources for public health.").

33. Id. at 6. 
The meeting of the 2nd Expert Consolation focused almost exclusively on the technical side of the positive synergies mandate. This is a daring gamble - trying to maintain a fragile political coalition, while hoping to make technical progress on a problem that is immensely complicated, if not intractable. The paper outlined a strategy to pursue three simultaneous tracks: (1) an academic track, (2) a civil society track and (3) an implementer track composed of those who will have to put any new proposals into practice. ${ }^{34}$ As a "starting point" for the conceptual framework, the $2 n d E x$ pert Consultation adopted the WHO's preexisting view of health systemsa series of interconnected building blocks - which was outlined in the 2007 WHO Report, Everybody's Business. ${ }^{35}$

\title{
C. 3rd Expert Consultation in Geneva (October 2-3, 2008)
}

"In October 2008, the [WHO] convened the third expert consultation to progress the work on maximizing positive synergies between health systems and Global Health Initiatives (GHIs). ${ }^{36}$ The primary focus was on the technical aspects of the GHIs/HSD challenge. Review of the existing evidence revealed that there was a dearth of research that met "conventional" standards. ${ }^{37}$ The evidence that did exist suggested that there are unlikely to be any universal, simple or comprehensive solutions. The question of whether greater integration within a health system increases or decreases the possibilities for positive synergies illustrates this point. ${ }^{38}$ One reason why generalizations about integration are difficult and dangerous is that local context is important and can have significant and varying impacts. ${ }^{39}$

\begin{abstract}
Arguments that promulgate the view that disease-specific initiatives and health systems strengthening exist in opposition, rather than in harmony, risk becoming counterproductive. If the Millennium Development Goals are to be reached, all those committed to global health must work together to produce the best possible health outcomes. All parties agree that any emerging divide must be urgently and satisfactorily resolved.
\end{abstract}

Id.

34. 2ND EXPERT CONSULTATION, supra note 25, at 2-3.

35. Id. at 3. The building blocks of a health system consist of: (1) service delivery, (2) health workforce, (3) information, (4) medical products, (5) financing and (6) governance. 2007 EVERYBODY's BUSINESS, supra note 9, at vi.

36. WORLd HEALTH ORG., REPORT ON THE 3RD EXPERT CONSUltation ON Maximizing Positive Synergies Between Health Systems and Globe Health INITIATIVES, WHO, GENEVA, 2-3 OCTOBER 2008, at 1 (2008) [hereinafter 3RD EXPERT CONSUltation] available at http://www.who.int/healthsystems/PosSyn3rdExpCons_ HR.pdf.

37. Id. at 2 ("Despite the intensity of debate around the integration of programmatic interventions into health systems, the results of a comprehensive systematic review of the existing evidence found very little evidence that was considered sufficient to meet conventional research expectations.").

38. Id. at 3 ("It is not possible to reach any firm conclusion on the question of whether an integrated health programme delivers better outcomes than a non-integrated programme because sufficient evidence on causality is not available.").

39. Id. ("The few published studies that document the integration of programmatic 
PSC's technical challenge is to define new research questions and to develop methodologies to address these types of questions. While it is a bold statement, the report is correct in its assessment that the "longer term agenda will, in effect, be about building a new science for health system research., ${ }^{, 40}$

The 3rd Expert Consultation outlines the agenda for the three PSC tracks: the Academic, Civil Society and Implementers Panels. The broad research question for the Academic Panel is straightforward: "[h]ow can GHIs and national health systems optimize their interactions to capitalize on positive synergies and minimize negative impacts thereby achieving their common goal of improving health outcomes?"41 While still somewhat ill-defined, the conceptual framework that will guide the project's initial inquiry is a blend of the traditional WHO building block understanding of health systems, with recognition of various plus factors such as the importance of interconnectedness and complexity. ${ }^{42}$ Once again, even this is ambitious. Openly recognizing complexity raises numerous challenges for conventional methodologies. "[T] tems and relationships is a relatively new field of research and one which neither quantitative nor qualitative research methods alone will capture sufficiently.,43

How does one go about approaching these research questions? "Meeting the challenge presented by the subject matter will require creative approaches that extend the frontiers of traditional research methodologies." ${ }^{.44}$ The paper provides some specific guidance. First, context is key.

The foremost challenge will be to capture the many contextual factors that can impact the interactions between GHIs and health systems. Research methodol-

interventions with health systems find that the results of integration vary widely depending on the context.").

40. Id. at 11 .

41. Id. at 5. More specifically, the academic panel will examine the following issues:

a) Identify relationships between GHI-funded programmes and health systems in varied country contexts;

b) Understand these relationships by establishing which factors influence the extent and nature of the interaction between GHI-funded programmes and local health systems;

c) Understand the impact by identifying the specific system designs and delivery strategies that have led to the most positive impacts and exploring how these designs and delivery structures influence the coverage of targeted and non-targeted interventions and health outcomes.

Id. at 7.

42. Id. ("It was stressed that the [building block] framework has limitations and is not being proposed as a health systems framework for any other purpose tha[n] to help organize the current programme of work.").

43. Id.

44. Id. at 5 . 
ogies must be sensitive to the fact that health systems are neither homogenous nor static and are subject to a wide range of social and political determinants. The work on positive synergies must show attention to such complexities and strive to produce a robust evidence base that combines context-independent findings that can be generally applicable, and contextspecific examples that can provide inspiration. By doing so, the work will test and challenge some of the thinking that exists and generate validity for best practice. $^{45}$

Second, researchers should employ mixed-methods. "There was agreement that a 'mixed-method approach' is an appropriate methodological response to the complexities inherent in the research agenda. A 'mixedmethod approach' can encompass quantitative and qualitative research and allow the use of new, alternate and unconventional information sources as well as involving multi-disciplinary teams. ${ }^{, 46}$ Finally, learning and adaptation must be an endogenous aspect of the research and ultimately the implementation process. "The meeting agreed that the work on positive synergies must strive to achieve a beneficial cycle of action guided by learning, and learning informed by action." ${ }^{, 47}$ The initial research, production of preliminary guidelines, and actual implementation must all be part of an open and ongoing process containing multiple feedback mechanisms.

The Civil Society Panel faces comparable challenges. PSC is innovative, in part, because of its efforts to incorporate civil society in its multiple roles of stakeholder, implementer and research subject. ${ }^{48}$ If one wants to

45. Id. at 6 .

46. Id. What does this mean in practice? With respect to the mixed-methods methodologies, the goal is a constant process of triangulation:

1. Global cross-country quantitative analysis-will look across many countries for the existence of statistical relationships between GHI investment and the inputs into and outputs from country health systems. 2 . Country level mixed-methods analysis-a series of studies that will investigate the operational detail of health care delivery and implementation to begin building theories about why the relationships (as identified in the cross-country analysis) exist. These are mixed methods studies that will use quantitative methods when possible to triangulate with qualitative results.

3. Provider unit level analysis-to gather data that will shed light on the impact of different system designs at the point of health care deId. at 7 . livery.

47. Id. at 6 .

48. Id. at 8 (Civil society actors are engaged in many different roles that have a bearing on the relationships between health systems and GHIs, including as service-users, advocates, and service- providers. It follows that, while the civil 
effectively link GHIs and HSD one must ultimately connect the global with the rural-local. Civil society will play an indispensable role in this process, and therefore, must be a critical part of the research agenda. The specific research questions defined by the 3rd Expert Consultation for the Civil Society Panel are as follows:

(a) Identify how and in what ways civil society participation can assist in maximizing positive synergies between GHIs and health systems;

(b) Understand and appreciate the views of civil society on how to maximize positive synergies;

(c) Increase awareness of the views of civil society on the modifications needed to increase the responsiveness of GHIs. ${ }^{49}$

This, also, will require new types of research methodologies. ${ }^{50}$ The civil society track is employing action research where traditional lines between academic and social practices are blurred. It is also another illustration of the need to make learning endogenous to the very process of research and implementation.

The Implementers Panel will play a different role from that of the Academic and the Civil Society Panels. PSC's approach is very pragmatic. To be effective, the end results must face real time political and logistical reality checks. "The implementers will not undertake original research but will play an advisory and an advocacy role, particularly in relation to the implementation of the WHO guidance that results from the work."

While the majority of the report from the 3rd Expert Consultation focuses on technical aspects of the GHIs/HSD problem, the political chal-

society partners enjoy valuable insight and access to civil society networks, the work must strive to achieve a balance between a descriptive, analytic and advocacy role.).

49. Id.

50. Id. The paper outlines the following methodologies to be employed:

1. Key informant interviews and semi-structured focus group surveys with country implementers, community health workers, advocates, and civil society policy makers (e.g. Global Fund Country Coordination Mechanism members). There will be a focus on obtaining information from grassroots and underrepresented marginalized constituencies.

2. Real-time action learning will create a feedback "loop" between learning and doing. The research will seek to identify where civil society is already using existing opportunities at [the] country level to maximize positive synergies between disease-specific interventions and health systems. Such light as can be shed on current good practice and will feed into the development of WHO guidance.

Id.

51. Id. at 9. The Implementers Panel consists of representatives from GHIs, recipient countries and non-governmental implementation bodies. One objective is to help "bridge the gap between research findings, recommendations and implementation by fostering country participation and by ensuring that the reality of country experience is taken into account at all stages." Id. 
lenge of maintaining the cooperative framework is an important subtheme. The report's summary of existing evidence is willing to indirectly criticize GHIs by stating that "[d]isease-specific initiatives have not created significant additional capacity in health systems." 52 The report is careful, however, not to make any direct criticisms. "Despite the emerging evidence of stresses, particularly on the human resource capacity of health systems, there is no conclusive evidence to suggest that HIV/AIDS-specific initiatives have produced adverse effects on other areas of health service delivery or health outcomes." 53 The claim of no "conclusive evidence" of damage may be correct according to conventional research standards, but it stands in interesting tension with the paper's critique of the inadequate state of extant social science research. In the end, PSC is willing to employ different standards in pursuit of its political and technical objectives. This is understandable. To be successful, PSC must maintain its political consensus. Politics and a complete fidelity to the truth are not always compatible objectives.

The PSC formula for maintaining political consensus takes more definitive shape in the paper. It can be summarized as follows: first, the present moment is no time for blame. ${ }^{54}$ Second, the positive synergies frame will remain a faithful statement of the underlying cooperative framework. Future action will be restricted to win-win options in the perceived selfinterest of all stakeholders. Parties will not cheat on the framework and the Campaign will not be used as a surreptitious effort at resource reallocation. $^{55}$ Third, parties must avoid rigid, ideological positions. ${ }^{56}$ As such, the process should focus on common goals, not areas of disagreement. "Reaching the hard-to-reach, including rural and marginalized communities, is now the major challenge facing all those involved in global public health and in disease-specific initiatives and health systems alike." ${ }^{, 57}$

52. Id. at 4 .

53. Id. (emphasis added).

54. Id. at 11 ("The focus must be on a counter-factual approach that can describe what might be achieved if things are done for the best and draw on this understanding to move forward.").

55. Id. ("It is essential that the work should not lead to any de facto cuts in diseasespecific spending but rather contribute to additional impact and real increases in resources.").

56. $I d$.

The debate around the interplay of disease-specific health initiatives and health systems has been characterized in the past by a polarization of views that can prove reductionist and counterproductive. The effort on maximizing positive synergies aims to nurture a new spirit of cooperation and this demands that passionately held positions should be set aside.

Id.

57. Id. 


\section{The Lancet Article and Venice Recommendations}

The first phase of PSC came to completion with the publication of $A n$ Assessment of Interactions between Global Health Initiatives and Country Health Systems, in the June 20, 2009 issue of The Lancet ${ }^{58}$ and the subsequent convening of the High Level Dialogues held in Venice, Italy on June $22-23,2009 .^{59}$ This is not the place to summarize the substantive findings of the WHO's year-long examination of the interface between GHIs and HSD. For that, one should read the article itself, as well as the final reports of the Academic ${ }^{60}$ and Civil Society Panels. ${ }^{61}$ Instead, this section examines the conceptual model of health systems underlying the project's analysis, reflects on PSC as a novel type of open, process-oriented policy making and considers PSC's recommended next steps.

Any effort to forge potential synergies between GHIs and HSD requires a conceptual framework that, among other things, defines what a health system is. PSC employs what is best thought of as a BuildingBlocks-Plus Framework for understanding health systems. ${ }^{62}$ The WHO's building blocks of a health system consist of: (1) service delivery, (2) health workforce, (3) information, (4) medical products, (5) financing and (6) governance. ${ }^{63}$ The plus factors stem from an appreciation that, in isolation, the building blocks provide only a static and rigid framework, one incapable of fully capturing a country's health system. Which plus factors to include and how they are described often varies. One factor is a focus on the interconnectedness of the building blocks. ${ }^{64}$ Related factors reflect concerns of complexity, localism (content-specificity) and dynamism. In the PSC's phraseology: "health systems are complex, context-specific and changing." 65 An additional plus-factor is the role that civil society unavoidably plays in the functioning of the health system. ${ }^{66}$

The relationship between the community and the building block aspects of health systems is captured in Figure One of The Lancet article, Conceptual Framework of the Interaction Between Global Health Initia-

58. PSC Lancet Article, supra note 6.

59. Venice Recommendations, supra note 11.

60. World Health Org., The Maximizing Positive Synergies academic Consortium, InTeractions Between Global Health Initiatives and Health Systems: EVIDENCE FROM COUNTRIES (2009).

61. World Health Org., The Maximizing Positive Synergies Civil Society CONSORTIUM, INTERACTIONS Between Global Health Initiatives and Health Systems: EVIDENCE FROM COUNTRIES (2009) [hereinafter FINAL REPORT CIVIL SOCIETY CONSORTIUM].

62. PSC Lancet Article, supra note 6, at 2139-40.

63. Id. at 2140 .

64. Id. ("Although these building blocks help to clarify the essential functions of health systems, efforts to address health systems should recognise the interdependence of each part of the health system.").

65. Id.

66. $I d$. 
tives and Country Health Systems. ${ }^{67}$ In this framework, both GHIs and country health systems directly impact the five building blocks of Governance, Financing, Health Workforce, Health Information Systems and Supply Management Systems, which are then influenced by the Community to affect Health Service Delivery. ${ }^{68}$ Health Service Delivery, in turn, determines Health Outcomes. This is a helpful starting point, but the article acknowledges that the conceptual framework "is not optimal" because it does not adequately capture the various plus factors associated with the health system, nor the fact that the entire health system, as well as individual health outcomes, are influenced by broader "economic, social, political, environmental, and other factors that are not included in our analysis."69

Critical to the success of future efforts will be their ability to fill in and supplement the components of the Building-Block-Plus Framework for $H S D$. In this process, theories underlying the various plus factors must be developed and integrated back into the foundational understanding of the role the various building blocks play individually and in combination. The three most important plus factors are: (1) context-specificity, (2) interconnectedness, and (3) the role of people and civil society.

Building-Block-Plus Framework for HSD

Building Blocks $\quad$ Plus-Factors

\begin{tabular}{|l|l|l|}
\hline Governance & & Context-Specificity \\
\hline Finance & & (Institutional Economics) \\
\hline Health Service Delivery & & Interconnectedness \\
\hline Health Work Force & & (Complex Adaptive Systems) \\
\hline Health Information System & & Civil Society \\
\hline Medical Products & & (Community System Strengthening) \\
\hline
\end{tabular}

Each plus factor can be associated with a different set of tools and theories. The tools of institutional economics can assist in understanding issues of context-specificity. ${ }^{70}$ Recent work in complex adaptive systems can be applied to address issues of interconnectedness. ${ }^{71}$ Finally, work on Community System Strengthening (CSS) can help address the plus factor of civil society. $^{72}$

Without doubt, these are complicated issues, but such complications are an inherent part of any honest effort to address this type of problem. Conventional policymaking, social science methods and systems of data

67. Id. fig.1.

68. $I d$.

69. Id.

70. See infra Part III.A.

71. See infra Part III.C.

72. See infra Part V. 
collection often fail to appreciate this fact. As a result, conventional tools are frequently of little use in providing credible insight at the interface between GHIs and HSD. What is as refreshing, as it is unusual, is how frank PSC is about the nature of these difficulties and how ambitiously it is committed to trying to transcend the limits of traditional approaches.

After spending twenty pages summarizing the findings of its year-long examination of the individual building blocks of the health system, the article begins a section captioned What we know and what we do not know. ${ }^{73}$

Despite the amounts invested and the important part played by health systems and GHIs, investigators do not have appropriate methods, or sufficient incentives (largely as a result of insufficient investment and political will), to assess the quality and effectiveness of the complex and context-specific interactions between health systems and GHIs. The paucity of robust evidence is testament to these methodological and other shortcomings. ${ }^{74}$

The complexity of the problem, the absence of information and the limits of existing methodologies must affect the very process of future policy making. This is a formidable, but exciting undertaking. What is called for is the co-construction of policymaking, theoretical framing, empirical methodologies, evidence gathering, learning, feedback and adaptation. PSC is aware of these challenges. ${ }^{75}$

No rigorous studies exist in which the effect of GHIs on health systems has been prospectively examined. In view of the amounts of resources that are being invested in health systems, new efforts are needed to improve data gathering, and new methods should be designed to specifically measure and investigate

73. PSC Lancet Article, supra note 6, at 2160.

74. Id.

75. Id. at 2161.

Two points have become clear from our assessment. First, GHIs and country health systems are not independent but are inextricably linked. Second, the two are dynamic, complex entities, such that examination of their interactions cannot be a simplistic, single variable, linear analysis, therefore raising caution about generalisations. Moreover, although the GHIs that we have focused on share key features, the many variations that exist between them contribute to the determination of their different effects on country health systems. 
health systems. $^{76}$

This will not be easy.

PSC ends this first phase of its work with a set of recommendations on how to move forward in this difficult environment. ${ }^{77}$ According to The Lancet article, the "purpose of these recommendations is to increase and expedite efforts to address the gaps in knowledge, and to encourage the creation of a new framework in which the disease-specific and health-systems approaches are mutually interdependent and have a common goal to improve the health of all people." ${ }^{, 78}$ The working paper produced by the High Level Dialogue in Venice outlines a complementary set of recommendations and makes a bold pronouncement. ${ }^{79}$ "The Venice Recommendations lay the foundations for a new paradigm in global public health-one in which more consistently productive and constructive interactions between Global Health Initiatives (GHIs) and country health systems will mean better value for money and better health outcomes." 80

The short version of the Venice Recommendations is: (1) be bold; (2) set targets; (3) enhance leadership; (4) engage communities; and (5) improve evidence. Being bold entails "[i]nfus[ing] the health systems strengthening agenda with the sense of ambition, the scale, the speed, and the increased resources that have characterized the GHIs." to be an ongoing political challenge. Despite the undeniable truth that health systems are essential, it is difficult to generate enthusiasm, in any policy setting, for the infrastructure of public action. Infrastructure is boring. Directly saving individual lives is exciting. Being bold over a long period of time will take effort and creativity. The recommendation of "setting targets" entails agreeing on "clear targets and indicators for health system strengthening." 82 One of the innovations propagated by GHIs has been the use of results-based financing. The difficulty with health systems, however, is that there are few clear, objective targets or performance measures. While targets are important, it is equally important that those targets be flexible and properly updated with improved understandings. Rigid and misguided targets could be worse than no targets at all.

There is an interesting difference between how the recommendation of "enhancing leadership" is characterized in The Lancet article versus in the Venice Recommendations. The Lancet recommendation is as follows: "[i]mprove alignment of planning processes and resource allocations among

76. Id.

77. Id. at $2161-63$.

78. Id. at 2161 .

79. Venice Recommendations, supra note 11, at 2.

80. Id. at 2.

81. Id.

82. Id. at 4 . 
GHIs, and between GHIs and country health systems." ${ }^{83}$ The Venice Recommendations, in contrast, has an almost exclusive in-country focus: "[p]romote country capacity for strong national planning processes and better alignment of resources with national planning processes. ${ }^{, 84}$ In fact, both are needed. Greater international harmonization is a perennial challenge, a fact acknowledged in the Paris Declaration. ${ }^{85}$ There is also a need for greater leadership (and capacity building) at the national level, country-led processes for defining national priorities concerning health system development, better coordination between countries and GHIs and harmonization amongst GHIs themselves. The multiple tiers connecting the-global-to-thenational-to-the-local must all be kept in mind.

The recommendation for "engaging communities" is recognition of the importance of localism and the increasingly significant role of civil society in global health. The old adage is that all politics are local. This is even truer with health care. Again, many GHIs have pioneered efforts to improve community participation in public health governance. Given the weaknesses in many national administrative and bureaucratic structures, new forms of collaboration with communities and with civil society will be critical for improving health systems. As recognized by the Civil Society Panel, the interface between a civil society, GHIs, HSD and the nation-state will require its own new theorizing and intellectual agenda.

The last recommendation may be the most important of all: improve evidence. "Improve evidence-based decision making in health by building the capacity of countries to generate and use knowledge." 86 This reflects the need for openness, adaptation and learning in forging policy under conditions of complexity and uncertainty. ${ }^{87}$ This will not be an easy task to sustain over time. But, this is also what makes the PSC so important and unusual from a standpoint of policy studies. The rest of this article is de-

83. PSC Lancet Article, supra note 6, at 2162.

84. Venice Recommendations, supra note 11, at 4.

85. Paris Declaration on Aid EfFectiveness: OWNership, Harmonization, ALIGNMENT, RESUlTS AND MUTUAL ACCOUNTABILITY (2005), available at http://www.alliance2015.org/fileadmin/user_upload/Paris_Declaration_on_Aid_Effectivenes s_.pdf.

86. Venice Recommendations, supra note 11 , at 6.

87. Id. The Venice Recommendations outline the difficulties:

Efforts to assess the quality and effectiveness of health systems and of the complex and context-specific interactions between health systems and GHIs are challenged, in part, by a lack of appropriate tools for analysis. Evidence generation is also dependent on the collection of good quality data through well-functioning country health information systems. New approaches to health systems strengthening, and to scaling up services for targeted diseases, must be accompanied by appropriate country-based operational research that can support better evaluation with an emphasis on interactive learning and "learning by doing." 
voted to exploring the challenges inherent in these efforts and what might be done to improve PSC's chances of success.

\section{Theoretical Challenges-CONCEPTUAlizIng Health Systems}

Developing a workable conceptual framework to explain what health systems are and how they operate will be critical to forging positive synergies in the future. The notion of building blocks provides a useful, even if incomplete, foundational set of intuitions. The objective of the BuildingBlock-Plus Framework is to incorporate additional concerns such as (1) context-specificity, (2) interconnectedness, and (3) civil society. Each of these plus factors, in turn, can be associated with a theoretical perspective that can permit its further development. Context-specificity can be associated with theories on institutional economics. Interconnectedness can be associated with theories of complex adaptive systems (systems thinking). Finally, civil society can be associated with theories of Community System Strengthening ("CSS").

Significantly, previous work by the WHO, largely neglected by PSC, already exists that sheds important light on the question of contextspecificity and the application of the tools of institutional economics to health systems. This work is the 2000 World Health Report, Health Systems: Improving Performance ("2000 WHR"). ${ }^{8}$ These lessons need to be reexamined and reclaimed: Shortly after the PSC Lancet article was published, the WHO-affiliated Alliance for Health Policy and Systems Research ("AHPSR") issued a report, Systems Thinking for Health Systems Strengthening (Systems Thinking), examining the challenges of interconnectedness and complexity. ${ }^{89}$ This section traces the development of international theorizing about health systems from the 2000 WHR through Systems Thinking to sketch the outlines of a viable conceptual framework for HSD. The plus factor of civil society will be examined in Part V with an exploration of Community System Strengthening.

\section{A. A Team of Rivals: 2000 World Health Report}

The issue of HSD first emerged on the international radar screen with the publication of the 2000 WHR. A little recognized fact, however, is that the 2000 WHR was the unusual product of a team of rivals, produced by a

88. World Health Org., The World Health Report 2000: Health Systems: IMPROVING PERFORMANCE (2000) [hereinafter 2000 WHR].

89. Alliance For Health Policy \& Systems Research \& World Health Org., Systems ThINkING For Health Systems StrengthenING World Health ORganization (2009) [hereinafter SYSTEMS THINKING], available at http://whqlibdoc.who.int/publications/ 2009/9789241563895_eng.pdf. 
collection of World Bank and WHO economists and health experts. ${ }^{90}$ It is an important document in the history of global public health, but unfortunately, it is also a largely forgotten document. Understanding its origins helps explain both its significance and subsequent neglect. In opening the report, the reader is in for a number of surprises. While the WHR is the flagship publication of the WHO, the document is clearly written by economists, not an epistemic community typically associated with the WHO. Furthermore, the brand of economics contained in the report is not that of conventional neoclassical theory; it fits much more comfortably in the domain of institutional economics. ${ }^{91}$ There is yet another surprise when one looks at the list of principal writers and finds a team heavily comprised of World Bank economists. The 2000 WHR is a document that the WHO could not have unilaterally produced, drafted by a group of World Bank economists, who probably could not have published the same work at their home institution. It is an exotic hybrid, but as horticulturists are well aware, not all exotic graphs take hold. Certain aspects of the report's economic reasoning were stillborn inside the WHO and did not bare fruit after the departure of the World Bank economists. At the same time, a number of the lessons of the 2000 WHR did take root at the World Bank, at least within its Health Nutrition and Population ("HNP") section. ${ }^{92}$

Inside the WHO, the 2000 WHR is largely remembered for initiating the building block framework for understanding health systems. ${ }^{93}$ What is forgotten, however, is why the $2000 \mathrm{WHR}$ was focusing on particular health system functions in the first place. The focus on health system functions

90. 2000 WHR, supra note 88 , at ii (listing principal writers).

91. The stamp of institutional economics is clear in the 2000 WHR. These tools and perspectives are responsible for a number of the report's innovative contributions. The recovery of these lost insights will be an important resource for the next phase of PSC's work, particularly as it wrestles with the context-specific aspects of health systems. Institutional economics affords a useful temperament for policy analysis, as well as a flexible set of tools. It should be acknowledged, however, that the tools of institutional economics are seldom definitive in their application. Moreover, work in this field is still tentative and like other aspects of the conceptual framework for HSD still require additional development and refinement.

92. These lessons are reflected in subsequent World Bank publications, such as the 2007 HNP sector paper 2007 HEALTHY DEVELOPMENT, supra note 9. Surprisingly, however, there is not a single citation to Healthy Development in the PSC Lancet article or in any of the preceding PSC reports or Expert Consultations.

93. The $2000 \mathrm{WHR}$ initially identified only four functions (building blocks): (1) stewardship, (2) financing, (3) creating resources and (4) delivering services. 2000 WHR, supra note 88 , at 25 . In subsequent analyses, the WHO subdivided the creating resources building block into its labor (workforce) and non-labor (medical supplies) components. 2007 EVERYBODY'S BUSINESS, supra note 9, at vi. The last stage of the evolution of the contemporary building block framework was the addition of information as a distinct building block for health systems. The significance of information, however, is extensively discussed in the 2000 WHR. 2000 WHR, supra note 88, at 129-32. This process yielded the six building blocks framework found in the 2007 WHO publication 2007 Everybody's Business and subsequently employed in PSC. 
was part of a larger argument that the what (functions) in health systems needs to be separated from the how. ${ }^{94}$ The separation of form and function is one of the most important teachings of institutional economics-many different organizational forms can accomplish the same identical function. ${ }^{95}$ Determining which organizational form is most appropriate depends heavily upon a country's culture, history and the composition of other prevailing institutions (context). ${ }^{96}$

In deciding which one of two (or more) institutional forms is most appropriate, policy makers need to engage in a process of comparative institutional analysis. ${ }^{97}$ This consists of a careful, side-by-side examination of the strengths and weaknesses of each alternative, based on their likely performance under real world conditions. This should be approached as an empirical and not an ideological undertaking. The important consideration is what works, not whether the proposal is consistent with the policy maker's a priori ideological beliefs. Furthermore, in designing a workable system, the 2000 WHR warns of the dangers of institutional fragmentation ${ }^{98}$ and stresses a countervailing need to seek institutional coherence, ${ }^{99}$ or what can also be thought of as intrasystem rationality. ${ }^{100}$ At the same time, policy makers need to be modest. Few projects will work strictly according to plan. Consequently, the capacity for learning and adaptation must be built into the process, sometimes by consciously affording discretion to front-line agents to make changes and alterations as events unfold. ${ }^{101}$

The $2000 \mathrm{WHR}$ warrants careful reevaluation by those seeking positive synergies between GHIs and HSD. The following is intended to simply suggest some of the lessons that need to be reclaimed. First, incentives

94. 2000 WHO, supra note 88 , at 61 (arguing for the need to separate the what from the how).

95. Id. at 45 (providing illustrations of how entire health systems can be organized within a single, integrated governmental organization, to systems with substantial vertical segmentation, to highly decentralized systems); see also id. at 63 ("Health services, like many other forms of production, can be implemented in more dispersed or more concentrated configurations, or in hybrid arrangements that combine some concentrated with some dispersed elements.").

96. Id. at 61 ("Both among and within countries there are marked differences in all these features, reflecting the complexity of the production process for health interventions and the variations in culture and tradition.").

97. Id. at 63 .

98. Id. at 68,120 (discussing the dangers of fragmentation).

99. Id. at $66,108,110,112$ (discussing the importance of coherence and consistency in structural design).

100. Peter J. Hammer, Arrow's Analysis of Social Institutions: Entering the Marketplace with Giving Hands?, 26 J. HEALTH POL. POL'Y \& L. 1081, 1095 (2001) (discussing the importance of intrasystem rationality); Peter J. Hammer, Competition and Quality as Dynamic Processes in the Balkans of American Health Care, 31 J. Health POL. Pol'Y \& L. (SPECIAL ISSUE) 473, 474 (2006) (same).

101. 2000 WHR, supra note 88 , at 64 (One must "balance the need for broad policy oversight with sufficient flexibility so that managers and providers can innovate and adapt policies to local needs and contexts in a dynamic way."). 
matter and actors will systematically respond to them. Different organizational structures create different types of incentives. In coherent systems, structures, incentives and objectives align in complementary directions. ${ }^{102}$ In dysfunctional systems, they do not. Similarly, policy makers need to be sensitive to the transaction costs associated with different alternatives. ${ }^{103}$ In this setting, nothing can be taken for granted. Governance (stewardship) not only matters, it comes at a cost. ${ }^{104}$ Those costs should be expressly considered and built into the system. The same can be said for information. ${ }^{105}$ In addition, agents and institutions will act strategically in their own perceived best interest. Accounting for such strategic behavior and taking appropriate counter-measures must be part of the initial and ongoing planning process. ${ }^{106}$ Like a good chess player, policy makers must be thinking many moves ahead of the game.

These considerations are illustrated at length in the 2000 WHR's discussion of organizational form as it relates to the function of service delivery. ${ }^{107}$ In 1937, Ronald Coase demonstrated how the same economic functions could be performed by a range of different private organizational forms, ranging from firms to contracts to markets. ${ }^{108}$ There is a public analogue to Coase's theory of the firm. The same public function can be performed by different organizational forms. Here the continuum starts with the direct provision of services by the state, then moves to various forms of quasi-public and non-governmental service provision and ends with the provision of services by private markets. ${ }^{109}$ Which organizational form is best depends upon a careful, context-specific exercise of comparative institutional analysis. "Each of these ways to organize health services has its strengths and weaknesses in various contexts and when applied to different types of population-based and clinical services." identify the dimensions upon which the organizational forms vary and assess what combinations of factors are most important for the underlying policy objectives.

For example, one consideration is the affect that organizational forms

102. Id. at 69.

103. Id. at 104 (discussing the role of transaction costs).

104. Id. at 126 .

105. Id. at 129 .

106. Id. at xvi (discussing how experiments with contracting and decentralization can trigger behavioral changes that must be accounted for in the planning process).

107. 1d. at 63-68.

108. Ronald Coase, The Nature of the Firm, 4 EconomiCA 386 (1937).

109. 2000 WHR, supra note 88 , at 62 ("Health services can be organized in three fundamentally different ways-via hierarchical bureaucracies, through long-term contractual arrangements under some degree of nonmarket control, and as direct, short-term marketbased interactions between patients and providers. These arrangements are independent of whether ownership is public or private.").

110. Id. at 62 . 
can have on incentives. ${ }^{11}$ To illustrate, the 2000 WHR identifies five types of incentives and examines how a range of different organizational forms map on to each of the relevant incentive components. ${ }^{112}$ This type of analysis begins to establish a fairly sophisticated framework to assess the strengths and weaknesses of different organizational forms. ${ }^{113}$ It is important to remember, however, that no system is perfect. It is likely that some organizational forms will rate high on some dimensions and not others. Comparative institutional analysis often serves to highlight the type of stark policy tradeoffs entailed in choosing between different organizational forms. The report continually stresses the importance of designing organizational forms of health service delivery that maintain appropriate levels of coherence $^{114}$ and avoid the dangers of fragmentation. ${ }^{115}$

The 2000 WHR aptly illustrates the tools and tactics of institutional economics as applied to the cause of HSD. These techniques and methods have been lost in the international discourse and need to be reclaimed.

\section{Id. at 65 .}

112. Id. at 66 fig. 3.4. The incentives examined include: (1) degree of autonomy (decision rights); (2) degree of accountability; (3) degree of market exposure; (4) degree of financial responsibility and (5) degree of unfunded mandates. Id. at 65 . The range of organizational forms being considered includes: (1) bureaucratic units; (2) contracted units; and (3) market units. Id. at 66 fig. 3.4.

113. The report engages in a similar detailed institutional economic assessment of the financing building block. The same function (financing) can be accomplished by a range of different organizational forms. Again, the what can be separated from the how. Some of the different organizational forms include centralized state control through the Ministry of Health with financing through general tax revenue, to social security type organizations with mandatory work-based contributions, to private health insurance markets. Id. at 108. Each of these organizational forms is associated with a different set of strengths and weaknesses. The exercise of comparative institutional analysis entails a mapping exercise of the different organizational forms with the range of factors policy makers deem most relevant to obtaining their objectives. Id. at $111-12$ (table 5.4 and 5.5).

114. Id. at 66.

The coherence of organizational incentives is especially important in the hospital sector because of the central role of these organizations in service provision. Countries that have introduced consistent objectives and that have aligned the five organizational incentives appear to have been more successful than countries that have ended up with conflicting ob-

Id. jectives and incentives regimes.

115. Id. at 68 .

As organizational units like hospitals or clinics become more autonomous, the service delivery system is at risk of becoming fragmented. Fragmentation may occur among similar provider configurations (hospitals, ambulatory clinics, or public health programmes) or between different levels of care. Such fragmentation has negative consequences for both the efficiency and the equity of the referral system unless explicit policies are introduced to ensure some sort of integration among the resulting semi-autonomous service delivery units. 
They will be instrumental in addressing the "content-specific" aspects of the PSC challenge as we move forward and fill in an important missing part of the Building-Block-Plus Framework.

\section{B. A Team No More: Differences Between the World Bank and WHO}

What was the fate of the 2000 WHR when the team of rivals decamped and returned to their home institutions? In 2007, the World Bank and the WHO separately produced reports where health systems and HSD played critical roles. The World Bank published its HNP Sector Paper, Health Development. ${ }^{116}$ The WHO published Everybody's Business. ${ }^{117}$ This section focuses on how each of these reports addresses the conceptual framework for HSD. ${ }^{118}$

It is telling how much the 2000 WHR influences the World Bank's 2007 sector paper. There is strong intellectual continuity between the two documents, partly due to overlapping personnel. The leader of the Healthy Development team was also part of the group that generated the 2000 WHR. ${ }^{119}$ Substantively, health systems and the importance of HSD assume central roles in the Bank's sector strategy. "'Strengthening health systems' may sound abstract and less important than specific-disease control technology or increased international financing to many people concerned about achieving HNP results. But well-organized and sustainable health systems are necessary to achieve results." 120 These and other sentiments expressed in Healthy Development resonate strongly with what would become core components of PSC. ${ }^{121}$

How does the Bank understand what a health system is and how it operates? Healthy Development imports the four-function approach of the 2000 WHR. "These key functions are: health services delivery, resource (input) generation (e.g., human resource training, and generation of technological knowledge for disease control, pharmaceuticals, and medical equipment), and system oversight (stewardship)."122 Unfortunately, although themes of institutional economics implicitly emerge in the discussion of certain issues, such as health care finance, ${ }^{123}$ an express reliance on the

116. 2007 HEALTHY DEVELOPMENT, supra note 9.

117. 2007 EVERYBODY's BUSINESS, supra note 9.

118. Aspects of the external political environment in which these reports were generated will be examined, in Part IV when the Global Fund's experience with HSD is addressed.

119. 2000 WHR, supra note 88 , at ii; 2007 HEALTHY DEVELOPMENT, supra note 9 , at 8 .

120. 2007 HeALTHY DEVELOPMENT, supra note 9 , at 14.

121. Id. at 25 ("There is now consensus that, for the renewed commitments of client countries and the international community to realize their full potential, synergy must be ensured between efforts to strengthen the health system and a focus on priority-disease results in LICs."). Not surprisingly, HSD assumes an important role in the World Bank's new "strategic directions" outlined in the report. Id. at 31 .

122. Id. at 45.

123. Id. at 51,170 . 
tools of institutional economics as a means of in-depth, context-specific analysis is missing from the 2007 report. ${ }^{124}$ Healthy Development makes two important contributions to the conceptual framework for HSD. The first is to begin to model the health sector as a complex adaptive system. The second is to begin to view HSD in terms of an increasingly disaggregated and stratified framework, where notions of institutional comparative advantage and division of labor can be applied to facilitate more effective cooperation.

Annex $L$ of Healthy Development is devoted to the question "What is a health system?"125 "A 'system' can be understood as an arrangement of parts and their interconnections that come together for a purpose.",126 The paper then explores the complexity of health systems. Each of the building blocks can be understood as a sub-system within the larger health system. Moreover, the health system itself is influenced by factors external to it. ${ }^{127}$ The paper proceeds to classify health systems as "open," "complex" and "adaptive." "28

Given the purpose, scale, and scope of a country's health system, it is not effectively controlled central$1 y$, and changes in a system are not predictable in great detail (even if some parts of the system appear to behave predictably). This is partly because people and organizations innovate, learn, and adapt to change and partly because reorganization occurs continually in health systems in both formal and informal ways. ${ }^{129}$

Like opening Pandora's Box, this raises difficult challenges. ${ }^{130}$ Neverthe-

124. See id. at 14. Healthy Development does, however, maintain many of the sensibilities of the institutional economic approach, stressing the interconnectedness of the building blocks and dynamic concerns. "[I]n practical terms," HSD "means putting together the right chain of events (financing, regulatory framework for private-public collaboration, governance, insurance, logistics, provider payment and incentive mechanisms, information, welltrained personnel, basic infrastructure, and supplies) to ensure equitable access to effective HNP interventions and a continuum of care to save and improve people's lives." Id. In this assessment, it is the sequencing and chain of events that matter.

125. Id. at $168-71$.

126. Id. at 168 .

127. Id. at 167 ("Many factors outside the health system influence people's health, such as poverty, education, infrastructure, and the broader social and political environment.").

128. Id.

129. Id.

130. A building-block-orientation without an appreciation of complexity can lead to unintended and counterproductive results. "In adaptive systems, optimizing one part of the system may lead to poor overall system performance." Id. at 171 . Health care presents a web of complex interrelationships. "Adaptive systems, on the other hand, have the freedom to respond to different stimuli in different and unpredictable ways and are interconnected with the actions of other parts of a system." Id. at 170-71. Complexity is also a reminder of 
less, policy makers must begin to pragmatically accommodate the complex nature of health systems in their planning, without becoming distracted or overwhelmed by it. ${ }^{131}$

Healthy Development's second contribution is to advance a framework for HSD that is increasingly stratified and disaggregated. ${ }^{132}$ The paper envisions "a collaborative division of labor with global partners along each organization's comparative advantages." 133 To this end, the paper introduces a new taxonomy of "main health system functions, system activities, and other determinants of system performance." 134 This taxonomy should be viewed as complimentary to and not a substitute for the building block framework. While neither elegant nor comprehensive, these main health system functions identified by the Bank are as follows:

(a) Health financing; ${ }^{135}$

(b) Fiduciary, logistical, and financial management arrangements of the system;

(c) System governance; ${ }^{136}$

the importance of context. "Systems exist within systems, and this context matters, because one part of a system affects another." Id. at 171 . Finally, complexity complicates and therefore limits the role of prediction.

Forecasting and modeling in health systems can be done to predict effects on health and poverty, but they are not predictable in detail because the elements and relationships are changeable and nonlinear, often in creative ways. The only way to know what complex adaptive systems will do is to observe them.

Id.

131. Id. at 168. We will return to Healthy Development's assessment of the implications of complexity for policymaking in the next section where the AHPSR's report on Systems Thinking for Health System Strengthening is examined.

132. This analysis was not done in isolation. The Bank's work is a direct response to the 2005 Paris Declaration's call for greater harmonization and the Global Task Team Final Report's call for a more conscious awareness of the underlying comparative advantages of different international organizations as a basis of more rational divisions of labor. UNAIDS, Global TASK TEAm ON IMPROVING AIDS COORDINATION AMONG Multilateral INSTITUTIONS AND INTERNATIONAL DONORS, FINAL REPORT (2005), available at http://data. unaids.org/publications/irc-pub06/jc1 125-globaltaskteamreport_en.pdf.

133. 2007 HEALTHY DEVELOPMENT, supra note 9, at 46.

134. Id.

135. Id. ("Funding policy (level, source, fiscal space); risk-pooling organization (health insurance); insurance regulation; health service purchasing and provider payment mechanisms; design of financing incentive framework for efficient allocation of R\&D and human resources.").

136. Id. at 46.

Accountability arrangements for providers, insurers, and government in health care investments; regulatory framework for private-public collaboration in the health sector; decisions on delegation of decision rights and market exposure for public providers; fiduciary arrangements for fiscal resource management in the public and private sectors; linkage of specific HNP sector reforms to cross-sectoral public sector reforms (e.g., civil service reforms to attract practitioners into rural areas). 
(d) Positively influencing household demand for effective HNP interventions; ${ }^{137}$

(e) Stewardship (sector oversight); ${ }^{138}$

(f) Organization and management of providers; ${ }^{139}$

(g) Technical aspects of disease control;

(h) Human resource training and creation of medical technologies and advances; ${ }^{140}$ and

(i) Clinical and field research on disease control intervention effectiveness and clinical protocols. ${ }^{141}$

This taxonomy is not intended to be definitive. What is important is that the typology starts to move beyond simple calls for greater "harmonization" and categorical approaches to building blocks. In this process, the taxonomy starts to recognize the multiple distinct levels and combination of functions needed to connect the-global-to-the-national-to-the-local, as well as the highly differentiated nature of the health system itself. For effective planning, harmonization and cooperation to take place, there will need to be an increasingly stratified and differentiated understanding of the GHIs/HSD interface. Once this threshold is passed, basic notions of authentic comparative advantage and divisions of labor will provide appropriate sets of intuitions about how cooperation and harmonization might best proceed.

The WHO's 2007 report Everybody's Business, provides a window into the influence of the 2000 WHR on subsequent WHO thinking about health systems. Everybody's Business is a slick, nicely produced document that persuasively presents the WHO's belief in the importance of HSD and advocates for future change. ${ }^{142}$ It is certainly more reader friendly than Healthy Development. While the 2000 WHR is a document clearly written by economists, Everybody's Business is a document that clearly was not. Not surprisingly then, the report reveals very little advancement in the WHO's substantive understanding of health systems in the seven years since the publication of the 2000 WHR. The four functions (building blocks) have cosmetically evolved into six building blocks, but little else has changed. Indeed, many understandings have atrophied and appeared to

137. Id. ('Demand-side interventions (such as conditional cash transfers, girls' education, community-driven development, and voice and choice reforms in health service delivery).").

138. Id. ("Overall sector leadership; sectoral strategic planning; provider regulation; inputs and health service quality control; epidemiological surveillance; identification of health priorities for setting mandatory basic benefits packages.").

139. Id. at 47 ("How to run a clinic, hospital, or provider network; organizing village volunteers; organizing NGO or private for-profit health service delivery.").

140. Id. ("Human resources; R\&D and manufacturing of drugs and supplies (beyond contributing to global financing and incentives for development and production of orphan drugs); R\&D and generation of medical technology.").

141. Id. ("Defining effective production functions; testing them in the field.").

142. See 2007 EVERYBODY's BUSINESS, supra note 9. 
have been forgotten. In the 2000 WHR, health system functions (building blocks) were separated from organizational form as part of a larger institutional economic argument that deepened the context-specific understanding of health systems. ${ }^{143}$ This perspective is largely absent in subsequent WHO publications. ${ }^{144}$ Everybody's Business makes the obligatory admonitions that the building blocks cannot be viewed in isolation and that interrelationships between the blocks are important, ${ }^{145}$ but the report offers very little in terms of suggesting how one could begin to understanding these dynamic interrelationships.

That said, Everybody's Business contains a number of positive attributes. More than a group of economists would appreciate the WHO recognizes the significance of the political and social dimensions of health systems. HSD "requires both technical and political knowledge and action." 146 This is an important reminder, even for institutional economists who are more open to such concerns than their neoclassical colleagues. "This means health system strengthening requires careful judgment and hard choices. It can be better informed by evidence and by the use of technical tools, but ultimately it is a political process and reflects societal values."147 As such, these processes are best served by ongoing interdisciplinary dialogue. This is perhaps what was really missing between 2000 and 2007. In the end, the power of the 2000 WHR was not the presence of World Bank economists, but the diverse disciplinary and institutional makeup of its group authorship. Fortunately, this ground is reclaimed in PSC. ${ }^{148}$

143. See discussion supra notes $92-101$ and accompanying notes.

144. There is another difference between the 2000 WHR and 2007 Everybody's Business reports. Rather than advancing economic understanding of health systems, 2007 Everybody's Business tries to re-frame the issue of health systems and HSD within the context of the Primary Health Care Movement and the Declaration of Alma Ata. 2007 EVERYBODY's BUSINESS, supra note 9, at 2 ("The directions set out for WHO in this document are determined by the values and goals enshrined in the Alma Ata Declaration."); see also id. at 5 (Box: "What can we learn from the primary health care values and approach?"). This connection is made even stronger in WORLD Health ORG., THE World Health RePORT 2008: Primary Health Care: Now More Than Ever xv, 26 (Box 2.1), 64 (2008), available at http://www.who.int/whr/2008/whr08_en.pdf. Discussion of the wisdom of linking the GHIs/HSD agenda with that of Alma Ata and primary health care will be addressed in Part VI of this article.

145. 2007 EVERYBODY's BusINESs, supra note 9, at v ("While the building blocks provide a useful way of clarifying essential functions, the challenges facing countries rarely manifest themselves in this way. Rather, they require a more integrated response that recognizes the inter-dependence of each part of the health system."); see also id. at 4 ("A health system, like any other system, is a set of inter-connected parts that must function together to be effective. Changes in one area have repercussions elsewhere. Improvements in one area cannot be achieved without contributions from the others. Interaction between building blocks is essential for achieving better health outcomes.").

146. Id.

147. Id. at 7 .

148. The WHO's Everybody's Business and the World Bank's Healthy Development 


\section{Confronting Complexity: An Introduction to Systems Thinking}

The WHO's PSC has made important progress toward improving our conceptual understanding of health systems and HSD. This progress continues. Health systems are "complex, context-specific and changing."149 The institutional economic approach of the 2000 WHR provides guidance on better understanding context-specificity through the tools of institutional economics. The 2007 Healthy Development paper begins to address the challenge of complexity. The understanding of interconnectedness and complexity is further advanced by the Alliance for Health Policy and Systems Research's 2009 report, Systems Thinking for Health System Strengthening (Systems Thinking). ${ }^{150}$

Readers are likely to be intimidated by the concept of complexity. Indeed, the report eschews the term as much as possible, using the rhetoric of "systems" and "systems thinking" rather than the more common references in the literature of complex adaptive systems. ${ }^{151}$ The report examines what complex systems are and how these characteristics improve our understanding of health systems. Properly understood, the logic of complexity is actually a call for modesty and simplicity. It is a rejection of elaborate metaplans in favor of more simple, process-oriented methods of policy formation and implementation. To that end, Systems Thinking outlines a relatively straightforward ten-step process of policy design and evaluation. ${ }^{152}$

Why is system thinking important in trying to understand health systems? Even the most well-intentioned intervention is likely to fail unless broader systemic implications are taken into account in the design and implementation of the undertakings. ${ }^{153}$ This has the potential to pile up unintended failure after unintended failure, with these failed interventions

embody some important commonalities. Both reports acknowledge the lack of a complete understanding of health systems, as well as the need to improve monitoring and evaluation in a manner that facilitates learning and new understanding. HEALTHY DEVELOPMENT, supra note 9, at 54-55; EVERYBODY's BuSINESS, supra note 9, at 24, 31. Both reports are frank about serious weaknesses within each institution in their capacity for effective future action given the complex challenges of HSD. HEALTHY DEVELOPMENT, supra note 9, at 30; Shakow, supra note 9, at 9; EVERYBODY's BUSINESS, supra note 9, at vi, 24, 26-27. Both reports outline sets of internal reforms and changes that would be necessary to better enable the respective institutions to undertake future work in the area. HEALTHY DEVELOPMENT, supra note 9, at 54, 59; Shakow, supra note 9, at 10, 55-56; EVERYBODY's BUSINESS, supra note 9 , at $28-30 ; 35-37$. These are honest and fair assessments. As PSC makes clear, substantial changes within every international organization and GHI will be required to make sustained progress in developing positive synergies.

149. PSC Lancet Article, supra note 6, at 2140.

150. See generally SYSTEMS THINKING, supra note 89.

151. Id. at $40 \mathrm{n} .2$ ("Our definition of 'system' is described in the literature as a 'complex adaptive system' - one that self-organizes, adapts and evolves with time. 'Complexity' arises from a system's interconnected parts, and 'adaptivity' from its ability to communicate and change based on experience.").

152. Id. at 54 (Box 3.2).

153. Id. at 19 ("Within such unmapped and misunderstood systems, interventionseven the very simplest-often fail to achieve their goals."). 
themselves, becoming obstacles to future actions. ${ }^{154}$ The hope is that planning undertaken from a system's perspective will have a greater chance of success. ${ }^{155}$ What then is "systems thinking?"156
Systems thinking is an approach to problem solving that views 'problems' as part of a wider, dynamic sys- tem. Systems thinking involves much more than a re- action to present outcomes or events. It demands a deeper understanding of the linkages, relationships, interactions and behaviours among the elements that characterize the entire system. ${ }^{157}$

The foil to systems thinking is what the report terms the "input-blackboxoutput paradigm." "The systems thinking approach goes beyond this 'input-blackbox-output' paradigm to one that considers inputs, outputs, initial, intermediate and eventual outcomes, and feedback, processes, flows, control and contexts." 158 This is a challenge to much of mainstream social science, including neoclassical economics, which treats the firm, the market and the state largely as content-less black boxes.

How does this approach relate to the building block orientation that

154. Id. at 51 ("'A systems perspective can minimize the mess; many of today's problems are because of yesterday's solutions."' (internal quotation marks omitted) (quoting Dr. Irene Akua Agyepong, Ghana Health Service Ministry of Health (2009))).

155. Id. at 19 .

If we accept that no intervention is simple, and that every act of intervening has effects-intended and unintended-across the system, then it is imperative that we begin to understand the full range of those effects in order to mitigate any negative behaviour and to amplify any possible synergies. We must know the system in order to strengthen it-and from that base we can design better interventions and evaluations, for both health systems strengthening interventions and for interventions targeting specific diseases or conditions but with the potential of having Id. system-wide effects.

156. A classic Swiss watch or an automobile engine is a complex system, but not an adaptive one. Systems Thinking lists eight characteristics that are common to complex adaptive systems. By understanding these characteristics, one begins to develop a set of intuitions for dealing with complex systems. Complex adaptive systems are:

1) Self-organizing;

2) Constantly changing;

3) Tightly linked;

4) Governed by feedback;

5) Non-linear;

6) History dependent;

7) Counter-intuitive; and

8) Resistant to change.

Id. at 40 (Box 2.1).

157. Id. at 33 .

158. Id. at 34 . 
lies at the center of existing conceptual frameworks for health systems? The approaches are relatively easy to meld together. Systems Thinking deepens the intuition of the Building-Block-Plus Framework's notion of interconnectedness. The WHO building blocks can be reconfigured as subsystems within the larger health system.

Systems are dynamic architectures of interactions and synergies. WHO's framework of health system building blocks effectively describes six sub-systems of an overall health system architecture. Anticipating how an intervention might flow through, react with, and impinge on these sub-systems is crucial and forms the opportunity to apply systems thinking in a constructive way. ${ }^{159}$

It must be clear, however, that the individual building blocks cannot be confused with the health system itself.

The building blocks alone do not constitute the system, any more than a pile of bricks constitutes a functioning building. ... It is the multiple relationships and interactions among the blocks-how one affects and influences the others, and is in turn affected by them-that convert these blocks into a system. ${ }^{160}$

In terms of the broader conceptual framework, the report makes another contribution. Systems Thinking stresses the role of people and communities as essential plus factors.

It is critical that the role of people is highlighted, not just as the centre of the system as mediators and the beneficiaries but as actors in driving the system itself. This includes their participation as individuals, civil society organizations, and stakeholder networks, and also as key actors influencing each of the building blocks, as health workers, mangers and policymakers. ${ }^{161}$

As complexity moves to simplicity and the elaborate formal blueprints of the past move to incremental, process-oriented planning, people and partic- 
ipation will play central roles. ${ }^{162}$

While it is important to know what systems thinking is, it is also important to understand what systems thinking is not. Systems thinking is not a promise of easy answers. "Systems thinking is not a panacea. Its application does not mean that resolving problems and weaknesses will come easily or naturally or without overcoming the inertia of the established way of doing things. But it will identify, with more precision, where some of the true blockages and challenges lie.,"163 It offers a new set of tools and tactics. It helps chart a new direction. ${ }^{164}$ That said, it is also true that existing practices in governments, in academics and in the learned professions are strongly biased in the traditional direction. ${ }^{165}$ Advocates and policy makers likely will be confronted with significant opposition in efforts to implement new processes of systems thinking and planning.

How does one make policy in the domain of complex adaptive systems? Systems thinking advises asking three questions: (1) "how can we anticipate potential effects?"; (2) "how can we conceptualize the actual behavior of the intervention?"; and (3) "how can we redesign a more sophisticated intervention that accounts for those potential effects?" 166 The report outlines a pragmatic ten-step process governing the design of the intervention and its evaluation from a systemic perspective. ${ }^{167}$ Substantial attention

162. This challenge is taken up again in Part $\mathrm{V}$ of the Article where the role of community systems strengthening and civil society is examined in greater detail.

163. SYSTEMS THINKING, supra note 89 , at 20.

164. Table 2.1 of the report contrasts traditional approaches to understanding and policy making with a systems thinking orientation. Id. at 43 . Traditional approaches are static and focus on particular events, often in isolation. Systems thinking seeks to frame problems in terms of patterns and behavior over time. Traditional approaches see behavior generated by the system as exogenously driven by external forces. Systems thinking is open to the reality that many aspects of the systems behavior are self-generated and endogenous. Traditional approaches focus on the trees and specific, isolated details. Systems thinking focuses on the forest and seeks to understand relationships. Traditional approaches utilize straight line thinking and direct theories of causation. Systems thinking encourages loop thinking and an openness to complex cycles of cause and effect playing out jointly over time. The lesson is not that one approach is good and the other is bad. The lesson is that the orientation must be correctly mapped onto the nature of the problem. Different problems require different approaches. Id.

165. The concept of "non-linearity" can be particularly difficult for traditional policy makers to comprehend and appreciate in practice. "[R]elations within a system cannot be arranged along a simple input-output line. System-level interventions are typically nonlinear and unpredictable, with their effects often disproportional or distantly related to the original actions and interactions." Id. at 41 . Trying to absorb and incorporate all of these considerations requires a change in traditional frames of thinking. It will be argued in the next section that the Global Fund's failure to make effective progress in HSD can be attributed, in part, to its failure to approach the problem of HSD from a systemic perspective.

166. Id. at 51 .

167. Id. at 20,54. The ten-step process is as follows:

I: "Intervention Design

1. Convene stakeholders

2. Collectively brainstorm

3. Conceptualize effects 
must be paid to the design phase. The convening of stakeholders and collective brainstorming are indicative of process-oriented methods to incorporate the plus factor of people and participation. ${ }^{168}$ This process must be open and inclusive to be effective. ${ }^{169}$ Ideally, the collective brainstorming process will identify a range of potential implications (traditionally unforeseen?), triggered by the interventions' impact on other parts of the system. In what should become an ongoing pattern of adaptation and course adjustments, there is the possibility to redesign the intervention in light of these concerns even before it is slated for implementation.

The design phase focuses not only on the structure of the intervention, but on how that intervention will be evaluated once implemented. This is innovative for a number of reasons. Oftentimes policies having systemwide effects are designed and implemented without any efforts at ex post evaluations. If evaluations are undertaken, it may only be as an afterthought. Evaluations conceived of after the intervention has been designed and implemented are seriously constrained in the types of methods they can employ and the data that can be collected. Building considerations of evaluation into the design process itself is reflective of an attuned, systems thinking orientation that will not only improve the design itself, but will also make for more innovative and effective forms of evaluation.

Because the focus of the ten-steps is on the design phase, inclusive of planning for evaluations, it does not expressly examine what should be done with the information collected from the evaluations. The logic of systems thinking makes the answer to this question obvious. There has to be a feedback mechanism built into the policy making and implementation process itself, where the results of the evaluations can lead to changes in the design and implementation of the intervention. Planning is not an event that ends with design and implementation. Planning must become an ongo-

\author{
4. Adapt and redesign \\ II: Evaluation Design \\ 5 . Determine indicators \\ 6. Choose methods \\ 7. Select design \\ 8. Develop plan and timeline \\ 9. Set a budget \\ 10. Source funding."
}

Id. at 54 (Box 3.2). This is just one of many possible ways one could envision policy making in the context of complexity, but it serves as a useful illustration. Rigid concepts and templates are to be avoided. "These steps are less an exact and rigid blueprint and more a conceptualized process. They are flexible and may be adapted to many different situations and possibilities." Id. at 54 .

168. Shifting to a process orientation and incorporating greater stakeholder participation can help make the transition to systems thinking self-sustaining. SYSTEMS THINKING, supra note 89 , at 74 ("Health system stewards can use the systems thinking perspective to increase local ownership of multi-stakeholder processes and respond to the dynamic of disease-specific, sometimes donor-driven 'solutions."').

169. Id. at 55 ("At a minimum, at least one knowledgeable representative of each subsystem (or building block) is required, plus at least one representative of the research community and one from a funding partner."). 
ing process with multiple structured occasions for learning, adaptation and change. In what must become a mantra on systems thinking analysis, evaluation must be the first step of a larger process of learning and adaptation.

Is any of this practical in the real world? "[M]any practitioners still tend to dismiss it as too complicated or unsuited for any practical purpose or application." "170 This is an important concern to address. Ironically, the primary challenges in implementing systems thinking may stem not from the complexity of the approach, but rather from the difficulties in changing the mindsets of traditional policy makers. ${ }^{171}$ It is important to draw the correct lessons from complexity. The World Bank paper Healthy Development is useful in this regard. Recognizing complexity is not a call for drawing up and more and more elaborate and detailed plans. This is the fundamental error of mechanistic thinking. A true appreciation of complexity calls for greater simplicity in initial planning, a dramatic change in the processes of policy implementation, a greater use of heuristics in guiding decisionmaking and a commitment to learning and adaption through time.

What are the practical implications of viewing health systems as complex adaptive rather than mechanical systems? In the first place, giving up a mechanical approach means spending less time on blueprints and detailed plans. It also means that it is less important to search for the "correct" health financing or organizational approach for a given country or a given context. $^{172}$

170. Id. at 75 .

171. Id. ("The first of the 'fundamental impediments' to the adoption of systems thinking is that we're prisoners of our frame of reference.") (quoting BARRY RICHMOND, SYSTEMS THINKING: FOUR KEY QUESTIONS 802 (1991)).

172. 2007 HeAlthy DeVElopment, supra note 9, at 170. Healthy Development outlines a number of common sense lessons for future HSD initiatives:

- Understand the context, look for connections between the parts (e.g., between programs, between demand and supply, across sectors), anticipating downstream consequences and identifying upstream points of leverage.

- $\quad$ Focus on simple rules to produce complex outcomes. Balance three types of rules that: (1) set direction (e.g., leadership and vision); (2) set prohibitions (e.g., regulations and boundary setting); (3) provide permission (e.g., setting incentives or providing resources).

- Understand how organizational structure influences behavior. How Ministries are organized, and how development assistance is provided matter a great deal. Health workers hired and trained under a centrally managed disease program will work differently from those accountable for all outpatient conditions and hired by a local health service organization.

- Use data to guide decisions. Constantly looking at how health systems perform is the best way to see how it is actually behaving and whether a project or new intervention is making a difference. 
An incremental, process-oriented approach to HSD is likely to be less frustrating and less complicated than approaching HSD using existing tools and temperaments. ${ }^{173}$

\section{ADMINISTRATIVE CHALlENGES-THE GLOBAL FUND's EXPERIENCE WITH HEALTH SYSTEMS}

This may be the most important section in the article, because it highlights the serious, but often underappreciated administrative challenges that can prevent GHIs from achieving positive synergies in practice. It is not enough for sophisticated, well-intentioned organizations to make official commitments to HSD. Indeed, the need to address disease specific interventions in a manner that constructively engages health systems is expressly recognized in the Global Fund's Framework Document. ${ }^{174}$ Nevertheless, the Fund's experience with HSD has been far from an unmitigated success. Ultimate success requires a GHI to make HSD a real institutional priority. It further requires a workable theoretical framework for HSD capable of informing the mundane administrative tasks that guide actions inside a large bureaucracy. Countries submitting applications have to know what types of proposals are viable. GHI administrators drafting application forms, writing guidelines and reviewing proposals have to understand how health systems function. They must eschew rigid, linear understandings of causation as they relate to positive synergies and embrace the broader notions of multiple and indirect forms of causation associated with systems thinking. Finally, the GHI itself must maintain receptivity to learning and adaptation in light of its own experiences. To make all these elements coalesce within a . complicated bureaucratic structure is not an easy task, but this is the essence of the administrative challenges.

A careful case study of the Global Fund permits us to take a long view of the relatively young field GHI experience with HSD. The Global Fund has been wrestling with these issues for nearly a decade. The story of the Global Fund's work is best told in three chronological chapters. Between 2002 and 2010, the Global Fund issued ten Rounds of calls for proposals. HSD in Rounds 1-4 (2002-2004) lacked both coherent direction and any identifiable results. This era also marked the beginnings of external complaints about the potential harmful impacts the Global Fund and other GHIs had on HSD. Rounds 5-7 (2005-2007) were periods of experimentation,

Id. at 170 . One can see the many parallels between this advice and the 10 -step process for designing interactions and evaluations in Systems Thinking.

173. No one person has to master all aspects of a complex system. The necessary collective knowledge and collective understanding can be created by convening the right sets of stakeholder groups.

174. Framework Document, Global FUnd to FigHT AIDS, TuBERCulosis AND MALARIA \& IV: Scope (F)(1) (2002) [hereinafter Framework Document], available at http:/www.theglobalfund.org/documents/core/framework/Core_GlobalFund_Framework_en /. 
consultation but ultimate retrenchment. Rather than aiming to help build health systems, Round 7 called for the demonstration that Global Fund projects would at least do no harm to existing structures. Rounds 8-10 (20082010 ) began to demonstrate slow progress and the evolution of new standards in the grant making process that should place the Fund in a constructive position to partner with future PSC efforts. The case study also highlights how the "political," "theoretical," and "administrative" challenges discussed throughout this article unavoidably overlap, in practice, in the quest for positive synergies.

\section{A. Rounds 1-4 (2002-2004): Is There any Real There, There for Health Systems?}

Getting the Global Fund up and running was a tremendous task and no one should expect perfection in such an undertaking. Unfortunately, one area that was neglected in the early years was HSD. This is surprising, because it was understood at the Global Fund's inception that HSD was essential to public health and that no sustainable progress could be made against HIV/AIDS, tuberculosis and malaria, without an effective public health infrastructure. The Global Fund Framework Document commits the Fund to support programs that "[a]dress the three diseases in ways that will contribute to strengthening health systems." 175 The "core principles" of the Framework Document further commit the Fund to support interventions against these three diseases in an manner that will "strengthen systems for working[] within the health sector; across government departments; and within communities." "176

Why then did the Global Fund get off to such an inauspicious start? The Fund has completed a number of internal evaluations of its early experience and is honest about its difficulties in addressing HSD. ${ }^{177}$ The Global Fund's Five-Year Evaluation cites the lack of external guidance and conceptual frameworks as one of the explanations for its initial poor performance. "The collective findings on health systems must also be placed within a broader information context that includes a general dearth of both data and validated methods to assess health systems performance globally." 178 That said, the Global Fund could have done more with what intellectual resources were at hand. Tellingly, the Fund's Five-Year Evaluation

175. Id. § IV: Scope (F)(I).

176. Id. § III: Principles (H)(3).

177. James Sherry et al., The Five-Year Evaluation of the Global Fund to Fight AIDS, TUBERCULOSIS AND MALARIA: SYNTHESIS OF STUDY AREAS 1, 2 AND 3 (2009) [hereinafter FIVE-YEar EVALUATION].

178. Id. at 22. Even today, the co-construction of a more workable conceptual framework is a necessary part of future action. "These recent developments illustrate increasing demand for more and better assessment of health systems performance, but also an implicit recognition that necessary frameworks, data systems, and methods are not yet in place." Id. 
arguably misidentifies the date of origin of the WHO's building block framework. "The WHO conceptual framework that identifies the six building blocks of health systems is quite recent (2007)," citing the WHO's report Everybody's Business. ${ }^{179}$ Once again, the 2000 WHR is the forgotten stepchild. It is true that Everybody's Business cosmetically refined the previous four building blocks (functions) of the $2000 \mathrm{WRH}$, but the core of the idea clearly lay in the earlier document. This is significant because it means that the substantial intellectual resource of the 2000 WHR was available at the 2002 launching of the Global Fund.

The real truth is that despite commitments in its Framework Document, HSD was simply not a high priority for the Fund in the early years. HSD "was not a first-order preoccupation at the time." 180 The Global Fund mistakenly believed that HSD would somehow take care of itself with the simple increase in spending on HIV/AIDS, tuberculosis and malaria. "The establishment of the Global Fund was with the expectation that strengthened health systems (including health information systems) would be an almost inevitable consequence of increased health sector spending." ethos is reflective of a strong and misguided belief in private ordering; the belief that markets and other systems will miraculously self-organize to respond to social needs. Even a casual reading of the 2000 WHR or an appreciation of its institutional economic underpinnings would have cast substantial doubt on this premise. ${ }^{182}$ Effective governance structures and well-functioning social institutions are too often the exceptions in human history, not the rule. Their creation and cultivation cannot be an afterthought left to chance. ${ }^{183}$

179. Id.

180. Id. at 12 .

181. Id. at 11-12; see also id. at 12 ("So while strengthened health systems were broadly appreciated as a desirable outcome of greater levels of investment, they were not generally seen as a necessary precondition for those investments.").

182. A true understanding of the institutional economic lessons inherent in the 2000 WHR-lessons lost on the WHO itself-would have helped the Global Fund avoid the mistake of not prioritizing HSD and wrongly believing that HSD could somehow take care of itself.

183. The Global Fund's retrospective assessment is consistent with contemporaneous documents of the time. While the absence of evidence of careful Global Fund thinking about HSD is not necessarily evidence of absence, one cannot help but be disappointed with the Global Fund's early work product. In 2005, the Fund published a document, MEASURING THE SYSTEM EFFECTS OF THE GLOBAL FUND WITH A FOCUS ON ADDITIONALITY, PARTNERSHIPS and Sustainability. Global Fund to Fight AIDS, Tuberculosis and Malaria, MEASURING THE SySTEM EFFECTS OF THE GLOBAL FUND WITH A FOCUS ON ADDITIONALITY, PARTNERSHIPS AND SUSTAINABILITY (2005). Thinking about domestic health systems plays at best a very minor role in the report. The standard international phrase and acronym, Health System Strengthening ("HSS"), does not even merit an entry on the list of abbreviations used. This is true despite the fact that the ostensive purpose of the report was to "better define measurements of the systems effects of [the Global Fund's] activities." Id. at 5. The factors of additionality, partnerships and sustainability are critical and remain so for future system-wide action, but HSD is critical as well. The absence of a focus on health system 
What fills the void of a working conceptual framework for health systems and a strong commitment to HSD in the early grant making Rounds? The answer is in the bureaucratic logic of the Global Fund process itself. Guidelines must be written. Application forms must be drafted, filled out and reviewed. Just as the 2000 WHR is a document clearly written by a particular brand of economists, the stamp of bureaucrats and lawyers clearly marks the Global Fund's initial efforts to define and implement criteria for HSD. This is a dangerous setting where lengthy and complicated forms can and did trump substance.

The Global Fund's ostensive objective was to draft a set of administrative materials that were consistent with its Framework Document. The Framework Document commits the Global Fund to support programs that "[a]ddress the three diseases in ways that will contribute to strengthening health systems." 184 This language was interpreted-and it is an act of interpretation-to require a clear link between any proposal for HSD and one of the three targeted diseases. But, this proposition too requires further interpretation. What does it mean for a proposal to be "linked" to one of the three diseases? Here, the lack of a conceptual framework for HSD becomes critical. Notions of linkages and causation should be derived from defensible theories about what health systems are and how HSD can best be accomplished. Rather than drawing from lessons of systems thinking with multiple and indirect forms of causation and layers of interconnectedness, the Fund reverted to mechanistic, linear modes of thinking and causation. In the wrong setting, these assumptions can be misguided, wrongheaded and even dangerous. Such standards will almost unavoidably generate a poor set of HSD proposals that will be considered by an increasingly frustrated Technical Review Panel. Keeping these dynamics in mind helps explain much of what is disappointing about the Global Fund's early experience with HSD.

To say that the Framework Document raises issues of interpretation is not to deny that there are difficulties inherent in trying to square the circle of GHIs and HSD.

Recognition of the critical role of health systems in supporting service delivery gives rise to a complex challenge: how should funding agents such as the GF best target their resources in order to build stronger health systems while retaining a primary focus upon

development in this Report is in line with the admission that health systems were simply not "a first-order preoccupation at the time." FIVE-YEAR EVALUATION, supra note 177, at 12. The importance of health systems was only hinted at in the 2005 Report. The Report makes no effort to define health systems or to develop or discuss potential conceptual frameworks. Tellingly, there is no citation to, nor discussion of the WHO's $2000 \mathrm{WRH}$.

184. Framework Document, supra note 174, at $\S$ IV: Scope (F)(1); see also id. $\S$ III: Principles $(\mathrm{H})(3)$. 
the diseases which constitute their core mandate? ${ }^{185}$

This is not an easy task. "According to guidelines for Round 1, a proposal 'may include interventions to improve national capacity associated with the delivery and monitoring of programmes but should not have capacity building as its main focus." 186 The phraseology in Round 3 was slightly more accommodating to $\mathrm{HSD}$, but still required a direct connection between HSD and the covered diseases. "A proposal must address one or more of the three diseases (HIV/AIDS, tuberculosis, or malaria) and may also address system-wide/cross-cutting aspects of these diseases in ways that will contribute to strengthening health systems."187

According to the Global Fund, HSD work and the specific diseases must be linked. Round 1 Guidelines "state any proposed actions must be shown to be linked to achievement of clear, measurable and sustainable HIVAIDS, TB and malaria outputs and outcomes."188 This is contrary to the teachings of complex adaptive systems. Requiring direct notions of causation that will produce measurable outcomes with a short timeframe, ultimately rules out a wide-range of legitimate HSD initiatives that would in fact make the Global Fund's work in HIV/AIDS, tuberculosis and malaria more effective. Workforce investments provide one illustration of the problem.

[P]roposals are asked to demonstrate a direct link between spending on the health workforce and effects on the patient/target population. Studies have shown this link at the macro level demonstrating a correlation between health outcome indicators (i.e. child

185. Kate Stillman \& Sara BenNett, Systemwide Effects of the Global Fund: INTERIM FINDINGS FROM THREE COUNTRY STUDIES 1 (2005) available at http://www.theglobalfund.org/documents/library/library_iepnadf196_report_en/. The same challenge is described elsewhere as a "tightrope walk." Sigrid Drager et al., Health Workforce Issues and the Global Fund to Fight AIDS, Tuberculosis and Malaria: An Analytical Review, 4(23) HUM. ReSOURCES FOR HEALTH 1, 3 (2006), available at http://www.humanresources-health.com/content/pdf/1478-4491-4-23.pdf. "[T]he Global Fund has entered a kind of tightrope walk by focusing on its clearly defined goal to fight the three targeted diseases, but at the same time recognizing that adequate capacity of the health system is a prerequisite for any successful intervention." $I d$.

186. Drager et al., supra note 185 , at 3.

187. SARa BenNetT \& Alan FaIRBank, THE System-Wide EfFeCtS OF the Global FUND TO FIGHT AIDS, TUBERCULOSIS AND MALARIA: A CONCEPTUAL FramEWORK 6 (2003), available at http://www.healthsystems2020.org/files/1559_file_Tech031_fin.pdf (quoting Global Fund to Fight AIDS, TUBerculosis aNd Malaria, GUIDELINES For Proposals 7 (2002)).

188. World Health Org., The Global Fund Strategic approach to Health SYSTEM STRENGTHENING: REPORT FROM WHO TO THE Global Fund SECRETARIAT 37 (Annex 5) (2007) [hereinafter WHO-GF CONSULTATION], available at http://www.who.int/ healthsystems/GF_strategic_approach_\%20HS.pdf. 
mortality) and the density of the health workforce. However, it is quite a different challenge to prove such a direct connection for specific interventions to invest in human resources for health that are described in Global Fund proposals. One of the main obstacles is certainly the long time lag, which is typical for many investments for the health workforce, such as training of health professionals. ${ }^{189}$

Not surprisingly, workforce proposals faired very poorly in the early rounds of Global Fund review. Malawi's proposal in Round 1 is an important illustration. "Malawi's GF proposal included comprehensive and crosscutting systems issues such as broad human resources and infrastructure development, in alignment with a broader national strategy which recognized the importance of such issues to the implementation of activities targeted to the focal diseases." 190 The rationale for the proposal was highlighted in the accompanying cover letter from the Principal Secretary for Health. "Priority should be given to systems strengthening in the first year, so that all future expanded support from the Fund can be wisely, confidently and effectively directed." 191 Malawi's broad proposal was rejected. "Unfortunately, most health system strengthening elements were removed from the scope of activities approved in the final grant agreement."192

The Global Fund is committed to results-oriented funding. If one judges the Fund by its own standard, HSD performance in the first four Rounds was very disappointing. The Global Fund received a total of ten applications for all four Rounds and funded only one of those ten applications. ${ }^{193}$ Rounds $1-4$ of the grant making process had failed to produce a workable system for identifying and encouraging proposals that contributed to HSD.

[F]or the first four grant rounds, proposals were submitted under different rubrics that responded to the three focal diseases supported by the GF . . . . there

189. Drager et al., supra note 185 , at 4 (citations omitted).

190. STILLMAN \& BENNETT, supra note 185 , at 2 .

191. Id. at 3 (quoting cover letter from Dr. R.B. Pendame, Malawi Principal Secretary for Health, accompanying Malawi's Round 1 Global Fund Proposal (Mar. 2002)).

192. Id.

193. Global Fund to Fight AIDS, Tuberculosis and Malaria, Mid-Term Review of THE SeCOnd Voluntary RePLENISHMENT 2008-2010, Progress Report on Health System Strengthening 4 (2009) [hereinafter MID-TERM REVIEW 2008-2010], available at http://www.google.com/url?sa $=t \& r c t=j \& q=\&$ esrc $=s \&$ source $=$ web\& $c d=1 \& \mathrm{cad}=$ rja\&sqi $=2 \& v e d=0$ CD8QFjAA\&url=http $\% 3 \mathrm{~A} \% 2 \mathrm{~F} \% 2 \mathrm{Fwww}$.theglobalfund.org\%2Fdocuments $\% 2 \mathrm{Freplenishment} \% 2$ F2009\%2FReplenishment_2009CaceresHealthSystemStrengtheningProgress_Report_en\%2F\&ei= EvErUJyDIqrMyQGnxIH4 $\bar{A}$ Aw\&usg=AFQjCNG-oV_zif4usIOURADpAD - daBsuzJg\&sig2=6b7DP3Z_EonTEOfpGN8kxw. 
lacked any guidance from the GF about what types of broader health systems strengthening-if any-could be included in proposals to the GF. Thus during early rounds, many country proposals avoided health system strengthening interventions, as it was uncertain how acceptable they were. ${ }^{194}$

This is clearly not what the Framework Document had in mind when it committed the Fund to operate in a fashion that contributed to HSD. The promise of the Global Fund and HSD remained unfulfilled. ${ }^{195}$ The lack of a viable conceptual framework played an important role in explaining this failure. ${ }^{196}$

\section{B. Rounds 5-7 (2005-2007): Experimentation, Consultation but Re- trenchment}

In Round 5, the Global Fund introduced a potentially innovating experiment for HSD funding. Rather than requiring HSD initiatives to be tied to specific disease proposals, the Fund opened a separate window for HSD evaluation. ${ }^{197}$ This was similar to an experimental approach being introduced by GAVI. ${ }^{198}$ The change was welcomed by many as a substantial improvement in HSD strategy. "The GF's recent policy shift-including health systems strengthening in its Round 5 application process-appears essential to the achievement of its disease-related objectives." "199 If one evaluated the substance of the underlying documents, however, the actual contents of the Round 5 Guidelines were not substantially different from the standards employed in the previous Rounds. ${ }^{200}$

Thirty applications were submitted to the Round 5 HSD window. Only three proposals, however, were funded, including an application from Malawi to address the same workforce concerns that were the subject of their unsuccessful Round 1 application. ${ }^{201}$ In light of its growing experi-

194. STILLMAN \& BENNETT, supra note 185 , at 2 (emphasis in original).

195. Id. at 48 ("[T] to be small.").

196. Id. at 49 ("For many elements of the health system, there is no clear vision or agreed strategy for how to strengthen them-this is true both at the global and the country levels.").

197. Id. at 3 ("In Round 5, the GF for the first time included in its call for proposals, a health systems strengthening component in addition to components addressing the three priority diseases.").

198. WHO-GF CONSUlTATION, supra note 188 , at 41.

199. STILLMAN \& BENNETT, supra note 185 , at $\mathrm{xxi}$.

200. WHO-GF CONSULTATION, supra note 188, at 36 ("Round 5 introduced a separate 'Health Systems Strengthening' component, to improve upon and clarify the 'Integrated' component of Round 4. In practice, the guideline definitions for both were very similar.").

201. ERIC Friedman, Guide to Using the Global Fund to Fight AIDS, 
ence, the Global Fund's Technical Review Panel ("TRP") issued a report detailing certain deficiencies with HSD applications, as well as the Global Fund application process for dealing with health systems. The report included the following criticisms:

- The definition of HSS proposals in the Proposal Form and Guidelines was too vague and too broad, with little guidance to applicants on any specific focus for these proposals.

- The Proposal Form has been designed for the disease specific components, and is largely unsuitable for the submission of HSS proposals.

- There has been insufficient consideration given to the impact of inviting separate HSS proposals, while insisting that there be a specific linkage to one or more of the three diseases.

- Applicants were not given any specific guidance on what an effective linkage between HSS and a disease component should or could look like. ${ }^{202}$

The TRP report concluded that the "GFATM System is not currently set up to generate strong HSS proposals, nor to evaluate these effectively."203

In light of these problems the TRP sought advice from the Global Fund Board on the following issues:

- Whether to retain a separate category of HSS proposals, or to reintegrate these within disease proposals, while making it clear that disease proposals can encompass a broader range of HSS elements than was previously accommodated.

- Whether or not HSS elements are submitted separately, or within disease proposals, the precise range of HSS elements that GFATM wishes to fund should be carefully defined.

- Depending on the resolutions achieved on the above issues, other important issues such as appropriate CCM composition, content of Proposal Forms and Guidelines, and TRP composition, will also need to be addressed. ${ }^{204}$

In the wake of the Round 5 experience, the Global Fund was still struggling to define the meaning of HSD in light of its Framework Document and was gaining very little traction. It is important to read the TRP evaluation of the Round 5 proposals not as a specific critique of the notion of a separate win-

TUBERCULOSIS AND MALARIA TO SUPPORT HEALTH SySTEMS STRENGTHENING IN RoUND 6, 11 (2006), available at http://www.equinetafrica.org/bibl/docs/FRIehs.pdf.

202. Global Fund to Fight AIDS, Tuberculosis and Malaria, Eleventh Board MEETING: REPORT OF THE TECHNICAL REVIEW PANEL AND THE SECRETARIAT ON ROUND FIVE Proposals 24-25 (2005) [hereinafter TRP REPORT ON ROUND FIVE], available at http://www.who.int/healthsystems/gf8.pdf.

203. Id. at 25 .

204. Id. 
dow for HSD funding, but rather as a cumulative critique of the Global Fund's failure to find satisfactory answers to the underlying relationship between the Fund and HSD over the first five rounds of its grant making process.

The issues raised by the TRP are not only technically complicated, but they are politically charged. ${ }^{205}$ Politics play an important role within the diverse Board of the Global Fund, as well as in the broader international public health architecture. The next two years marked a period of intrigue, external consultations and intense fighting over the Global Fund's role in HSD. In 2005, factions inside the Global Fund and the World Bank commissioned a study of the roles that both institutions should play in the future of international HSD. ${ }^{206}$ The paper, Global Fund-World Bank HIV/AIDS Programs Comparative Advantage Study, was prepared by Alexander Shakow, a retired World Bank consultant. ${ }^{207}$ Shakow was properly critical of the limitations of the Fund's previous ad hoc approaches to HSD.

[T]he Global Fund argues that about half its financing has gone to support systems development (even before the Fifth Round established a special category for this purpose), but what research evidence there is suggests that relatively little disease-specific investment of this kind actually has a lasting impact on delivery systems, unless it is designed with that objective in mind. ${ }^{208}$

Shakow's primary conclusion, however, was that there should be a new international division of labor where the Global Fund would limit its activities to an express focus on the three target diseases-HIV/AIDS, tuberculosis and malaria. $^{209}$ Who should take broader responsibility for HSD? Shakow asserted that the World Bank should play the leading role. $^{210}$ In practical terms, this implied that the Global Fund should close

205. SHAKOw, supra note 9, at 27 ("This category was added despite the reluctance of some Board Members and staff who considered this a dilution of the Global Fund's core focus on the three diseases.").

206. Ctr. for Global Dev., Where is the Comparative advantage? The Global FUND AND WORLD BANK HIV/AIDS PROGRAMS MOVING FORWARD 5 (Feb. 7, 2006) available at http:/www.cgdev.org/doc/event\%20docs/2.7.06\%20HIV/transcript\%202.7.06.pdf (noting that the Report was commissioned by Christopher Benn, Director of External Relations of the Global Fund and Jonathan Brown, Operations Advisor, Global HIV/AIDS Programs at the World Bank).

207. SHAKOW, supra note 9.

208. Id. at 38 .

209. Id. at 47 ("Its main focus in this regard should be on financing directly the prevention and treatment of the three diseases.").

210. Id. at 8 ("[T] he Bank should take the lead in this area. This does not mean that the Global Fund should not be concerned with health system strengthening, but it should mean 
the Round 5 window for HSD. "The Global Fund should not include health system strengthening as a separate priority category in its Round 6 and future Requests for Proposals. Instead, the World Bank should take the lead in this area." 211 While the World Bank sought to return the Global Fund to a narrow disease-specific focus, the Global AIDS Alliance and Health Gap, with the support of thirty plus experts and at least 300 non-governmental organizations ("NGOs"), fought to keep HSS interventions as its own category in the Global Fund proposal form. ${ }^{212}$ To their dismay, in April of 2006, the Global Fund Board adopted a new proposal application which did not include a separate category for HSD interventions. ${ }^{213}$

A return to the old format did not improve the quality of the applications. The TRP was as critical of the Round 6 applications as it was of the Round 5. "[T]he TRP was again disappointed and concerned by the low overall quality of the HSS elements proposed within many of the Round 6 proposals reviewed."214 The problems remained largely the same. "Many of the weaker HSS elements within proposals demonstrated several of the typical problems of other unsuccessful proposals, including being too broad and ambitious, too vague in their objectives and/or proposed activities, and with poor work plans and/or budgets." 15 Much of the blame had to rest with the lack of a clear vision and guidance on the part of the Global Fund itself.
As noted after Round 5, the Global Fund has yet to clearly define the scope and extent of activities that it is willing to fund under the rubric of HSS activities. This leaves the scope and definition of such activities too vague and broad, and the current proposals there- fore range widely. ${ }^{216}$

In the end, the TRP concluded that these are policy questions that must be

that the lead role in this area should generally be assigned as a matter of policy to the World Bank.").

211. Id. at 50 .

212. Gorik Ooms et al., Medicines without Doctors: Why the Global Fund Must Fund Salaries of Health Workers to Expand AIDS Treatment, 4 PLOS MEDICINE (2007), available at http://www.plosmedicine.org/article/info\%3Adoi\%2F10.1371\%2Fjournal.pmed.0040128.

213. MID-TERM REVIEW 2008-2010, supra note 193, at 4; WHO-GF ConsUlTATION, supra note 188, at 36 ("In Round 6, there was no separate component for HSS. Applications for activities . . . could only be included within the disease component for which such activities were deemed necessary.").

214. Global Fund to Fight AIDS, TubERCulosis and Malaria, FourteEnTH Board MEETING: REPORT OF THE TECHNICAL REVIEW PANEL AND THE SECRETARIAT ON ROUND 6 PROPOSALS, GF/B14/10 REVISION 225 (2006) [hereinafter TRP REPORT ON Round 6], available at http://www.theglobalfund.org/documents/board/14/GF-BM-14_10_TRPReport Round6.pdf.

215. Id. at 26 .

216. Id. 
resolved by the Global Fund Board. ${ }^{217}$

The issue was debated at the 15th Board meeting in April 2007. This provided another opportunity for proponents of the idea to raise the possibility of funding HSS through a separate window. Others expressed concern that the WHO be brought into the consultation process, not just the World Bank. $^{218}$ Decision Point GF/B15/DP6 directed the Global Fund Policy and Strategy Committee to study and make recommendations to the 16 th Board Meeting on the following questions:

- Whether the Board should continue to fund "Health-Systems Strengthening" (HSS) interventions exclusively within disease components or, in addition, establish a separate HSS component for proposals to the Global Fund;

- The appropriate parameters for allowable HSS activities;

- The possible use and nature of conditionality for applying for HSS funding; and

- The possible use and nature of ceilings for HSS funding. ${ }^{219}$

Furthermore, these recommendations were to be made after seeking consultation with the WHO. ${ }^{220}$

In response, WHO convened what it called a "Jury Consultation" to discuss the broad impact of the Global Fund's investment strategy, and more narrowly, to brainstorm ideas in response to the four questions posed by the Global Fund Board. ${ }^{221}$ After surveying the changing landscape between GHIs and HSD and noting the significance of country context and diversity, the WHO framed its challenge as follows:

The question is how to ensure the Global Fund's investment approach to HSS adequately reflects this [country-specific] diversity; does so in a way that reduces uncertainty and is based on clear criteria; has benefits for other health priorities-or at least does no harm, and stays true to its business model of being

217. Id. ("The TRP therefore recommends that the Board convene a suitable forum which can discuss and attempt to resolve the question of the appropriate scope and definition of acceptable HSS activities prior to Round 7.").

218. Global Fund to Fight aidS, Tuberculosis and Malaria, Sixteenth Board MEETING: REPORT OF THE FIFTEENTH BOARD MEETING, GF/B16/2 REVISION 18 (2007), available at http://www.theglobalfund.org/documents/board/16/GF-BM16-02-Report_ Fifteenth_Board_Meeting.pdf.

219. Id. at 12 .

220. $I d$.

221. This process generated the WHO document, The Global Fund Strategic Approach to Health System Strengthening Report from WHO to the Global Fund Secretariat, which was to assist the Policy and Strategy Committee in preparing its HSD recommendations to the Sixteenth Board meeting. WHO-GF ConsulTATION, supra note 188. 
country led, multi-stakeholder-driven innovative and results focused. ${ }^{222}$

This is a tall order. In its efforts to address these issues, one can see the seeds being laid for what, in six months time, would become the WHO PSC.

In response to the question of possible "parameters for allowable HSS activities," the WHO warned of the dangers of rigidity. ${ }^{223}$ What the Global Fund needed was a process that facilitated systemic, rather than isolated health system interventions and a process that was true to the Fund's core business model.

The key problem seems to be less the lack of more specific parameters and more that many proposals still contain actions that are vague, and proposed in isolation from the wider health system. This makes it difficult to judge the extent to which the mix of activities proposed constitute or are part of a balanced package of interventions that fit with national policy and strategy in the country concerned. ${ }^{224}$

If this is the case, then narrow parameters are to be avoided. "The parameters for allowable HSS activities should remain broad. . . [T] strong view that there should be few prescriptions. Flexibility is key because of country diversity, and because it helps encourage innovation."225

The treatment of parameters laid the foundation for the dominant themes of the report. The specific criteria matter less than constructing healthy, open processes and stimulating a more effective, enabling environment for generating high quality HSD proposals. The key is to focus on what works. ${ }^{226}$ The report quotes one participant of the July consultation as stating: "the Global Fund should retain the principle of 'give us a good plan and a good justification and we'll fund it."'227 The challenge then is how does one create the environment that generates sound proposals? The WHO suggests the following:

- Better guidance is needed ... but no blueprints

- Co-operation/coordination among partners is very important to

222. Id. at 3 .

223. Id. at 4 .

224. Id. at 5 .

225. Id. at 6 .

226. Id. at 5 ("A strength of the Global Fund's business model is that it is prepared to fund technically sound and well-justified proposals.").

227. Id. at 6 . 
ensure most effective use of all available funds

- Funding for TA [Technical Assistance] for proposal development and implementation is essential

- Partners need to strengthen capacity to deliver relevant TA for health system strengthening--both for proposal development and implementation. $^{228}$

The question of what role "conditions" should play received the same answer as that of parameters. Strict conditions should be avoided. "The fewer conditions the better, but countries need to know what is expected. Guidance is needed and wanted.",229

The role of ceilings for HSS funding raises a different set of questions. In this new, uncertain environment, ceilings could help control organizational risk and insure against dilution of the Global Fund's core mandate. ${ }^{230}$ Indeed, while GAVI has maintained a separate window for HSS applications since 2005, it has imposed ceilings on potential expenditures at both the aggregate and the country-specific levels. ${ }^{231}$ If the underlying problem is uncertainty, however, ceilings have their limitations. Ceilings may cap risk, but they do not help manage risk by generating new knowledge and understanding. In the end, the WHO argues that the underlying risk associated with HSD should be managed through well-functioning processes, rather than being arbitrarily capped by ceilings. As a result, the report recommends that the Global Fund "[a]void ceilings.",232 This advice, however, requires no small leap of faith and substantial trust in the power of well-designed (but still undeveloped) processes.

The rest of the report is devoted to making the case that the Fund should take such a leap of faith. The specifics of the debate come in the context of whether the Global Fund should maintain a separate window for HSS applications. In a subtle but important point, the report argues that the "question of an HSS window is a procedural not a policy question."233 In this sense, heated debates over whether there should be a separate window for HSD applications may be as unproductive as heated debates over vertical versus horizontal interventions. The report reminds the reader that the Global Fund's Technical Review Panel was equally critical of Round 5 applications (where there was a separate window) and Round 6 applications (where HSD applications were integrated into specific disease compo-

228. Id.

229. Id. at 7 .

230. Id. at 8 .

231. Id. at 41 (Annex 6) (Experiences of the GAVI Alliance Health System Strengthening Investment).

232. Id. at 10 .

233. Id. at 12 . 
nents). ${ }^{234}$ For the most part, they were all bad. For the WHO, the challenge is cultivating well-designed proposals, not the form in which such proposals are submitted.

That said, there are ways in which form can make a difference. The report raises a legitimate concern that the disease-specific application requirement may make it more difficult to generate proposals that are holistic and cognizant of the entire health system.

The practical problem with having HSS within a disease component application is to do with the process by which proposals are developed. If the process continues to be seen as largely the province of an individual programme and its more disease-focused partners, then few will address health system constraints in a truly systemic way, and the risk of unintended, unwanted repercussions on the other programmes and services will be greater. ${ }^{235}$

Conversely, there may be ways in which the frame of a separate window might be more conducive to systems thinking, and also be more open to the types of causation and interrelationships that characterize complex adaptive systems. The main arguments deployed for having a separate HSS component are that there are more opportunities for "integration;" that it is the only way to initiate truly systems-wide action; that it is an additional way of signaling the Global Fund's support for HSS, and might make it easier to mobilise HSS technical support. ${ }^{236}$ The report does not make a final recommendation on the question of the separate window for HSS support, noting that "opinion remains divided.",237 Instead, it concludes with an argument that if the right "enabling environment" is put into place, then the question of integrated disease-specific proposals for HSS verses a separate window really becomes academic. ${ }^{238}$ If the proper enabling environment is present, then the significance of what particular application form or process the Global Fund uses and how they are drafted will start to fade.

In response to the WHO consultation and the recommendations of the Fund's Policy and Strategy Committee, the 16th Board Meeting adopted

234. WHO-GF ConSUltation, supra note 188 , at 10.

235. Id.

236. Id. at 11 .

237. Id.

238. Id. at 12 ("The window question becomes less important if key aspects of the enabling environment are addressed: better access to information; access to the right sort of technical assistance, and procedures that further encourage a 'diagonal approach.'”). In retrospect, the significance of developing a workable conceptual framework, generating better empirical evidence and processes that would facilitate learning for HSD should be added to the definition of what constitutes an effective "enabling environment." 
Decision Point GF/B16/DP10, Strategic Approach to Health System Strengthening. ${ }^{239}$ The Global Fund renewed its commitment to "provide funding for health systems strengthening ("HSS") actions within the overall framework of funding technically sound proposals focused on the three diseases. $" 240$ The principles that it adopted to guide future HSS activities are consistent with the spirit of the WHO consultation. "The Global Fund shall allow broad flexibility regarding HSS actions eligible for funding, such that they can contribute to system-wide effects and other programs can benefit.",241 Ultimately, the Global Fund committed itself to develop a robust process to manage the HSS grant application process (and control the associated risk) rather than adopting a strict regulatory approach. It was willing to take the WHO's proposed leap of faith and trust process rather than prescription..$^{242}$

In a move that disappointed a number of critics, the Board did not reinstate the separate window for HSS applications. Instead, the Board continued to encourage the integration of "requests for funding HSS actions within the relevant disease component(s). ${ }^{9243}$ At the same time, the Board did permit certain "cross-cutting HSS applications," proposals that would affect two or three of the targeted diseases, to be submitted as a distinct part of one of the disease components. ${ }^{244}$ Furthermore, the TRP would be granted the discretion of approving the disease-specific and the cross-cutting requests, only the disease-specific component or only the cross-cutting component. ${ }^{245}$

The subtleties of creating process-oriented reforms can easily be lost on external audiences. Moreover, the effectiveness of new processes is an empirical question that can only be judged over time. The symbolic significance of the presence or absence of the separate window is what caught public attention, and the Board's decision was widely viewed as a retreat by the Fund of its commitment to HSD. This impression was reinforced by a change in the Round 7 Guidelines. "Round 7 emphasized for the first time a request for applicants to demonstrate that they had thought through the implications of proposed activities on other health services and had plans for risk mitigation where needed."246

239. Sixteenth Board Meeting, Decision Point GF/B16/DP10, Strategic Approach to Health System Strengthening, GLOBAL Fund to FIGHT AIDS, TUBERCuLOSIS AND MALARIA (Nov. 2007) [hereinafter Decision Point GF/B16/DP10], available at http://www.who.int/ healthsystems/round9_11.pdf.

240. Id. at 1 .

241. Id.

242. Id. ("Global Fund shall develop guidance with few prescriptions for applications for HSS funding.").

243. Id.

244. Id.

245. Id. at $1-2$.

246. WHO-GF Consultation, supra note 188, at 37 (italics omitted). 
From one perspective, this is a positive development. It stresses the "first do no harm" principle. Moreover, it reflects recognition that if the Fund is not careful, its programs can damage other aspects of health systems. From a different perspective, however, particularly in light of the Fund's failure to make substantial affirmative progress on the HSD front, the change could be interpreted by external audiences as a devolution of the Fund's commitment to HSD - a change from an affirmative commitment to help build health systems to a more modest and less ambitious pledge of avoiding undue harm.

In many respects, 2007 was a low point for the Global Fund. A December 2007 article in the L.A. Times reflected the critical public mood. ${ }^{247}$ According to the article, the Global Fund had only given one percent of its funds directly to HSS. ${ }^{248}$ In its defense the Global Fund claimed that almost half of its AIDS funds went toward training, monitoring, evaluation and administration, and thus a significant amount of money went indirectly to strengthening health systems. ${ }^{249}$ Nonetheless, the L.A. Times article criticized the Global Fund for its predominately vertical orientation, noting that a narrow focus on its own mandate could have negative effects on health systems as a whole. Simply put, "[m]any believe that its [the Global Fund's] tight remit is increasingly becoming a strait jacket." ${ }^{250}$ Ultimately, the article warned that the Global Fund must not assume that just because it is providing aid, that it was doing no harm. It must question whether the overall effect it is having is indeed positive.

\section{Rounds 8-10 (2008-2010): Time, Persistence and the Power of Adaptation}

The mark of a successful institution in a changing environment is its ability to learn and adapt. The core structure of the Global Fund gives it this potential. Its most recent experience with HSD illustrates that capacity. While it is still too early to make a pronouncement on the Fund's ultimate effectiveness in HSD (the same can be said of the entire WHO PSC effort), important changes between Round 7 and Round 10 place the Fund on a positive trajectory. Interestingly, in Round 8 the changes were associated less with what the Global Fund said (the governing language changed very little) and more with what the Fund did. By Round 10, there were substantial changes in the language the Global Fund used to guide its HSD work, as

247. Charles Piller \& Doug Smith, Unintended Victims of Gates Foundation Generosity, Donations to Fight AIDS, TB, and Malaria in Africa have Inadvertently put Many of those with Other Basic Healthcare Needs at Risk, L.A. TMMES (Dec. 16, 2007), available at $\mathrm{http}: / /$ www.latimes.com/news/nationworld/nation/la-na-gates 16 dec16,0,3743924.story.

248. Id.

249. Id.

250. Id. 
well as its actual conduct.

The Guidelines for Round 8 were revised in a manner to implement the 16th Board's directives in Decision Point GF/BI6/DP10. ${ }^{251}$ In March 2008, the Global Fund published a Fact Sheet: The Global Fund's Approach to Health System Strengthening, providing a statement that consolidated and synthesized its policies. ${ }^{252}$ As in the past, the Fund still required proof of a direct linkage between proposed HSD activities and improved outcomes for the three targeted diseases. ${ }^{253}$ How does one establish such linkage? The Facts Sheet uses buzz words such as "constraints," "weaknesses" and "gaps" in characterizing these assessments. "The Global Fund recognizes the importance of supporting the strengthening of public, private and community health systems where weaknesses and gaps in those systems constrain the achievement of improved outcomes in reducing the burden of HIV, tuberculosis and malaria.",254 Applicants must "clearly articulate how the interventions will address identified health systems constraints to improved HIV, tuberculosis and/or malaria outcomes (although [the Global Fund] recogniz[es] that interventions may benefit other disease outcomes also)."255

Ultimately, such demonstrations must be made within the context of some conceptual understanding of what health systems are and how they function. The Fact Sheet continues to discuss the building block approach developed by the WHO and specifically cites the 2007 WHO publication Everybody's Business.

In the context of the Global Fund's mandate, HSS refers to activities and initiatives that improve the underlying health systems of countries in any of the six areas [building blocks] identified above, and/or manage interactions between them in ways that achieve more equitable and sustainable health services and health outcomes related to the three diseases. ${ }^{256}$

251. Among other things, the "HSS funding framework was refined to integrate requests for HSS within a disease proposal or to use a distinct cross-cutting HSS section within a disease proposal." MID-TERM REVIEW 2008-2010, supra note 193, at 4. There remained no separate window for HSD applications.

252. Global Fund to Fight AIDS, Tuberculosis and Malaria, FaCt SheEt: THE GLOBAL FUND's APPROACH TO HEALTH SYSTEM STRENGTHENING (2008) [hereinafter GLOBAL FUND FACT SHEET], available at http://www.theglobalfund.org/documents/hss/HSS_ GlobalFundApproachToHSS_Factsheet_en/.

253. Id. at 1 ("With a strong focus on ensuring linkages between and outcomes for the three diseases, the Global Fund remains committed to providing funding for health systems strengthening (HSS) within the overall framework of funding technically sound proposals.").

254. Id.

255. Id. at 2 .

256. Id. at 1 . 
The building block approach has its limitations and risks static and stilted thinking. The mention of managing potential "interactions" between the functions is the only suggestion in the 2008 Fact Sheet of possible interrelationships and dynamic interconnections between the separate functions. Although the Fact Sheet makes multiple references to "cross-cutting" proposals, such proposals only envision potential interactions between the proposed intervention and two or more of the targeted Fund diseases. This is just a small first step. It is only when one acknowledges the cross-cutting aspects of the diseases, in combination with the cross-cutting aspects of the different health system functions that the true complexity and interconnectedness of the problem begins to be appreciated. ${ }^{257}$

There are creative ways in which the use of the application process itself can transcend the limits of a static framework. In particular, two Fund requirements help open the door to more complex and dynamic understandings of health systems, in practice, if not in theory. The Fund encourages HSS proposals to be consistent with broader in-country assessments and proposals for national HSD. ${ }^{258}$ In addition, the Fund encourages that the proposal be generated by a participatory, multi-stakeholder process (not unlike that advocated in the Systems Thinking ten-step design process).

To support the preparation of strong, appropriate requests for funding for HSS cross-cutting interventions, the Global Fund recommends that health systems and cross-disease focused in-country stakeholders are involved in the CCM and in proposal development. In particular, the Global Fund encourages applicants to include stakeholders who are involved in the planning, budgeting and resource allocation processes for the national disease programs and health system reform, and explain the role of these stakeholders in the proposal that is submitted. ${ }^{259}$

These devices provide avenues in which the complex, context-specific and interconnected aspects of health system interventions can begin to be incorporated.

257. The language that the Global Fund uses to establish "linkages" is not very helpful in this regard. "Constraints," "weaknesses" and "gaps" resonate more with mechanical systems and linear notions of causation than they do with complex adaptive systems. That said, there is nothing inherent in these terms or concepts that prevents them from being applied to a more dynamic and adaptive understanding of health systems, if decision makers were so inclined.

258. GLOBAL FUND FACT SHEET, supra note 252, at 2 ("Applicants are also encouraged to draw on recent assessments of health system weaknesses and gaps (which may be broader than the three diseases, where they exist) when preparing their proposals.").

259. Id. 
Furthermore, grant making processes, particularly within a broad framework that is results-oriented, can create a dynamic and evolutionary environment that is itself conducive to learning and adaptation. This learning can be inductive as well as deductive. One method of learning is the accumulation of successful examples and illustrations over time. The Global Fund Guidelines has used this approach. The Guidelines for Round 1 listed only one example of a potential HSS activity, "strengthening of comprehensive commodity management systems at the country level." In Round 2, the Guidelines included four examples, ranging from increased access to health services, to recruitment and training of community health workers to improved information systems. ${ }^{261}$ By Round 7, there was a diverse array of fifteen examples of HSS strategic actions. ${ }^{262}$ In addition to the accumulation of examples in the Guidelines, a small cottage industry has been created, which attempts to parse the Global Fund Guidelines and TRP Reports and to advise countries preparing their applications. ${ }^{263}$ As part

260. WHO-GF CONSULTATION, supra note 188 , at 37 .

261. Id.

262. Id.

263. Physicians for Human Rights has been one of the most active organizations in this regard. Eric Friedman, Guide to Using Round 9 of the Global Fund to Fight AIDS, Tuberculosis and Malaria to Support Health System Strengthening: Updated from March 2007 Guide Developed for Round 7, in PHYSICIANS FOR HUMAN Rights, TOOLKIT FOR UsING Round 9 OF THE Global Fund HeAlTh Systems STRENGTHENING (2008), available at http://pdf.usaid.gov/pdf_docs/PNADO138.pdf. The grant application and review process is not unlike the common law system for adjudicating disputes. One can distill from the process sets of principles that can help explain past conduct and possibly guide future action. Physicians for Human Rights has generated a list of features common in successful applications:

1. Strong links to reducing spread and impact of target diseases

2. Strong health system analyses

3. National commitment and strategies

4. Strong chance of success

5. Pro-poor and pro-marginalized populations

6. Support from other development partners

7. Discrete focus

8. Address major obstacles

Id. at 36-37. The WHO has conducted similar assessments. In advising applicants it stresses the importance of the following:

1. The proposed activities clearly respond to constraints ...

2. The proposed activities are required in order to in improve HIV/AIDS, TB or malaria service delivery ...

3. The proposed activities fit within overall national health policies ...

4. The proposed activities have been defined in consultation with key stakeholders ...

5. Proposed activities are clearly defined; of realistic scale, and credibly costed ...

6. Returns from investment are possible within a reasonable timeframe...

7. A small set of credible health systems indicators have been selected for tracking progress .... 
of an iterative, adaptive process, these considerations can collectively help define an increasingly viable set of effective HSS interventions.

The grant review process is subject to other influences as well. The broader political climate both inside and outside the Global Fund has changed in a manner that is more supportive of HSD efforts. Early Rounds made almost no progress on the HSD front. Things started to change by Round 5, as illustrated by the case of Malawi.

Commenting on the HSS proposal from Malawi the TRP reflects that although the human resources constraints were recognized as crucial in Round 1, "at that time the Global Fund was not keen to fund health system components," indicating that the approach of the panel has undergone some change since the early Rounds. ${ }^{264}$

This trend has continued. Whether looking at the number of applications (113 proposals with HSS Strategic Actions (Round 7) and 45 proposals with HSS components (Round 8)) or the amount of funding approved (\$364 million (Round 7) and \$591 million (Round 8)), applications in Rounds 7 and 8 were substantially more successful than those in previous Rounds. ${ }^{265}$

As a result of the Global Fund's cumulative experience and selfassessments, HSD has become a more active institutional priority. One of the findings of the Five-Year Evaluation was that "[h]ealth systems in most developing countries will need to be greatly strengthened if current levels of services are to be significantly expanded."266 Given that most of the progress the Fund has made to date has been in areas that already had somewhat functioning health systems, improving the performance of weak health systems is absolutely essential for future progress. ${ }^{267}$ "Going forward, the weaknesses of existing health systems critically limit the performance potential of the Global Fund."268 But if future HSD efforts are targeting weaker health systems, all parties involved must appropriately recalibrate what timeframes, outcomes and results are realistic under such circum-

The Global Fund and Health Systems Strengthening: How to Make the Case, in a Proposal for Round 8 ? (working draft), WORLD HEALTH ORG. 3, available at http://www.who.int healthsystems/gf_hss.pdf.

264. Drager et al., supra note 185, at 9 (quoting GLOBAL Fund TO FIGHT AIDS, Tuberculosis and Malaria, Eleventh Board MeEting: Report of the TEChNical Review Panel and the Secretariat on RoUnd Five Proposals (2005), available at http://www.who.int/healthsystems/gf8.pdf).

265. MID-TERM REVIEW 2008-2010, supra note 193, at 4.

266. FIVE-YEAR EVAlUATION, supra note 177, at 21.

267. Id. at 24 ("Study Area 3 found that the scale-up of HIV services has primarily occurred thus far in districts with stronger health systems and higher levels of socioeconomic development--so it is likely that health system constraints will become increasingly important as services roll out to weaker districts in the future.").

268. Id. at 21 . 
stances. Weaker infrastructures will require a focus on more basic HSD interventions and will require longer timeframes. "In particular, for countries with weak health systems and/or high disease burden, grants should either focus more on investing in long-term capacity building, or demonstrate partner contributions to capacity-building."269

The most significant external event influencing Global Fund thinking about health systems has been the WHO PSC. PSC has helped transform the political and analytic environment for HSD. Changes in Global Fund Guidelines governing Round $10^{270}$ and the recently published Information Note on the Global Fund's Approach to Health System Strengthening ("HSS"), ${ }^{271}$ illustrate the dramatic impact of these developments. While some of the terminology remains the same, ${ }^{272}$ there have been important changes in the contexts in which this language is applied. First, rather than being neglected as in early rounds, the Fund now recognizes HSD as a top priority and as a fundamental prerequisite to accomplishing sustained health outcomes.

Strong and effective health systems are increasingly considered a prerequisite to effective implementation of disease control interventions. Recognizing the critical importance of the linkages between health systems strengthening (HSS) and outcomes for HIV, TB, and malaria (as well as other health outcomes), the Global Fund is committed to providing funding for HSS within the overall framework of funding technically sound disease proposals. ${ }^{273}$

This changes the baseline against which HSD proposals are evaluated in a manner that should fundamentally change old notions of linkage and causation. While applicants still bear the burden of making a persuasive case, the inherent significance of HSS to effective action is now the default value for analysis. In asking "[w]hy is it important to address health systems strengthening in funding proposals to the Global Fund?" the Fund answers

269. Id.

270. Guidelines for Proposals-Round 10 Single Country Applicant, GLOBAL FUND TO FIGHT AIDS, TUBERCULOSIS AND MALARIa (2010) [hereinafter Round 10 Guidelines], available at $\mathrm{http} / /$ web.nbnet.co.ke/globalfundnew/images/R10\%20Proposal\%20Guidelines.pdf.

271. Global Fund to Fight AIDS, Tuberculosis and Malaria, Global Fund INFORMATION Note: The Global FUND's APPROACH to HEALTH SYSTEMS STRENGTHENING (HSS) (2010) [hereinafter HSS INFORMATION NOTE].

272. Id. at 1 ("The Global Fund recognizes the importance of supporting the strengthening of public, private and community health systems where weaknesses and gaps in those systems constrain the achievement of improved outcomes in reducing the burden of HIV, tuberculosis and malaria.").

273. Id. 
itself: "[t]here is a strong link between health systems and the Global Fund's mission to fight the three diseases.",274

Second, Round 10 now expressly recognizes the need to consider complexity and interdependence in its analysis of health systems. The new HSS Information Note makes obligatory reference to the WHO's building blocks, but there is a stronger appreciation that the building blocks cannot be understood in an isolated or static manner. Significantly, the HSS Information Note cites the Alliance for Health Policy and Systems Research's 2009 publication Systems Thinking for Health Systems Strengthening as one of its two suggested references for further reading ${ }^{275}$ "Lessons learned from previous funding rounds underscore the importance of ensuring that applicants provide a holistic consideration of these building blocks when integrating them into a funding request. Applicants should pay particular attention to the interdependence of blocks, rather than a fragmented consideration of individual blocks.",276

In elaborating on the lessons learned from the TRP, the document stresses the need to "describe the linkages and interactions present in the health system." 277 The document continues:

Many applications in previous rounds have often requested a "shopping list" of all theoretical HSS needs, without giving thought to longer-term HSS programmatic planning and expected impact. Applicants are encouraged to base their HSS proposals on an understanding of the complex nature of the interactions between health systems components, functions, institutional and structural elements. In addition to focusing on specific health system components, HSS proposed interventions should also consider interactions among the components and the broader context in which they exist. ${ }^{278}$

One implication is that the Global Fund calls for a more balanced approach to HSS. ${ }^{279}$ These changes should create the space for more innovative, far-

274. Id. at 2 (emphasis added).

275. Id. at 5 (citing Alliance for Health Policy and Systems Research \& World HEALTH ORG., SYSTEMS THINKING FOR HEALTH SYSTEMS STRENGTHENING (2009), available at http://whqlibdoc.who.int/publications/2009/9789241563895_eng.pdf). For an extensive discussion of Systems Thinking for Health Systems Strengthening see supra Part III.C.

276. Id. at 2 .

277. Id. at 4 .

278. Id.

279. Past Rounds, for example, seemed to focus predominately on service delivery, often to the neglect of finance and governance. $I d$. at 4-5 ("Applicants are thus encouraged to propose more balanced HSS interventions based on country needs that cover a range of 
reaching and effective proposals to be considered as part of the Global Fund's future grant making process.

Third, in addition to changes in analytic content, Round 10 represents an important broadening of the scope of the Fund's HSD efforts. Significantly, the Global Fund is now willing to consider HSD proposals that will benefit women and children in addition to the three traditionally targeted diseases. ${ }^{280}$ "The Global Fund recommends integrated approaches to achieve the following Millennium Development Goals ("MDGs"): 4 (reducing child mortality), 5 (improving maternal health) and 6 (combating HIV, malaria and other diseases) and improve health outcomes for women and children."281 This is an important development that should encourage holistic proposals that approach health systems as a more integrated whole. "Countries that fail to take advantage of this miss an important opportunity to develop strong health sector systems which benefit health outcomes beyond the three diseases."282

Finally, Round 10 also broadens the scope of HSS activities to expressly embrace communities and civil society as plus factors in the quest for positive synergies.

The Global Fund also recognizes that non-
government organizations, the private sector and
communities affected by the disease(s) are each an in-
tegral component of the health system, as is the gov-
ernment sector. Likewise, community systems
include government, non-government and private ac-
tors working at the community level. Health systems
and community systems are connected and comple-
mentary to each other.

The Global Fund now maintains that building community systems will be an essential part of strengthening health systems. ${ }^{284}$ Round 10 will support

health system components.").

280. Id. at 2 ("The Global Fund shall however allow broad flexibility regarding HSS actions eligible for funding, such that they can contribute to system-wide effects and other programs, particularly those affecting the health of mothers and children, can benefit (not only those addressing the three diseases."). The focus on women and children is part of a call for greater sensitivity to gender issues more generally. "It is important to use a gender sensitive approach to the three diseases. Proposals should be based on an assessment of how the diseases impact women and girls differently compared to boys and men, and take actions to respond to these differences." Round 10 Guidelines, supra note 270 , at 4.

281. HSS INFORMATION NOTE, supra note 271 , at 2.

282. Id. at 4 .

283. Round 10 Guidelines, supra note 270 , at 60.

284. Global Fund to Fight AIDS, Tuberculosis and Malaria, Global Fund INFORMATION NOTE: COMMUNITY SYSTEMS STRENGTHENING (2010) [hereinafter CSS INFORMATION NOTE], available at www.theglobalfund.org/documents/rounds/10/R10_ InfoCSS_Note_en/ ("Community systems are community-led structures and mechanisms used by community members and community based organizations and groups to interact, coordi- 
"Health and Community Systems Strengthening to improve implementation and service delivery, and in particular, strengthening core institutional capacity through physical infrastructure development, and organizational and systems strengthening." ${ }^{285}$ Community System Strengthening ("CSS"), like HSS, is to be a routine part of the Global Fund grant making process. ${ }^{286}$

From 2002 to 2010, the Global Fund has gone from embracing misguided assumptions that health systems would somehow take care of themselves, to taking bold new action where HSD is recognized as essential to its core mission. This vision has now been extended beyond health systems to embrace community systems as a plus factor for HSD. The challenges that this will entail are examined next.

\section{COMMUNITY CHALLENGES-INCORPORATING A ROLE FOR CIVIL SOCIETY}

Holistic thinking about HSD has to include a role for people, participation and civil society. PSC and the Global Fund have both striven to incorporate Community System Strengthening ("CSS") into their health systems agendas. This section examines these developments and considers how civil society and community systems fit as plus factors within the broader Building-Block-Plus Framework for HSD. The tremendous changes that have taken place just from 2008 to 2010 are a further indication of how far and how fast activities are evolving at the GHI/HSD interface in the wake of PSC.

\section{A. The Convergence of Civil Society, Community Systems and Health Systems}

Given the inherent locality of health services, sustainable public health intervention must ultimately be rooted in the community. The PSC Civil Society Panel explains the rationale: "Communities and civil society are at the heart of strong, accountable health systems at the grassroots level, they represent the end users of health services; they are also engaged in implementation, service delivery, planning and priority setting, advocacy, and monitoring and evaluation (M\&E), ${ }^{287}$ As with other dimensions of the

nate and deliver their responses to the challenges and needs affecting their communities.").

285. Round 10 Guidelines, supra note 270 , at 86 .

286. Id. at 61 (" $[\mathrm{T}]$ he Global Fund encourages the applicant to include community systems strengthening measures on a routine basis in proposals to the Global Fund.").

287. FINAL REPORT CIVIL SOCIETY CONSORTIUM, supra note 61, at 1 . Active civil society participation is the lifeblood of most public health movements. "The crucial contributions of empowered and informed civil society in stimulating community demand, expanding access to health services, extending coverage for marginalized populations, protecting and promoting rights-based approaches to health, and strengthening health systems governance precede and contributed greatly to the recent launch of new Global Health Initiatives (GHIs)." Id. 
GHI-HSD interface, we are still, both theoretically and empirically, at the early stages of the learning curve in understanding how civil society can best assist GHIs and other local HSD efforts. Many important questions remain unanswered. "What are the right roles of civil society in optimizing the interactions between global health initiatives and national health systems, in order to capitalize on positive synergies and minimize negative impacts?"288 "What reforms and actions should GHIs take to be more responsive to grassroots civil society priorities and health needs?"289 "How can CSOs [Civil Society Organizations] work with governments and/or GHIs to navigate implementation roadblocks? What are CSOs doing already?"290 Much can be learned from experience in recent decades, but more work still needs to be done.

Just as there have been profound changes in the Global Fund's understanding of HSD, there have been similar advancements in the Global Fund's understanding of Community-Based Organizations ("CBOs") and CSS. The primary strength of the Fund is its capacity for learning and adaptation. ${ }^{291}$ These traits have led the organization to recognize the importance of community systems and make serious commitments to their development. Starting with a Resolution at the 15th Board Meeting and first implemented in the Round 8 Guidelines, the Global Fund recommended "the routine inclusion, in proposals for Global Fund financing, of requests for funding of relevant measures to strengthen community systems necessary for the effective implementation of Global Fund grants. ${ }^{, 292}$ Appreciating the complexity of social-health dynamics, CSS efforts are being taken in tandem with efforts to address the complementary challenges of gender inequality and the needs of other marginalized groups. ${ }^{293}$

Global Fund's understanding of CSS has progressed substantially even between the March 2008 publication of its first Fact Sheet: Communi-

288. Id. at 2 .

289. Id. at 3 .

290. Id.

291. Global Fund to Fight AIDS, Tuberculosis and Malaria, Civil Society SuCCESS ON THE GROUND: COMMUNITY SySTEMS STRENGTHENING AND DUAL-TRACK FINANCING: NINE IlLuSTRATIVE CASE STUdIES 3 (2008) [hereinafter CIVIL SOCIETY SUCCESS ON THE GROUND], available at http://www.theglobalfund.org/documents/civil_society/ CivilSociety_CSSAndDualTrackFinancing_CaseStudy_en/.

Many would recognize that the Global Fund to Fight AIDS, Tuberculosis and Malaria is a continually developing institution, evolving as a result of feedback from its key stakeholders. The organization's eighth funding round, launched in March 2008, and its impending Round 9 to be launched in October 2008 represent the culmination of a number of mechanisms to harness and enhance the role of civil society in the implementation of Global Fund grants.

Id.

293. Id. at 7. 
ty Systems Strengthening ${ }^{294}$ and the May 2010 publication of its updated Information Note: Community Systems Strengthening ${ }^{295}$ and accompanying report Community Systems Strengthening Framework. ${ }^{296}$ The Global Fund's interest in community systems is very pragmatic. The Fund cares about community systems because it believes that community organizations are important to the sustainability and effectiveness of the Fund's work. ${ }^{297}$ As such, communities, community systems and civil society are important pieces to the puzzle of HSD.

Theorizing about health systems is a new and quickly evolving field. Initial HSD work largely overlooked civil society, leaving the role of communities undervalued and under-analyzed. ${ }^{298}$ Neglect in conceptualization inevitably leads to neglect in terms of funding. ${ }^{299}$ Upon reflection, however, it is clear that every HSD framework, including the WHO building block approach, implicitly incorporates roles for civil society. ${ }^{300}$ None of these building blocks exists in social isolation. Building on this insight, community systems and health systems need to be viewed as overlapping and in-

294. Global Fund to Fight aids, Tuberculosis and Malaria, Fact SheEt: COMMUNITY SYSTEMS STRENGTHENING (2 OF 5) (2008).

295. CSS INFORMATION NOTE, supra note 284.

296. Community Systems Strengthening Framework, Global FUND To FIGHT AIDS, TUBERCULOSIS AND MALARIA (2010) [hereinafter CSS Framework], available at www.who.int/entity/tb/dots/comm_hss.pdf.

297. CSS INFORMATION NOTE, supra note 284 , at 1.

Community organizations and networks have a unique ability to interact with affected communities, react to community needs and issues and connect with affected and vulnerable groups. They provide direct services to communities and advocate for improved programming and policy environments. This enables them to build community contributions to health, and to influence the development, reach, implementation and oversight of public systems and policies.

298. FINAL REPORT CIVIL SOCIETY CONSORTIUM, supra note 61, at 55 ("Although GHIs have helped to advance new standards of civil society involvement in health service delivery and governance, constituencies focused on health systems strengthening often do not embrace a model of the health system that fully integrates civil society involvement at all stages.").

299. CSS Framework, supra note 296, at 11. The Report speculates as to the possible reasons for this neglect.

Lack of clarity in the past has made it difficult to discuss how community systems relate to health outcomes and how they link with health systems. One reason may be that community systems are often more fluid and harder to define than the structured systems of a health or social support service. Another reason is that it is difficult to define exactly what the boundaries between health and community systems are, and to identify the links between them.

Id. at 12.

300. FinAl RePORT Civil SocIETY CONSORTIUM, supra note 61, at 3 ("WHO describes six essential building blocks needed for strong health systems . . . . Although not explicit in WHO's model, civil society and communities cut across each building block, engaging in distinct activities in each category."). 
terdependent networks. ${ }^{301}$ "This approach by the civil society consortiumof communities at the centre of thriving health systems, and of health systems strengthening and community systems strengthening as interdependent efforts-complements the conceptual framework of the [PSC] academic consortium., ${ }^{302}$ These understandings are also consistent with incorporating civil society as a plus factor within the Building-Block-Plus Framework developed earlier.

But what does CSS entail? According to the Global Fund, CSS is:

an approach that promotes the development of informed, capable and coordinated communities and community-based organizations, groups and structures. It involves a broad range of community actors and enables them to contribute to the long-term sustainability of health and other interventions at the community level, including an enabling and responsive environment in which these contributions can be effective. ${ }^{303}$

Developing a more formal framework for understanding the relationship between community systems, health systems and health outcomes is important. At one level, this will be a necessary underpinning for informed policy making. At another level, it will provide a more rational and integrated superstructure in which the mechanics of grant writing, application review and program evaluation can proceed (Administrative Challenges). Just as with HSD, an effective meta-framework requires the convergence of thinking on the political, theoretical and administrative fronts before effective policies can be designed, implemented and funded. ${ }^{304}$

301. CSS Framework, supra note 296, at 10.

Through community systems, community actors currently provide several categories of activities or services that directly or indirectly affect health outcomes. These categories are not mutually exclusive and there are many synergies and overlaps within and between community systems and health systems, especially within integrated packages of care,

Id. support and protection.

302. FINAL REPORT CiVIL SOCIETY CONSORTIUM, supra note 61, at 4.

303. CSS Framework, supra note 296 , at 7.

304. The Global Fund requires linkage between CSS efforts and the three targeted diseases. A workable conceptual framework, therefore, must address the causal relationship between supporting community systems and the likelihood of improving outcomes for AIDS, tuberculosis and malaria. The Fund, however, is adopting more open understandings of causation with CSS, than it initially did with HSD. Indeed, fundable CSS projects may even lie outside the traditional health sector.

In the past, it has been difficult for community actors to explain clearly 
CSS efforts are taking a proactive role in this process. In its early days, the Fund neglected HSD on the mistaken belief that the strengthening of health systems would naturally follow the development of GHI programming. This reflected a strong, and ultimately misguided, faith in the powers of private ordering. The difference between this perspective and the CSS Framework parallels that between night and day. In many respects, the CSS Framework is a comprehensive effort to identify the multiple factors that prevent effective forms of private ordering in remote corners across the globe and to develop plans to help facilitate more effective forms of local cooperation. This realization also explains one of the frustrations in reading the CSS Framework Document. It is diffuse, multi-layered, and difficult, if not impossible, to summarize in a short, concise manner.

Two sets of intuitions are useful in making sense of the CSS Framework. The first is derivative of the standard state-market-civil society model from political science. In robust and effective polities, civic society interacts with the state and with private markets in ways that make each component function more effectively. Civil society can be a source of thinking, inspiration and advocacy for public programming. Civil society can monitor state and market performance and act as a watchdog. Monitoring and advocacy work is an ongoing process to prod, push and lead social policy in directions that better serve the public interest. One objective of CSS, therefore, is to empower civil society to more effectively serve these traditional functions.

The second set of useful CSS intuitions is derivative of institutional economics. The state (and the market) can only function when they are supported by robust and effective institutional infrastructures. GHIs have illustrated how these institutional infrastructures are often weak and dysfunctional in many developing countries. The weaknesses of public institutions become more prevalent the greater the geographic and social distance these institutions are from the center of state power. In geographically remote rural areas, the public institutional infrastructure may be nonexistent. The same observation often applies when considering the needs of socially distant and politically disenfranchised subpopulations. Often, no effective public institutional infrastructure exists to serve their needs either. One strategy for addressing this problem is to strengthen the public institutional infrastructure from the center-out. Much of traditional HSD fits this model. A different strategy is to help build the functional equivalents of the public institutional infrastructure from the periphery in, or from the grassroots up.

the connections between health outcomes and community activities that have potential impacts on health but are not directly related to health service delivery, for example advocacy, social protection and welfare services, home-based care or legal services. The Framework provides a structure for addressing this and enabling inclusion of relevant nonhealth activities in funding mechanisms and allocations for health.

Id. at 6 . 
This is one of the primary tasks of new CSS efforts. ${ }^{305}$ Painting with very broad strokes, the Global Fund's CSS Framework defines six core components of community systems. The Global Fund's objective is to take a complicated, abstract issue like "the community" and to break it down functionally into an administrative framework that can be used to guide grant making and subsequent performance evaluation. In listing the components, one can get partial glimpses of the traditional state-market-civil society model and the institutional economic model outlined above. The six core components of the CSS Framework are as follows:

1. Enabling environments and advocacy-including community engagement and advocacy for improving the policy, legal and governance environments, and affecting the social determinants of health[;]

2. Community networks, linkages, partnerships and coordination enabling effective activities, service delivery and advocacy, maximising resources and impacts, and coordinated, collaborative working;

3. Resources and capacity building-including human resources with appropriate personal, technical \& organisational capacities, financing (including operational and core funding) and material resources (infrastructure, information and essential commodities, including medical and other products and technologies);

4. Community activities and service delivery-accessible to all who need them, evidence-informed and based on community assessments of resources and needs;

5. Organisational and leadership strengthening including management, accountability and leadership for organisations and community systems;

6. Monitoring \& evaluation and planning including M\&E systems, situation assessment, evidence-building and research, learning, planning and knowledge management. ${ }^{306}$

This is an ambitious and expansive list of activities to target for funding. The report proceeds to provide careful descriptions of each component, along with the specification of ten ancillary Service Delivery Areas ("SDAs") (discrete domains of community service activities and interventions) associated with the various elements. ${ }^{307}$

305. This will not be easy. Establishing effective forms of local cooperation is part of the defining struggle of human history. Attempting to parachute in and stimulate effective forms of self-organization in geographic and socially remote communities that have not previously come together and worked effectively in a collective manner is a daunting challenge.

306. CSS Framework, supra note 296, at 4 (italics omitted).

307. Id. at $8, \mathrm{n} .19$ ("Programmematic interventions by civil society actors are often called activities; in health systems, interventions are usually called services; the Global Fund and other agencies use the term service delivery area to cover the full range of programmematic activities and services-this is a key term used in this Framework."). 


\section{B. A Functional Approach to Community Systems}

To illustrate these principles, it is helpful to focus on different functional aspects of community systems. These insights help orient one's understanding of the relationship between health systems and community systems. This section examines two such functional roles. First, community systems can perform functions that might otherwise be performed by the state or the market-a surrogate or gap-filling role. Second, community systems can be a bridge that connects traditional health systems with the broader social-economic determinates of health. Analysis of these two functions is intended to be suggestive and illustrative of CSS efforts. It is by no means comprehensive.

\section{Civil Society a Surrogate Health Service Provider}

Civil society and community-based organizations are often used as a surrogate to provide health services in otherwise dysfunctional states and markets. $^{308}$ It is not surprising that the importance of community systems was re-discovered when GHIs experienced serious administrative and logistical constraints in attempts to implement their ambitious agendas. The need for HSD generally is predicated on the weakness of the public health infrastructure in most developing countries. Civil society and communitybased organizations play their most important roles where state apparatuses do not exist or do not function effectively. This can consist of quite a large domain. In many developing countries, the reach of state bureaucratic structures seldom extends beyond major provincial towns. ${ }^{309}$ Administrative structures are particularly anemic in rural areas. As such, substantial portions of the population simply live outside of the shadow of the state's health care infrastructure. ${ }^{310}$ In these settings; community systems may be the only networks capable of facilitating the type of coordinated efforts necessary to take action to advance public health. ${ }^{311}$

308. Final Report Civil Society Consortium provides a number of case studies and illustrations. FINAL REPORT CIVIL SOCIETY CONSORTIUM, supra note 61, at 51 ("In the same vein, civil society involvement in programme implementation at community level should be encouraged, especially in settings where public health institutions lack capacity.").

309. The same observation can be made about well-functioning private economic markets. Dysfunctional markets and dysfunctional states, for the most part, go hand in hand.

310. FINAL REPORT CIVIL SOCIETY CONSORTIUM, supra note 61, at 6.

Evidence shows that GHIs are investing significant funding through civil society groups, ranging from indigenous community-based groups to large NGOs. CSOs have played a key role in connecting communities to health care services, and helping patients navigate the health system as well as implementing health programming-especially where the health sector is weak, such as in rural areas.

311. While this discussion has focused on geographically remote rural communities, the same analysis applies to marginalized and vulnerable populations who are socially, if not 
Again, the tools of institutional economics are useful. One of the main lessons of the 2000 WHR was the utility of separating the issue of function from the issue of organizational form. This logic naturally extends from the state to the market to civil society. The same health function can be performed by a continuum of organizational forms ranging from public to quasi-public to non-governmental to private market:

[I]t is probably best to distinguish health system interventions from others based on what the intervention is rather than who is providing it. To take an obvious example ... provision of TB medication is clearly a health system intervention, which may be provided by the national health system, by a faithbased organisation or another community actor. Examples ... are health-focused, but the best option for delivery at community level may be through functioning community systems rather than through the formal public health system. ${ }^{312}$

How one decides which organizational form should be used is contextdependent and best determined by a careful comparative institutional analysis. In this analysis, community systems may have a number of potential virtues.

[C]ommunity systems may have comparative advantage with respect to certain health-related activities. These are specific to local contexts, but may include ensuring that services and support are available close to people's homes, using the language skills of trusted, culturally competent community members, ensuring continuity of follow-up for people with chronic diseases, community-level promotion of health literacy, social and psychological support, changing harmful socio-cultural practices, outreach to key affected communities and individuals, and providing respite for home-based careers. ${ }^{313}$

This list is just suggestive of some of the factors that have to be considered.

The role of civil society as a surrogate service provider is incorporated in the CSS Framework. ${ }^{314}$ In the right settings, CBOs can play an important

geographically, distant from the state.

312. CSS Framework, supra note 296, at 10-11.

313. Id. 12-13.

314. The fifth Core Component of the CSS Framework is "Community Activities and Services." Id. at 24-27. 
role in providing or assisting in the provision of health services. ${ }^{315}$ The role of civil society as a surrogate provider of health services is the most obvious area of overlap between CSS and HSD. At the same time, the line between community systems and health systems can be hard to draw and the role of CBOs within the health system may shift depending upon local context. Given that community systems and health systems are in potential competition with each other as service providers, one should also expect areas of push-back and resistance within traditional health systems, such as perennial opposition by health professionals to community health workers. ${ }^{316}$ Openness and flexibility will be needed from both funders and organizations experimenting with these changing roles.

\section{Communities as a Bridge to the Social-Economic Determinants of Health}

One of the benefits of a complementary focus on health systems and community systems is the ability to better address the social and economic determinates of health. ${ }^{317}$ Even amongst those who agree upon the goal of

315. Id. at 25. Service Delivery Area 7, "Service Availability, Use and Quality," is associated with this component. Specific activities listed within SDA 7 include:

- Identification of populations most at risk and most in need of services;

- Identification of obstacles to accessing and using available services;

- Participatory development and implementation of referral systems to ensure access to and use of services, and referral to community systems for ongoing support;

- $\quad$ Planning for community based service delivery based on mapping and analysis of needs and gaps;

- Planning for continuous improvement of quality services through mentoring, updating of skills and information and regular reviews of service availability, use and quality;

- Development of integrated service delivery systems to address the range of health, social and related needs in communities ...

- Development of community support centres providing a range of services such as information, testing \& counselling, referrals, peer support, outreach to key affected people and communities, legal support

Id. etc. ...

316. FINAL REPORT CiVIL SoCIETY CONSORTIUM, supra note 61, at 15.

Community health workers (CHWs) remain one of the largest resources available to rapidly and effectively respond to health needs. In spite of significant recent improvements, $\mathrm{CHWs}$ and their referrals continue to be inadequately recognized by formal health systems. CHWs are very often poorly supported and equipped, and the vast majority of them are almost entirely uncompensated.

Id.

317. "These determinants affect people's mental and physical health and well-being at many levels. They include, for example: income and social or cultural status; education; physical environment; employment and working conditions; social support networks and 
improving community health, there are serious debates about the relative importance of medical interventions versus action directed at the broader determinants of health. The CSS Framework suggests ways in which some of these divides might be bridged. The community, by definition, encompasses health and non-health factors. As such, efforts to strengthen community systems may also permit the furtherance of a number of complementary social goals that might also improve health. For better or worse, the "health systems" frame is already burdened with certain implicit medical biases.

The possible dynamics of these interactions are illustrated in the CSS Framework. Figure 3 of the report portrays Community Actors and Systems and Health Actors and Systems as intersecting circles both operating within a broader context of Social, Cultural, Economic, Political and Legal Environments that influence health and the state-market-civil society construct, of which health systems and community systems are a part. ${ }^{318}$

Health systems are not something separated from communities. They are key community assets, part of the network of relationships and support that individuals, families and communities are entitled to rely on. Clearly, there are synergies as well as overlaps between health systems, community systems and social welfare systems, but these should be used as a stimulus for creative and innovative approaches to bring community, health and social systems into closer and more complementary partnerships. ${ }^{319}$

The proper blend of community-based and health-based interventions can help achieve this goal. "Community actors are in a unique position to work on these issues alongside health, social welfare and other actors and systems. Together, they can achieve the scale, range and sustainability of interventions that will help to realise people's rights and enable them to reach important goals for their health and well-being." ${ }^{\text {230 }}$ To improve health, one must help improve the community infrastructure.

In order to have real impact on health outcomes, however, community organisations and actors must have effective and sustainable systems in place to support their activities and services. This includes a strong focus on capacity building, human and financial re-

welfare services; genetics, personal behaviour and coping skills; gender." CSS Framework, supra note 296 , at 3 .

318. Id. at 13 fig. 3 .

319. Id. at 13 (footnote omitted).

320. Id. at 3 (footnote omitted). 
sources, with the aim of enabling community actors to play a full and effective role alongside the health, social welfare, legal and political systems. ${ }^{321}$

The CSS Framework places health systems and HSD in a much broader social context. ${ }^{322}$ It acknowledges the role of multiple actors and multiple causal influences. While it adds new dimensions of complexity, it also deepens the analysis of factors that might afford real and sustained progress on a range of social-health problems.

\section{Enabling the Enabling Environment: Capacity Building and Learning}

In theory, robust civil society and community systems help create an enabling environment that can lead to the more effective functioning of state and market institutions.

The importance of creating enabling legal, social, political and economic environments should not be underestimated. An enabling environment is essential for people to achieve their rights and for communities and community organisations to be engaged and effective. The contexts of interventions to improve health are always multi-layered, and effectiveness of interventions can be seriously impaired in environments that are hostile or unsupportive. ${ }^{323}$

But what enables the enabling environment? A full appreciation of community systems and CSS is another example of complex adaptive systems being applied to health policy making. Most diseases are complex, multi-factored medical and social phenomena. Consequently, the longterm effectiveness of GHIs requires addressing these problems not only in

321. Id. at v.

322. Some of the specific activities that could contribute to the broader determinants of health include:

- Participation in local and national fora for policy change;

$\cdots$

- $\quad$ Nutrition, housing, water, sanitation and other material support to vulnerable children and adults;

- Livelihood support programmes such as microcredit or savings schemes, training schemes for unemployed adults and youth and for growing food to support families[;]

- Support for civil rights and access to services, for example civ-

Id. at 12 . il registration of births and deaths[.]

323. Id. at 8-9. 
the medical context, but also in the social and political arenas. ${ }^{324}$ To engage these dimensions, it is necessary to focus on the basic building blocks of communities and the constituents of viable manifestations of civil society. $^{325}$

What does this mean in practice? The CSS Framework's Core Component 1, Enabling Environments and Advocacy, is associated with two SDAs. SDA 1 is Monitoring and Documentation of Community and Government Interventions. ${ }^{326}$ The theory is that community organizations are in the best position to access and report critical information. Gathering this information outlined in SDA 1 is the first step for future advocacy, action and/or shaming that can establish forms of social and political accountability. Additionally, the information will provide the raw materials (data) that can facilitate more rational forms of planning and learning on the part of governmental and civil society actors. ${ }^{327}$

SDA 2, Advocacy, Communication and Social Mobilization, takes the next logical step from monitoring and documentation to political and social action.

Community based organisations and networks have an important role to play in engaging with governments and other institutions at all levels (local, national, regional and global) to use well-informed dialogue and discussion to advocate for improved pol-

324. Id. at 15-16. The contexts of major diseases such as HIV, tuberculosis and malaria (and many others) are always multi-factored, and effectiveness of interventions can be seriously impaired in environments that are unsupportive or hostile. For example: adherence to treatment regimens is always at risk in environments with high levels of stigma and discrimination; prevention and harm reduction interventions may be extremely difficult or impossible to deliver when certain groups of people such as drug users or sex workers are criminalised and/or marginalised.

325. Id. at 9 ("More effective community engagement and stronger partnerships between community, public and private actors are therefore essential in order to build enabling and supportive environments and to scale up effective responses by community, health and social welfare systems.").

326. Id. at 16 .

327. As such, particular activities associated with SDA 1 include:

- [P]lans to monitor implementation of public policies and services related to health and social support;

...

- Participation of community actors in national consultative fo-

rums;

...

- Contributing community experience and perspectives to development of national strategies, including cross-sectoral and sector-wide approaches;

...

- Developing communication materials for specific audiences e.g. children, women, sexual minorities etc .... 
icies and policy implementation. In order to play this role, community based organisations and networks need support and assistance to create and implement effective communication and advocacy plans, and to develop systems for working with partners, government agencies, media, and broader constituencies. ${ }^{328}$

While not specifically focused on the enabling environment, the other Core Components of the CCS Framework are complementary to these objectives. These other components include Building Stronger, Community Networks, Partnerships and Coordination (Component 2), Improved Resources and Capacity Building for Community Organizations (Component 3) and Improved Internal Organizational and Leadership Capacity (Component 5). ${ }^{329}$

One must approach this endeavor with a heavy dose of skepticism and realism. These ideas sound wonderful in the context of a graduate seminar in Political Science. The lesson of history, however, is that vibrant forms of civil society and effective frameworks of local cooperation to provide even basic essentials, such as clean water and effective sanitation, are often the exception, not the rule. ${ }^{330}$ The Global Fund CSS Framework may have identified the appropriate set of levers and catalysts for social change, but making it all come together in practice will not be easy. The PSC Civil Society Consortium suggests some of the challenges that must be overcome.

Nonetheless, barriers at the country- and GHI-level continue to prevent civil society from acting as equal

328. Id. at 17. Specific Activities associated with SDA 2 include:

- Mobilization of communities and key affected populations to engage actively with decision makers, and represent community issues in major discussion forums relating to health and rights;

- Mobilization of key affected populations and community networks to engage in campaigns and solidarity movements;

- Informing and empowering community members to communicate and advocate for change and improving enabling environments at local level;

- Policy dialogues and advocacy to ensure that issues of key affected populations are reflected in allocation of resources and in national proposals ... ;

- Documentation of key community level challenges and barriers and development of advocacy messages and campaigns to communi-

Id. cate concerns of affected populations....

329. Id. at $18-26$.

330. Peter J. HAMmer, International Law and Health, in TeXtBook on Global Child 107, 108 (Depak M. Kamat and Philip R. Fischer eds.) (2012) (suggesting that the lack of clean water and sanitation in a community can also be viewed as evidence of the failure of effective forms of local cooperation). 
partners in the planning, implementation, oversight and evaluation of GHI-funded programmes. These barriers include marginalization of civil society participants in national decision-making bodies; weak accountability of civil society representatives in capitals to their constituencies at community level; lack of transparent mechanisms to participate in some GHI planning and implementation efforts, and lack of resources among civil society representatives to participate in relevant preparatory and planning meetings organized by government and donor partners. ${ }^{331}$

The CSS Framework Document lists a comparable set of obstacles. "[I]t is important not to overlook the inequalities, social hierarchies, discrimination and competitiveness that sometimes operate between community organisations, and between them and government structures." 332 Many aspects of the CSS Framework are appropriately targeted at overcoming these barriers, but the task remains formidable.

For real change to happen, members of the state, market and civil society will have to start changing their own mindsets. The PSC Civil Society Consortium Final Report and Global Fund CSS Framework contain useful diagrams to help visualize these desired processes and outcomes. The Civil Society Consortium envisions "community mobilization for comprehensive health services," sitting at the center of a number of attributes reflecting the comparative strengths of community-based organizations. ${ }^{333}$ "These areas of civil society expertise include evidence- and needs-based advocacy, implementation, grassroots community experience regarding what works, service delivery for excluded populations, the ability to identify gaps and challenges, and the provision of independent oversight and monitoring." 334 Another figure tries to portray a self-reinforcing chain of "community system strengthening," "advocacy optimizing GHIs" and "community led de-

331. FInAL REPORT Civil SOCIETY CONSORTIUM, supra note 61, at 2-3. The problems cited in Kenya are illustrative:

Despite welcome efforts to decentralize health planning, health workers and patients, including PLWHA at community level reported minimal to non-existent involvement in priority setting, and that current programmes did not accurately reflect changing needs at the community level. Layers of overlapping bureaucracy, poor coordination and lack of transparency and accountability within public and GHI-sponsored programmes has created lengthy roadblocks and disbursement delays for Id. at 22. programmes funded by the Global Fund, especially for CBOs.

332. CSS Framework, supra note 296, at 10.

333. FINAL REPORT CIVIL SOCIETY CONSORTIUM, supra note 61 at 3, fig. 1.

334. Id. at 3. 
mand creation.,335 The CSS Framework portrays "community actors" and "health actors" developing and managing "systems" to undertake "activities/services for communities" that will result in improved "health outcomes" and "other outcomes." 336 This is a helpful start, but the content and operation of community systems and health systems, while not quite black boxes, remain substantially under-theorized and underdeveloped. All the action in these diagrams takes place within "systems," but these systems are still not well understood.

Just as an open and evolving understanding of health systems resulting from PSC, the logic of the CSS Framework is predicated on a belief in incremental, process-oriented strategies, operating within overlapping complex adaptive subsystems. The effort to construct an effective enabling environment for state-market-civil society interaction, mediated through a process of community system strengthening, is a daring and exciting experiment. The question of where to begin this challenge is met with the realization that each of the different CSS components are important and interconnected. ${ }^{337}$ At the same time, the Global Fund is appropriately pragmatic about the challenge it is undertaking. All of the Core Components of CSS may be important, but action can only take place one step at a time.

CSS should always start with an analysis of how systems are already functioning, how they need to be strengthened and how they can be built into a functional and coherent whole. CSS is a gradual process and interventions should focus on addressing all the individual components and their combined functioning, in order to assure delivery of quality, equitable, appropriate and sustainable interventions and outcomes within empowered communities. ${ }^{338}$

As such, the CSS Framework provides a roadmap, not a blueprint.

Global health policy has arrived at an important juncture. The PSC

335. Id. at 4 fig. 3 .

336. CSS Framework, supra note 296, at 8 fig. 2.

337. Id. at 14

The core components described below are all regarded as essential for building strong community systems. Together, they will enable CBOs and other community actors to deliver activities and services effectively and sustainably. They also support development of strong links and coordination between different systems and actors working towards the shared goal of improving health.

Id.

338. Id. 
Civil Society Consortium identified CSS as a key future objective. ${ }^{339}$ The entire Global Fund's CSS Framework is devoted to that objective. These policies demonstrate an increasing appreciation of the normally invisible infrastructure that underpins action at the community level. Recognizing the infrastructure is the first step. Taking actions to improve it is the second. Significantly, the CCS Framework is dedicated to strengthening local capacity through the almost unheard-of provision of unrestricted core funding for local organizations.

Community based organisations are rich in experience and close to communities but they are often the most poorly resourced in financial terms. CSS must therefore prioritise adequate and sustainable funding for community actors-not only project funds for specific operational activities and services but, crucially, core funding to ensure organisational stability as a platform for operations and for networking, partnership and coordination with others. Unrestricted core funding, based on agreed structures and procedures, contributes to sustainability by ensuring continuity and allowing an organisation to have the appropriate paid staff, supplies and infrastructure to build up their chosen programmes in response to the needs of the communities they serve. ${ }^{340}$

This is an important and far-sighted strategy. It is also potentially a very expensive one.

Core Component 3, Resources and Capacity Building, is most directly targeted at this objective. ${ }^{341}$ The component outlines a strategy for investing in the human resources, technical and organizational capacities and material assets, including the physical and information infrastructures that are necessary for effective community systems. ${ }^{342}$ On a related note, Core Component 5 is targeted at increasing organizational and leadership capacity. ${ }^{343}$ Leadership is key, but so is accountability.

339. FINAL REPORT CIVIL SOCIETY CONSORTIUM, supra note 61 , at 3.

340. CSS Framework, supra note 296, at 9.

341. Id. at 19.

342. Id. ("Funding for core organisational costs and for capacity building are also vital for community actors in order to enable them to provide sustainable and effective responses, as well as funding for implementation of programmes and interventions."). Three SDAs are constructed around these objectives: SDA 4, Skills Building for Service Delivery, Advocacy and Leadership (Human Resources), id. at 20-21; SDA 5, Financial Resources, id. at 21-22; and SDA 6, Material Resources--Infrastructure, Information and Essential Commodities, id. at $22-23$.

343. Id. at 26-27. 
Accountability is an important aspect of strengthening organisations, assuring communities, stakeholders and partners that there is good stewardship of the organisations's resources .... Community organisations that hold themselves accountable to their communities will also build their capacity to engage in advocacy for greater transparency and accountability of public bodies and governments to communities. ${ }^{344}$

In the end, these factors are intertwined and interdependent and must be pursued in a self-reinforcing manner.

Just as the health system initiative, the CSS experiment critically depends on building learning and adaptation into the very DNA of the process. To this end, almost half of the document outlining the CSS Framework is devoted to developing workable indicators to assess results within each SDA. ${ }^{345}$ Additional research must take place in concert with the initiation of funded projects. ${ }^{346}$ Significantly, even the Framework Document itself is envisioned as an open and adaptable construct.

This first edition of the CSS Framework is a major step in the direction of enhancing community engagement and effectiveness in improving health outcomes and increasing their collaboration with, and influence on, the public and private sectors in moving towards this goal. Experience with implementation of the Framework will help to further improve the definition and scope of CSS, which will continue to be revisited and modified in the light of lessons learned in a wide variety of communities, countries and contexts. $^{347}$

Rooting GHI action in diverse communities around the world will not

344. Id. at 26.

345. Id. at $32-70$.

346. Id. at 13.

Much more evidence-building and research is needed on community systems and the role of community organisations and actors in health support for vulnerable communities. This applies especially to interventions indirectly related to health (such as those focused on poverty or other health determinants) and for health-related support interventions focused on prevention, access, care and advocacy rather than direct delivery of medical services.

Id. 
be easy, but action not rooted in the community is unlikely to be effective or sustainable. That said, in taking stock of where we are and where we are heading, it is instructive to examine the history of other such efforts. The closest analogy may be the primary health care movement of the 1970s. This movement shared many of the commitments and values of the WHO PSC and Global Fund CSS efforts. Unfortunately, the drive for primary health care and efforts to ground such action in the community did not bear the fruit its advocates desired.

\section{HISTORICAL CHALLENGES-LESSONS FROM PRIMARY HEALTH CARE AND ALMA-ATA}

One cannot read about communities, civil society, and the Global Fund's CSS Framework without thinking about how these developments relate to concepts of primary health care and the 1978 Declaration of AlmaAta. The CCS Framework Document acknowledges this heritage. ${ }^{348}$ This Part examines the relationship between the primary health care movement of the 1970s and the contemporary PSC and community-based initiatives reflected in the Global Fund's CSS Framework. Two lessons are stressed. First, there are important parallels between PSC as an open, processoriented policy making experiment and the early days of what became the primary health care movement. Many of these more positive attributes, however, got lost in the political dynamics that ultimately produced the Declaration of Alma-Ata. The pre-history of Alma-Ata serves as a cautionary tale as to how fragile process-oriented policy experiments can be.

The second lesson is related. At the community level, the power of the CSS Framework rests in its holistic, evolutionary methodology that seeks to ground action in the community. The Declaration of Alma-Ata

348. Id. at iv (footnotes omitted).

The concept of community involvement in improving health outcomes is not a new one. It has its roots in the action that communities have always taken to protect and support their members. Modern approaches to community health care are reflected in the Alma Ata declaration of 1978, the more recent work of WHO on the social determinants of health and the re-launch of the primary health care concept in 2008.

Id. The re-launching of the primary care concept took place in 2008 with the publication of the WHO World Health Report Primary Health Care: Now More than Ever. PRIMARY HEALTH CARE: Now MORE THAN EVER, supra note 144. In its only direct quotation from the Declaration of Alma-Ata, however, the CSS Framework cites the Declaration for its normative principles, not for its substantive treatment of communities or its approach to primary care. CSS Framework, supra note 296, at 2 (quoting DECLARATION OF ALMA-ATAInternational Conference of Primary Health CaRe 2 (1978)). A further indication of how those defining the contemporary civil society and community systems agenda may be distancing themselves from the traditional primary health care movement is the fact that there is not a single reference to the Declaration of Alma-Ata in the entire final report of the PSC Civil Society Consortium. See FINAL REPORT CIVIL SOCIETY CONSORTIUM, supra note 61. 
was also holistic, but it was largely devoid of workable mechanisms that could begin to deliver on its promises. Instead, the Declaration, and the very notion of primary health care that it trumpeted, became quagmires of inaction, statements without direction. Just as PSC has the potential to transcend old debates between vertical versus horizontal interventions, the CSS Framework has the potential to transcend old debates over selective versus comprehensive primary care. The irony, however, is that if one wants to fulfill the dream of Alma-Ata, one should draw a direct line between the early history of the primary health care movement and the Global Fund's CSS Framework, largely bypassing the 1978 Declaration and its legacy.

\section{A. The Positive Synergies Campaign and the Pre-History of Alma-Ata}

The pre-history of Alma-Ata is as much about a man, WHO Director General Halfdan T. Mahler, as it is about a time. There are interesting parallels between that period and today. Early in its existence, the WHO was preoccupied with vertical campaigns of disease eradication. While boasting a number of important successes, not all health problems are susceptible to this approach. International efforts against malaria, with its heavy reliance on DDT, became a particular source of disappointment. ${ }^{349}$ Critical of the predominantly vertical nature of the mass campaigns, some factions in the international health community advocated for a greater appreciation of basic health services. Others recognized that effective action against the disease-specific targets, such as malaria and tuberculosis, would require both better integration of these efforts with basic health services, as well as policies that challenged the largely medicalist orientation of national and international health policy. There were calls for the WHO to redefine its mission and objectives in light of these concerns. Realistically, however, any such reevaluation would have taken place in the politically charged environment of the Cold War.

These dynamics pre-date Mahler's Directorship (1973-88). Mahler was brought into the WHO's central leadership in 1969 when he was appointed Director of a new Project Systems Analysis unit. A window within the WHO and international health policy was opening that might permit new visions and new possibilities. The focus on basic health services trans-

349. Socrates Litsios, The Christian Medical Commission and the Development of the World Health Organization's Primary Health Care Approach, Public Health Then and Now, 94 AM. J. OF PUB. Health 1884, 1885 (Nov. 2004) [hereinafter Litsios, CMC]. For more than a decade, the global malaria eradication campaign had been WHO's leading program. Initiated in the mid-1950s, it was a strictly vertical program based on the insecticide power of DDT. Only in the 1960s was it acknowledged that a health infrastructure was a prerequisite for the success of the program, especially in Africa. Id. 
formed itself into a concern about primary health care. ${ }^{350}$ But what did these terms mean and how could the WHO help promote their development?

Mahler embodied many of the anti-establishment and anti-medicalist positions of the day, but he also held strong affirmative beliefs in the radical possibilities of people-centered processes of change. For Mahler, a focus on basic health services, if done right, had the potential to transform health, communities and the WHO itself. "The image of change that Mahler repeatedly evoked was change led by enlightened leaders emerging from within the system, preferably at the periphery where those in greatest need reside., ${ }^{, 351}$ The problem was that it was not very clear what basic health services or primary health care meant or how change centered on them could be obtained. These facts were viewed as a challenge, not an obstacle. A founding premise of the undertaking was an open acknowledgment that policy makers did not have all, or even most, of the necessary answers. A 1973 WHO report prepared by Kenneth Newell's newly created Strengthening of Health Services division illustrates this point.

The Report concluded that no single or best pattern existed for developing a health services structure capable of providing wide coverage and meeting the needs of the population being served: "Each country will have to possess the national ability to consider its own position (problems and resources), assess the alternatives available to it, decide upon its resource allocation and priorities, and implement its own decisions." 352

There was a role for the WHO, but not in its traditional capacity as the international source of technical medical expertise. "WHO, the report said, should serve as a 'world health conscience,' thereby providing a forum where new ideas could be discussed as well as a 'mechanism which [could] point to directions Member States should go."”353

How does one make policy when one is not certain of what one is doing, or where one is going? In this setting, it is necessary to adopt an incremental, process-oriented approach, where the creation of knowledge

350. Marcos Cueto, The Origins of Primary Health Care and Selective Primary Health Care, 94 (11) AM. J OF Pub. Health 1864, 1866 (Nov. 2004) ("From the late 1960s, there was an increase in WHO projects related to the development of 'basic health services' (from 85 in 1965 to 156 in 1971). These projects were institutional predecessors to the primary health care programs that would later appear.").

351. Socrates Litsios, The Long and Difficult Road to Alma-Ata: A Personal Reflection, 32 INT'L J. HEALTH SERVICES 709, 717 (2002) [hereinafter Road to Alma-Ata].

352. Litsios, CMC, supra note 349, at 1886 (quoting WHO Official Records No. 206, Annex 11, Geneva, 1973, 105).

353. Id. (quoting WHO Official Records No. 206, Annex 11, Geneva, 1973, 105). 
becomes part of the policy making process itself. Mahler acknowledged this fact in his first Annual Report of the WHO in 1974.

As there were few models to "demonstrate that primary health care can come out of the villages at a reasonable cost and in a manner that is technically and socially acceptable," he indicated that it was "an urgent task for WHO to seek a small number of innovator countries that will be willing and able to set up such systems of primary health care and demonstrate their effectiveness." 354

This is not unlike the incubator approach employed by venture capitalists in Silicon Valley and elsewhere. One needs structured experiments and learning, but Mahler believed that one must also change one's very understanding of what must be learned and how one defines knowledge. "Only by becoming their pupil could one hope to serve regions and individual member states." 355

Concrete steps in operationalizing these objectives came in the compilation of two series of case studies of innovative, non-traditional primary health care experiments. The first was the product of the UNICEF and WHO Joint Committee on Health Policy, Alternative Approaches to Meeting Basic Health Needs in Developing Countries, published in $1975 .^{356}$ That year also witnessed the publication of Health by the People, a similar compilation edited by Newell. $^{357}$ (The content of these studies will be examined in greater detail in the next section when the role of communities and community systems is examined in historical context.) If the larger undertaking was going to be successful, one or two volumes of case studies were clearly not enough. Experimentation, learning and adaptation must be a continuous and ongoing process. Mahler's embryonic vision was to retool the WHO to support such an evolutionary effort. The WHO's role would be to help identify, cultivate, refine and propagate successful innovative alternatives. This is an intensely pragmatic and experience-driven approach.

Let theoreticians work together with you, if you need

354. Socrates Litsios, Primary Health Care: Not the best of beginnings?, Presented at WHO, at 5 (Feb. 19, 2007) [hereinafter Litsios, Not the best of beginnings], available at http://www.who.int/global_health_histories/seminars/paper06.pdf.

355. Litsios, Road to A Alma Ata, supra note 351 , at 718 .

356. UNICEF-WHO JoInt Comm. On Health Policy, Alternative Approaches to MeEting Basic Health Needs In Developing Countries (V. Djukanovic \& E.P. Mach eds., 1975).

357. World Health Org., Health By the People (Kenneth W. Newell ed., 1975). 
their support, but do not let them dictate sophisticated methodologies that have not been rigorously tested . . .. The indispensable ingredient for successful health systems research is tough operational discipline combined with the political guts to use information generated by the research. ${ }^{358}$

Re-working the political environment would be just as important as re-working the methodological orientation of health policy research. Mahler went on to identify some of the mechanisms that would be necessary for effective health development

A new type of ministry of health was envisioned .... The advisory council, on which the community and sectors other than health would be represented, was one in which health development in all its intersectoral ramifications can be thrashed out and health economics and health ethics can be brought together. ${ }^{359}$

Such an advisory council could be a source of legitimacy, transparency and accountability, as well as a functioning mechanism for making the difficult economic, political and ethical trade-offs inherent in resource allocation decisions between competing goods.

As indicated, Mahler's vision had implications for the WHO itself. Its organization and structure had to be re-oriented. WHO's headquarter functions could be divided into two categories of tasks: one directed at generating information/knowledge and the other devoted to facilitating technical cooperation. ${ }^{360}$ WHO should become a neutral ground for the absorbing, distilling, synthesizing and disseminating of information that was of practical value for countries in solving their health problems. "In 1974, Mahler was already advocating for a strengthened role for the regional committees and regional offices ... a new. WHO statesmanship ... a new type of WHO staff members, one who was thoroughly reoriented in modern health management.",361 This was an ambitious vision for how knowledge could be created and disseminated, with a focus on innovation and learning.

How does this radical, process-oriented vision of the early 1970's compare to what actually happened? Litsios tells a story of how this vision was corrupted and co-opted in what ultimately became the much celebrated conference and Declaration of Alma-Ata. In his parable, the Soviet repre- 
sentative to the WHO, Dr. D. D. Venediktov, plays the role of the villain. It is a fact that the Soviets were long pushing the concept of basic health services at the WHO and they were the leading advocates for holding an international conference. ${ }^{362}$ It is also true that they did everything they could to see that the international conference was held in one of their Republics, in this case, Alma-Ata, the largest city in Kazakhstan. ${ }^{363}$ It should not surprise anyone that the Soviets also sought to showcase their own health system as a model of primary health care. Whether the Soviet model was a good model, however, is a question open for debate. "Mahler found the Soviet model totally inappropriate. It was heavily centralized with little hope for change from below. It was over-medicalized. There was little to be learned from the Soviet system that could be used by the developing world."

The real objection to holding an international conference at this time, however, goes far deeper than its location or the merits of the Soviet health system. If one is committed to an open, process-oriented approach to developing the meaning of primary health care, then an international conference risks sending exactly the wrong message. "Venediktov thought it was possible to draw up a model of a health service system that all countries would find useful.,"365 As it materialized, the conference communicated the misleading message that correct answers were in fact known and that concrete blueprints existed that could be readily followed and implemented.

The Alma-Ata paper clearly was saying that enough was known to implement PHC. This was a radical shift from the executive board's position paper in 1972, which called for the utilization of trial areas to test methods and means to make sure they are suited to local conditions and will enable the objectives to be attained with the resources available. ${ }^{366}$

Litsios fairly speculates that the world would have been much better off if the Alma-Ata Conference had never taken place and if the initial processoriented methodology had been permitted to take root. "Had WHO, jointly with UNICEF, been able to record and monitor innovations, learn from them, evaluate them, and make their results widely available, an earlier and more impressive start would have been made.",367

It is difficult to argue with the abstract normative principles enshrined

362. Id. at 710 .

363. Id at 715 .

364. Id. at 718 . One can only imagine the criticisms Mahler would have leveled at the U.S. model.

365. Id. at 713 .

366. Id. at 727 .

367. Id. at 728 . 
in the Declaration of Alma-Ata. Because of this, the Declaration has attained near mythic status. Like most myths, however, it is of little use in dealing with the practical health needs of the world's poorest and most disenfranchised citizens. The notion of primary health care enshrined in the Declaration of Alma-Ata is largely content-less and devoid of operational meaning. ${ }^{368}$ Proof of this claim lies in primary health care's chameleonlike capacity to mean all things to all people. Equally damning is the fact that the Declaration lacks any internal mechanisms to guide its future development and implementation. Even the seemingly simple questions such as: "what does primary care mean?," "how can primary care be implemented?" and "where do we begin?," do not have a clear answers.

The outstanding problem of how to integrate the various vertical components that hitherto had been the pillar of WHO's programmes was no longer being addressed. Did this mean that it was no longer an important issue? As an aside, one could argue that the quick emergence of selective PHC in the 1980s was not only due to external forces imposing that regressive vision on WHO but to the fact that WHO had not focused on the question of integration once it started moving towards the concept of $\mathrm{PHC}^{369}$

There was a similar failure to adopt new methodologies for research and policy planning to meet the challenges of primary health care.

But more importantly, the planning tools developed by the Organization were largely insensitive to the needs of PHC. For example, the systems analysts then present, including myself, had not found the way to incorporate the social orientation of PHC into their methodologies. Newell seems to have recognized this. In his first draft for the background paper for Alma-Ata, written in early $1977, \ldots$. [he commented that] "we had misunderstood the nature of the question we were asking and the capabilities of the sciences we were looking to for assistance.",370

Then, as now, there was the need to develop a new science of HSD.

368. Litsois, Not the best of beginnings, supra note 354, at 9 ("It is not surprising that many were honestly confused about what PHC was all about.").

369 . Id at 8 .

370. Id at 13 . 
These internal failings, as much as a host of external factors, ${ }^{371}$ go far in helping to explain why the primary health care vision of Alma-Ata was largely stillborn.

What might this mean for PSC of today? There is good reason to believe that the external international climate is more receptive today for PSC than it ever was for primary health care in the 1970s and 1980s. International politics are no longer dominated by Cold War competition. There is a shared, results-oriented commitment to the international health objectives embodied in the MDGs (a common vision). Contrary to the late 1970s, the WHO PSC has successfully cobbled together a broad political consensus and cooperative framework (positive synergies) that has brought together the leading stakeholders behind the efforts. Perhaps of most significance, is the modern advent of a host of GHIs themselves. These institutions help provide a global health architecture, as well as funding mechanisms, to help implement the PSC vision. It is also significant, that the core vision of PSC, embodying its open, process-oriented methodology, has proven fairly robust in its early stages.

That said, the pre-history of Alma-Ata suggests some reasons for concern. PSC is asking policy makers to openly acknowledge what most have been professionally and personally trained to deny-the existence of radical uncertainty, the reality of complex adaptive systems and the endemic failure of institutional infrastructures around the world to provide even the most basic health services. These factors are routinely and dogmatically ignored in almost all policymaking circles (and in most respectable corners of academia). The dominant illusions of modernity are so strong that most traditional policy makers are largely unaware of the existence of these troubling alternative realities. As such, policy makers persistently act surprised when their well-intentioned and rationally designed models fail to generate the intended results. Indeed, what is truly remarkable about PSC (and the early work on primary health care) is that the broader truths about the complex real world are not only being recognized, but the appropriate methodologies and policy making processes are being designed to meet their inherent challenges.

The concern is that the relentless operation of traditional politics and planning - the daily grind of business as usual-could still swamp these early efforts in much the same way that the early primary care philosophy was co-opted and corrupted by the policy and politics that resulted in the

371. Primary Health Care faced daunting external threats and opposition. See Cueto, supra note 350, at 1868-72; see also David Werner, The Life and Death of Primary Health Care, Part of a presentation for the International People's Health Council at the NGO Forum, United Nations "Global Summit," (Mar. 7, 1995), available at http://www.healthwrights.org/ hw/content/articles/Life_and_Death_of_PHC-Global_Summit_Sweden.pdf. Even if the initial process-oriented visions had been maintained, one can raise serious question as to whether and in what form that vision would have survived. 
Declaration of Alma-Ata. People like certainty. Clear, easy answers have a strong allure, no matter how wrong or misguided. Funders are impatient. Planners like quick results. Complexity is not an aesthetically pleasing condition. Almost every aspect of human psychology acts to oppose the type of policymaking experiment that lies at the heart of PSC. There is no way to resist these forces unless they are expressly acknowledged and guarded against. Even then, it will not be an easy task. PSC will not result in a single universal victory, or even, likely, a set of statically recognizable successes. PSC is initiating an incremental process to help manage a complicated but hopefully not intractable set of vital health concerns. Patience and a tolerance of failure will be essential components.

\section{B. Connecting Actions to Communities-Past and Present}

Legitimate enthusiasm about PSC and the Global Fund's CSS Framework needs to be tempered with the realization that we have all been here before. "The struggle against human oppression" really is "the struggle between memory and forgetfulness." ${ }^{372}$ Annex 1 of the 1975 Alternative Approaches to Meeting Basic Health Needs began by noting:

As early as 1951 , at a time when many developing countries were concentrating their efforts on specialized mass campaigns for the eradication of diseases, the Director-General of the WHO stated in his annual report that these efforts would have only temporary results if they were not followed by the establishment of permanent health services in rural areas to deal with the day-to-day work of the control and prevention of disease and the promotion of health. ${ }^{373}$

Few such programs were established. The document laments how little had been accomplished in the intervening twenty years. ${ }^{374}$ Sadly, nearly four decades later, very little seems to have changed.

The importance of empowering local communities to take action in furtherance of improving their own health is another largely forgotten truth. A 1975 WHO paper Promotion of National Health Services argued that "a series of major national efforts to develop primary health care at the community level is seen as the only way in which health services can develop rapidly and effectively." ${ }^{375}$ The core principles articulated in the $1975 \mathrm{Re}-$

372. Mahler, supra note 1 (internal quotation marks omitted).

373. Alternative Approaches to Meeting Basic Health Needs, supra note 356, at 108 (citing WHO Official Records, No. 38, 1952, p2).

374. Id. at 110 .

375. Litsois, Not the best of beginnings, supra note 354, at 1 (citing WHO, Documents 
port resonate strongly with contemporary theories of CSS:

(1) for PHC to be shaped 'around the life patterns of the population'; (2) for the local population to be involved; (3) for 'maximum reliance on available community resources' while remaining within cost limitations; (4) for an 'integrated approach of preventive, curative and promotive services for both the community and the individual'; (5) for all interventions to be undertaken 'at the most peripheral practicable level of the health services by the worker most simply trained for this activity'; (6) for other echelons of services to be designed in support of the needs of the peripheral level; and (7) for PHC services to be "fully integrated with the services of the other sectors involved in community development. ${ }^{, 376}$

While some of the terminology is different, many of the core values remain the same.

These principles were further fleshed out in Health by the People and Alternative Approaches to Meeting Basic Health Needs in Developing Countries. ${ }^{377}$ In terms of substance and methodology, these documents are direct precursors of the theories motivating contemporary HSD and CSS efforts. These documents were prepared in response to the realization amongst WHO leadership that while they knew that basic health services were essential and that such services must be effectively grounded in local communities, there were few good models addressing how this could be done. Rejecting the strictures of traditional research methodologies, the documents searched for truth in the form of lived experiences and the power of narratives. "While some data were necessary to put the changes in meaningful perspective, the authors were asked to give especial prominence to the process itself. What was wanted was a series of stories that would give life and colour to the sequence of events and decisions they considered important." 378 The stories that emerged are compelling.

What the stories revealed was the power of community action and community actors.

There are other similarities between the examples presented. Each country or area started with the for-

for the 55th Session of the EB, Jan. 1975, document EB55/9).

376. Id. (quoting WHO, Documents for the 55th Session of the EB," Jan. 1975, document EB55/9).

377. Health By the People, supra note 357; Alternative Approaches to Meeting BASIC HEALTH NEEDS, supra note 356.

378. HeAlth By THE PEOPLE, supra note 357 , at $\mathbf{x i}$. 
mation, reinforcement, or recognition of a local community organization. This appeared to have five relevant functions. It laid down the priorities; it orgaorganized community action for problems that could not be resolved by individuals (e.g., water supply or basic sanitation); it 'controlled' the primary health care service by selecting, appointing or 'legitimizing' the primary health worker; it assisted in financing services; and it linked health actions with wider community goals. ${ }^{379}$

While these commonalities are important, so are the differences. Again, context-specificity is a key lesson. "There appear to be many roads to success. Indeed, if there is a moral to this book it is that possibilities for change are open to all people but no standard method is applicable to all of them." 380

Alternative Approaches to Basic Health Needs employed a similar methodology, trying to break out of the conventional mold. "Clearly the time has come to take a fresh look at the world's priority health problems and at alternative approaches to their solution." 381 It was hoped that this effort would be just the beginning. ${ }^{382}$ This was supposed to mark the beginning of the end of business as usual.

All of this may sound fairly idealistic, but there is nothing naive about the study's assessment of the obstacles that had to be overcome. Serving as yet another indication of how little progress has been made, the discussion of various barriers being faced could easily have been written today. Some of the problem lies at the national level. The report identifies a "[1]ack of clear national health policies and poor linkage of health service systems with other components of national development."383 There are problems of planning and coordination. "The efforts made are fragmentary, not necessarily related to those of other sectors, and not directed at supporting national growth on a broad scale by fostering human wellbeing and resources." 384 The report also cites a lack of "clear priorities," noting that "scant attention is given to the balance between curative, preventative, and

379. Id. at 193.

380. Id. at xii.

381. Alternative Approaches to Meeting Basic Health Needs, supra note 356, at 7.

382. Id. at 8 ("It is hoped that these discussions will encourage further studies .... The emphasis is not on further development of health services as they are now organized, but rather on new ways of identifying basic health needs and of providing simple preventative and curative measures.").

383. Id. at 14 .

384. Id. at 15 . 
promotional activities and the division of resources among them."385 Opposition from the medical community is yet another obstacle. "Whatever the motives of these organizations - to defend their own interests or preserve cherished traditions-this resistance may have serious repercussions on health plans, programmes, and policies."386

Other problems lie at the community level. "Inadequate community involvement in providing health care" is an obstacle to change. ${ }^{387}$ Unfortunately, getting increased community participation on health-related problems will not be an easy task. The report highlights a number of barriers to community participation:

- in some countries a political system that does not encourage local self-governance - a prerequisite to local involvement in health development in general

- the rigid sectoral structure and centralized organization of most conventional government health services

- competition between the traditional system of health care already existing at the local level and the modern system of health care

- the system of beliefs (religion, caste, etc.) of communities in peasant societies. ${ }^{38}$

- Community participation is easy to discuss at a theoretical level, but it is very difficult to implement in practice.

In addition to obstacles at the social, cultural and governmental level, serious challenges exist within the structure and operation of most health service systems themselves. Again, it is interesting to note how prevalent these challenges are today. The report notes a general lack of "effective planning machinery."

The biggest weakness of many health planning endeavors is the lack of an overall health policy to guide them, of a political will to provide the resources necessary for implementation, and of an effective structure to implement the decisions. . . . Often health plans are not so designed that they fit into the country's socioeconomic development programmes and planning frequently focused on health services and not on meeting health needs. Information and effective machinery for national health planning are often 
lacking. ${ }^{390}$

In an insightful recognition of the importance of a multi-disciplinary teams and approaches the report observes that "[b]ehavioural scientists can make a considerable contribution to the planning and management of health, but their skills are little used.",391

Anticipating the need for systems thinking the report criticizes the "[w]eak development of the "total systems' concept." ery systems-public and private, national and international, curative and preventative, peripheral, intermediate and central - must be considered as a whole." ${ }^{\text {"393 }}$ Again, the problem is fragmentation and a lack of coherence. "The fragmentation of a health service into disparate elements, each designed to serve a small section of the population or a single purpose, militates against the goal of comprehensive and optimal utilization of limited resources." 394 This sentence could have been taken right out of the 2000 WHR or the 2009 AHPSR Report on Systems Thinking.

The same can be said of the last obstacle listed: "lack of adequate health information." 395 "Confusion between 'statistical data' and 'information' still reigns, with the result that many statistical services fail to provide public health administrators with the information they need for sound decision-making." 396 Information is critical to any process-oriented reform initiative, but it has to be the right information. The report stresses the significance of collecting information in terms of what is needed to facilitate problem solving. "If national systems are to be geared to solving the real problems of communities, a radical reform of objectives and methods of data collection is required." 397 . The report's recommendation is straightforward: "Information services should be recast according to the priorities of the health system and should be aimed strictly at problem-solving." 398

The theme about information and problem solving carries forward to the recommendations that the report makes to the governing bodies of the WHO and UNICEF. There was a call for the international organizations to institutionalize learning as it relates to the problems of community health and to develop a new methodology to govern a new field of research in the area.

WHO and UNICEF should study in detail not only

390. Id. 20-21.

391. Id. at 21.

392. Id.

393. Id.

394. Id. at 21-22.

395. Id. at 25.

396. Id.

397. Id.

398. Id. 
the innovations described in this study but also those that are occurring continuously in different parts of the world under different sponsorship; they should record and monitor them; evaluate them; make their results widely available; assist them when necessary; adapt them; build upon them; and encourage similar endeavors, even though some may present some risk in the sense that favorable outcome is not clearly predictable. $^{399}$

This is in essence a call for the creation of a new field of policy studies and aptly anticipates much of PSC's own methodology. "WHO and UNICEF should pursue research on the effects of rural and community development of the health of people and on the role that other sectors can play in the delivery of primary health care, develop methodology for application of the findings, and assist in its implementation. ${ }^{, 400}$

One can draw a direct line between the recommendations of the 1975 Alternative Approaches to Basic Health Needs and the work of PSC and the 2010 Global Fund CSS Framework. Tellingly, this line would largely bypass the 1978 Conference and Declaration of Alma-Ata. Sadly, we have lost three-and-a-half more decades. The social problems and research questions are largely the same. The obstacles and challenges remain. The needs are still pressing. The good news is that we have regained focus on what needs to be done and we have reminded ourselves of the paths that need to be taken.

Is there any reason to be optimistic that today's efforts under the auspices of PSC and the CCS Framework will be any more successful than the pre-Alma-Ata days of the primary health care movement? The current agenda is ambitious. It is also going to be more medically driven, at least with respect to the HIV/AIDS component, than primary health care advocates may have envisioned in the past. Perhaps the most significant difference is the prominent role played today by GHIs. These organizations are helping to fill gaps in the global health architecture. They promise to increase the capacity to effectively link the-global-to-the-national-to-thelocal. These same organizations bring funding mechanisms that were not imaginable in decade's past. This has positive and negative elements. A central component of the primary health care movement was sustainably working within the resource constraints of the various communities. Communities had to be involved if the effort was going to work and communities had to make hard choices regarding competing directions. While external resources expand the scope of what objectives can be accom- 
plished, external resources are often accompanied by external agendas. Keeping community systems authentically grounded in the community will be yet another ongoing challenge.

\section{CONCLUSION}

It is too early to know how the story will end. History teaches that the road ahead will not be easy and will be full of unexpected challenges. That said, the roadmap being put into place looks promising. We are at least trying to head in the right direction. Recent efforts at health system and community system development may someday help achieve the primary health care movement's dream of health for all.

Socrates Litsois reminisces that:

At some point in the late 1960 s I heard Mahler put forward the idea that only when change from below was consistent with the change that was coming from above, would health systems begin to 'swing,' one of Mahler's favorite terms for describing something good. It sounded good to me, which is no doubt why I remembered it, even though I wasn't quite sure what it meant at the time. The change from below would emerge from community involvement in health services and empowerment in development, while that from above would stem from any number of possible reforms as introduced by country health programming, intersectoral coordination, regionalization, health services and manpower planning, to name just a few..$^{401}$

Swing music, like all good jazz, taps into the ability for creative improvisation within established musical structures. The same ability to encourage improvisation, adaptation and variation within structured policy frameworks may also hold the key for future success in HSD. It is difficult for any constellation of actors to swing when confronting issues as complicated as global public health, but there is reason for optimism. Efforts at community system strengthening are starting to orchestrate constructive change from below. The PSC is coordinating more effective change from above. A thoughtful focus on health systems and the institutional infrastructure connecting those above with those below could start the whole system, if not swinging, at least moving step-by-step in a more positive direction. 


\section{EPILOGUE: GLOBAL FUND'S ROUND 11 CANCELATION}

Between the submission and publication of this article, some dramatic developments have taken place that will affect future health system development efforts. Parts IV and V tell a positive story of the Global Fund taking a new leadership role and demonstrating a significant institutional capacity for learning and adaptation. In funding Rounds 8-10, the Global Fund adopted an increasingly sophisticated approach to HSD. It charted new territory in its willingness to support HSD for child and maternal health in addition to AIDS, tuberculosis and Malaria. Finally, it was pioneering new approaches to community system strengthening (CSS).

No international organization has been immune from the negative effects of the Global Financial Crisis starting in 2008. "In the Fund's first seven years, donors fulfilled all their commitments, with some giving more than originally pledged. Almost 15 percent of donor pledges went unpaid in 2009. A year later, almost a quarter of donor pledges failed to materialize." ${ }^{402}$ Counties were in the midst of preparing applications for the Fund's eleventh round of grant disbursements when the bad news came down. "In November 2011, facing a deficit of about half a billion dollars due to unfulfilled donor pledges, the Global Fund to Fight AIDS, TB and Malaria was forced to cancel Round 11 of its funding." ${ }^{, 403}$ According to initial reports, there would be no new funds available until 2014. ${ }^{404}$

Reliable funding is essential if existing beneficiaries will continue to receive lifesaving treatments, such as antiretroviral therapy for AIDS. New funding rounds are also essential if the Global Fund's work is to be scaledup and expanded. Each round, however, represents more than just money. The melding of effective strategies to integrate the work of GHIs, HSD and CSS is being improved in each successive round of grant making. The cancelation of Round 11 cast a shadow of uncertainty over each of these efforts. Given the necessity to maintain clinical services, the work on health systems and the extension of new CSS initiatives may be the most immediate casualties. ${ }^{405}$

402. Laura Lopez Gonzalez, The First to Go: How communities are beIng AFFECTED BY THE GLOBAL FUND CRISIS 12 (2012) (Open Society Institute), available at http://www.osisa.org/sites/default/files/open_debate_4_-_global_fund_crisis_web.pdf.

403. Id. at 2.

404. Mara Kardas-Nelson, They Say We Can "End AIDS." But Who will Pay for It?, NAM AIDSMAP (July 24, 2012), available at http://www.aidsmap.com/They-say-we-canend-AIDS-but-who-will-pay-for-it/page/2448705/.

405. GONZALEZ, supra note 402 at 3 ("Round 11 funding would have also supported community-based NGOs to provide treatment literacy and adherence support; lead community education, mobilisation and prevention efforts; and address barriers to treatment, care, and support. A new funding window would have allowed countries to fill critical gaps in HIV and TB treatment, diagnostics, and other commodities; scale-up prevention interventions such as prevention of mother-to-child HIV transmission (PMTCT) services and medical male circumcision (MMC); and strengthen health systems."). 
The Global Fund has made substantial efforts to regroup. "To mitigate the impact of funding disruptions before a new funding model is rolled out under the new strategy, the Board decided to establish a Transitional Funding Mechanism (TFM), replacing Round 11."406 Unfortunately, during this transitional period "no stand-alone, cross-cutting [health system strengthening] HSS requests will be permitted."407 The Fund also intends to make substantial changes in the way it does business. This will include "a sweeping reorganization, focusing on the core business of grant management by significantly increasing the number of staff working in that area while streamlining staffing in supporting departments and taking steps to radically improve management." ${ }^{.08}$ On the positive side, the Fund forecasts that it will now have an additional $\$ 1.6$ billion in funds to disburse during the transition period. ${ }^{409}$

It is still unclear what the scope of organizational changes at the Fund will be and in what ways it may change its fundamental approach to grant making. Mark Eldon-Edington, the Global Fund Director of Country Programmes stated that "[w]e'll probably move away from a round-based system that comes every two years, to a series of funding windows." 410 One thing he says will not change is the Fund's commitment to civil society. "The Global Fund remains absolutely committed to civil society, and not solely for ideological reasons but for business reasons. If we are to deliver on our mission, we need to reach the people [that] governments can't or won't reach. Civil society is the way to reach those people."4ll No statements were made about the fate of the Fund's ambitious new CSS efforts or its commitment to HSD.

During a financial crisis, it is sometimes easy to be penny wise and pound foolish. Whatever organizational changes are made, it is important that key aspects of the Fund's original vision and structure be retained. More than almost any other international organization, the Fund was structured in a manner to facilitate its institutional capacity to learn and adapt.

406. Global Fund to Fight Aids, Tuberculosis and Malaria, Globál Fund Board Establishes a Transitional Funding Mechanism to Replace Round 11 and Revises the APplication and ApProval Process for Renewals, ANNOUNCEMENTs (December 1, 2011), available at http://www.theglobalfund.org/en/mediacenter/announcements/ 2011-12-01_Global_Fund_Board_establishes_a_Transitional_Funding_Mechanism/.

407. Id.

408. Global Fund to Fight Aids, Tuberculosis and Malaria, Global Fund

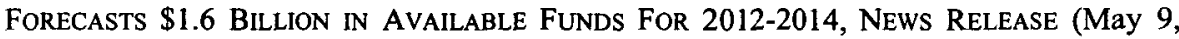
2012), available at http://www.theglobalfund.org/en/mediacenter/newsreleases/2012-0509_Global_Fund_Forecasts_USD_1_6_billion_in_Available_Funds_for_2012_2014_Major Shift_Reflects_Strategic_Choices_by_Board_Renewed_Confidence/.

409. Id.

410. IRIN, HIV/AIDS: STRAIGHT TALK WITH MARK ELDON-EDINGTON, GLOBAL FUND DiRECTOR OF COUNTRY PROGRAMMES, (July 24, 2012), available at http://www.plus news.org/Report/95941/HIV-AIDS-Straight-Talk-with-Mark-Eldon-Edington-Global-Funddirector-of-country-programmes.

411. Id. 
These key features need to be respected and preserved. The Global Fund has been far from perfect. It took ten rounds of trial and error to forge meaningful understandings of the importance of HSD and CSS and workable mechanisms as to how these goals could be pursued. For the sake of its own long-term effectiveness, it is important that these lessons not be lost within the reformulated organizational model.

Not all developments in the past year are troubling. The surprising appointment of Dr. Jim Yong Kim as President of the World Bank could help sustain the momentum of the WHO PSC and renewed efforts at HSD. "Dr. Kim is renowned not only for his pioneering, rights-based health care work for Partners in Health, but for being one of the driving forces behind the [WHO's] ' 3 by 5' Initiative -- a global push to provide 3 million people living with HIV/AIDS with antiretroviral treatment (ART) by the end of 2005. ${ }^{, 412} \mathrm{Kim}$ is the first World Bank President ever to appear at the International AIDS Conference. In his address, he focused on the importance of health systems development. "Today, in health, the World Bank's comparative advantage is in systems building. Our health sector strategy is focused on supporting countries to create health systems that deliver results for the poor and that are sustainable. ${ }^{, 413} \mathrm{Kim}$, however, seeks to join the economic expertise of the World Bank with the moral passion of someone who has worked in the trenches of global public health. "I want the Bank to lead the world in joining systems knowledge with clear moral values to help countries solve their toughest problems." 414 This work must be done in the form of collaborative partnerships. "Success in the AIDS response depends on partnerships. On a very personal level, I am committed to strengthening the World Bank's multilateral alliances with UNAIDS and the Global Fund; our partnerships with UN technical agencies, including WHO and UNICEF; and our collaboration with PEPFAR and other bilaterals. Moreover, strong partnership with civil society that delivers results for the poor will be a signature of my presidency." 415

The future of global public health remains as uncertain as its past. The cancellation of the Global Fund's Round 11 may have taken efforts one step backwards. It is time to push to take at least two steps forward.

412. Kolleen Bouchane, We can End AIDS, HufFINGTON Post (July 21, 2012), available at http://www.huffingtonpost.com/kolleen-bouchane/international-aids-conference_b_ 1692017.html.

413. Jim Kim, ENding AIDS and Poverty, World Bank Group President Jim Yong Kim Remarks at the Opening Plenary of the International AIDS CONFerence 2012 (July 22, 2012), available at http://www.worldbank.org/en/news/2012/07/22/world-bankgroup-president-jim-yong-kim-remarks-at-the-opening-plenary-international-aidsconference-2012.

414. Id.

415. Id. 